\title{
TASK 2.5.5 NATURAL EXPOSURE TESTING IN CALIFORNIA
}

William (Bill) Miller, Ph.D.

Oak Ridge National Laboratory

Research Engineer

Building Envelope Program

Ronnen Levinson, Ph.D.

Lawrence Berkeley National

Laboratory

Acting Leader, Heat Island Group
Meng-Dawn Cheng, Ph.D.

Oak Ridge National Laboratory

Research Engineer

Building Envelope Program

Hashem Akbari, Ph.D.

Concordia University, Montreal

Retired from $L B N L$

Founder, Heat Island Group
Joshua New, Ph.D.

Oak Ridge National Laboratory

Computer Science Specialist

Building Envelope Program

Paul Berdahl, Ph.D.

Lawrence Berkeley National

Laboratory

Retired (Physicist)

\section{ABSTRACT}

Airborne particulate matter that settles on a roof can either reflect or absorb incoming solar radiation, dependent on the chemical content and size of the particles. These light scattering and absorption processes occur within a few microns of the surface, and can affect the solar reflectance of the roof. Wilkes et al. (2000) tested 24 different roof coatings on a low-slope test stand and observed about a $25 \%$ decrease in the solar reflectance of white-coated and aluminum-coated surfaces as the time of exposure increased; however, the decrease leveled off after 2 years. SPRI Inc. and its affiliates studied the effect of climatic exposure on the surface properties of white thermoplastic single-ply membranes and determined that membranes lose from 30 to $50 \%$ of their reflectance over 3 years (Miller et al. 2002). The CMRC and its affiliates AISI, NamZAC, MBMA, MCA and NCCA exposed unpainted and painted metal roofing on both steep- and low-slope test roofs and found that after $3 \frac{1}{2}$ years, the painted polyvinylidene fluoride (PVDF) metal roofs lost less than $5 \%$ of their original reflectance (Miller et al. 2004). The results of the three different weathering studies are very interesting in terms of their solar reflectance after $3 \frac{1}{2}$ years of exposure. The white thermoplastic membrane and white ceramic coating with white topcoat had original reflectance measures that were about 20 percentage points higher than the painted metal; however, after 3-years of field exposure the solar reflectance of the painted metal exceeds that of the thermoplastic membrane and equals that of the coating. The long-term loss of reflectance appears driven by the ability of the particulate matter to cling to the roof and resist being washed off by wind and or rain.

Miller et al. (2002) discovered that aerosol deposition introduced biomass of complex microbial consortia onto the test roofs and the combination of contaminants and biomass accelerated the loss of solar reflectance for the thermoplastic membranes and the roof coatings. Airborne contaminants and biomass were also detected on the painted metal roofs; however, the loss of solar reflectance was less than $5 \%$ for the painted metal roofs. The chemistry of the PVDF paint resin system uses similar organic film bonding to that responsible for Teflon ${ }^{\circledR}$, making it extremely chemical resistant and dirt shedding. Miller and Rudolph (2003) found the PVDF painted metals maintained solar reflectance even after 30 years of climatic exposure. Therefore the reduction of roof reflectance is 
closely related to the composition of the roof and to the chemical profile of the contaminants soiling the roof.

Contaminants collected from samples of roof products exposed at seven California weathering sites were analyzed for elements and carbons to characterize the chemical profile of the particles soiling each roof sample and to identify those elements that degrade or enhance solar reflectance. The losses in solar reflectance varied from site to site and also varied at a give site based on the color of the coupon. The least drop in reflectance was observed in the alpine climate of McArthur while the largest drop occurred in sites near urban development. Light color samples were soiled after just one year of exposure. The darker color coupons did not show the same seasonal variations in solar reflectance as observed for the lighter colors. However, after an additional year of exposure the samples at all sites regained most of their solar reflectance due to rain and/or wind washing. The loss of reflectance appears cyclical with the onset of seasons having more rainfall.

Solar reflectance of the cool pigmented coupons always exceeded that of the conventional pigmented coupons. Climatic soiling did not cause the cool pigmented roof coupons to lose any more solar reflectance than their conventional pigmented counterparts. The effect of roof slope appears to have more of an effect on lighter color roofs whose solar reflectance exceeds at least 0.5 and visually shows the accumulation of airborne contaminants. The thermal emittance remained invariant with time and location and was therefore not affected by climatic soiling.

A thin-film deposition model was developed based on first principles, which simulates light interaction with a soiled substrate. This model was used in combination with the measured data to determine the solar absorptance and reflectance of particulate matter at each of the sites calculated using least squares fitting routines. Principal Component Analysis was used to determine the most important combinations of chemicals correlated with changes in solar absorption. Linear regression helped extract an approximate correlation using chromium, iron and elemental carbon concentrations. It appears that chromium ranks first, iron ranks second, and elemental carbon ranks third in importance to soil absorptance in the data

\section{INTRODUCTION}

The objectives of this task are (1) document the drop in solar reflectance and the change in thermal emittance for roof products having cool color pigments, (2) characterize the particulate matter deposited on roof samples of different materials, (3) establish the relationship between the deposited particulate matter and reduction of solar reflectance, and (4) quantify the contributions of the chemical composition of the particulate matter on the enhancement or loss of solar reflectance on a roof material.

The long-term benefits of cool pigmented roofing systems (Akbari et al. 2004) can be compromised if a significant loss in solar reflectance occurs during the first few years of service life. Ultraviolet radiation, atmospheric pollution, microbial growths, acid rain, temperature cycling caused by sunlight and sudden thunderstorms, moisture penetration, condensation, wind, hail, and freezing and thawing are all thought to contribute to the loss of a roof's solar reflectance.

Field data reported by Miller et al. (2002) suggests that the loss of reflectance is due to dust load and or biomass accumulation, which in turn is affected by the climatic 
conditions. Biomass may be due to the growth of fungi and/or mold species that were transported by airborne particulate matter blown by the wind. Deposition of atmospheric carbon, nitrogen, and moisture accumulation on the roof provide suitable conditions for the colonization of these microbes.

Results published by Berdahl et al. (2002) indicate that "the long-term change of solar reflectance appears to be determined by the ability of deposited soot to adhere to the roof, resisting washout by rain." Samples studied were bare metal and polyvinyl chloride (PVC) roofing weathered for 18 years. Berdahl attributed soot, also known as black carbon and elemental carbon, to be the primary cause of long-term reflectance loss. Other potentially important light absorbing particles are organic carbon (OC) and ironcontaining minerals such as hematite. Further, we will present here new preliminary data that indicate that anthropogenic chromium compounds are an additional cause of light absorption. Organic carbon consists of hydrocarbon substances from combustion and carbon in the form of biomass. However, it is plausible that the aged solar reflectance of roofs is affected by many factors including atmospheric deposition of soot particles and dusts (e.g., dirt, road dust, and soil particles). To study the issues further, characterization of the chemical and physical attributes of the deposited particles was conducted in the diverse climates of California.

\section{WEATHERING SITES IN CALIFORNIA}

Seven sites in the diverse climates of California (Table 1) were selected for exposing painted metal, clay and concrete tile roof products with and without cool color pigments. Custom-Bilt Metal, Steelscape, BASF, MonierLifetile, US Tile, Maruhachi Ceramics of America (MCA), the Shepherd Color Company, American Rooftile Coatings, Metro Roof products, Elk Corporation, Certainteed and Owens Corning supported the initiative by field testing roof samples at their respective manufacturing facilities (Table 1) and/or by providing roof products for natural exposure testing. The California population is expanding rapidly in the Central Valley and around the LA basin, and the sites with Custom-Bilt (Sacramento) and Elk (Shafter) capture the effects of weather, urban pollution and the expanding population. These areas reflect the market for new homes. Weathering sites with Steelscape, BASF and MCA are located in existing densely populated areas of the San Francisco basin and LA, and represent the market for re-roofing existing homes. Samples were also exposed near weather stations maintained by the California Irrigation Management Information System (CIMIS). Sites in McArthur and El Centro, CA. were selected for acquiring exposure data in the more extreme climates. McArthur is located in the moderate alpine climate of northern California (climate zone 16); El Centro is in the extremely hot desert climate of southern California bordering the Arizona state line (climate zone 15). 


\begin{tabular}{|r|c|c|c|c|}
\hline \multicolumn{5}{|c|}{ Table 1. Weathering Sites for exposing roof products. } \\
\hline Company & City & County & Climate Zone & $\begin{array}{c}\text { Roof or } \\
\text { Ground Mount }\end{array}$ \\
\hline \hline $\begin{array}{r}\text { Department of Water } \\
\text { Resources ClMIS }\end{array}$ & $\begin{array}{c}\text { El Centro } \\
\text { (RS01) }\end{array}$ & Imperial & 15 & Ground \\
\hline $\begin{array}{r}\text { Maruhachi Ceramics } \\
\text { of America }\end{array}$ & $\begin{array}{c}\text { Corona } \\
\text { (RS02) }\end{array}$ & Riverside & 10 & Ground \\
\hline BASF & $\begin{array}{c}\text { Colton } \\
\text { (RS03) }\end{array}$ & San Bernadino & 10 & Roof \\
\hline ELK Corporation & $\begin{array}{c}\text { Shafter } \\
\text { (RS04) }\end{array}$ & Kern & 13 & Ground \\
\hline Steelscape & $\begin{array}{c}\text { Richmond } \\
\text { (RS05) }\end{array}$ & Contra Costa & 3 & Roof \\
\hline Custom-Bitt & $\begin{array}{c}\text { Sacramento } \\
\text { (RS06) }\end{array}$ & Sacramento & 12 & Roof \\
\hline $\begin{array}{r}\text { Department of Water } \\
\text { Resources ClMIS }\end{array}$ & $\begin{array}{c}\text { McArthur } \\
\text { (RS07) }\end{array}$ & Shasta & 16 & Ground \\
\hline
\end{tabular}

The CIMIS web site http://www.cimis.water.ca.gov/ has current weather data that can help estimate the loss of solar reflectance as affected by the climatic elements. In fact, CIMIS has 118 computerized weather stations acquiring hourly, daily, weekly and/or monthly solar irradiance, ambient air temperature and relative humidity as well as wind speed, wind direction and precipitation; Table 2 locates each weathering site and provides the closest CIMIS station to each weathering site. Solar reflectance (SR) of the new and aged samples is also provided for the different samples used for elemental contaminant determinations.

\section{Exposure Racks}

All roof samples were installed in exposure rack assemblies, which are 5.5-ft high by 9 -ft long, and divided into three sub-frames having respective slopes of 2-, 4- and 8-in of rise per 12-in of run (i.e., slopes of $9.5^{\circ}, 18.4^{\circ}$ and $33.7^{\circ}$ ). Each sub-frame can hold two sub-assemblies, which are designed to have 6 rows of samples with 34-in of usable space in each row. Sample size is 3.5-in by 3.5-in, a size that LBNL's spectrophotometer ${ }^{1}$ can easily accommodate for measuring the solar reflectance at discrete wavelengths. Finally all exposure rack assemblies were oriented facing south for full exposure to natural sunlight and weathering (Fig. 1).

\footnotetext{
${ }^{1}$ Perkin-Elmer Lambda 900
} 
Table 2. Sample Identifications and Solar Reflectance after 1.63 and 4.06 years of exposure.

\begin{tabular}{|c|c|c|c|c|c|c|c|}
\hline & $\begin{array}{c}\text { El Centro } \\
\text { (RSO1) } \\
\end{array}$ & $\begin{array}{l}\text { Corona } \\
\text { (RSO2) } \\
\end{array}$ & $\begin{array}{l}\text { Colton } \\
\text { (RSO3) } \\
\end{array}$ & $\begin{array}{l}\text { Shafter } \\
\text { (RSO4) } \\
\end{array}$ & $\begin{array}{c}\text { Richmond } \\
\text { (RSO5) }\end{array}$ & $\begin{array}{c}\text { Sacramento } \\
\text { (RSO6) }\end{array}$ & $\begin{array}{c}\text { McArthur } \\
(\mathrm{RSO7}) \\
\end{array}$ \\
\hline CIMIS Site ${ }^{1}$ & 87 & 44 & 44 & 5 & 157 & $131 \& 155$ & 43 \\
\hline Latitude & $32^{\circ} 48^{\prime} 24^{\prime \prime} \mathrm{N}$ & $33^{\circ} 57^{\prime} 54^{\prime \prime N} \mathrm{~N}$ & $33^{\circ} 57^{\prime} 54^{\prime \prime} \mathrm{N}$ & $35^{\circ} 31^{\prime} 59^{\prime \prime} \mathrm{N}$ & $37^{\circ} 59^{\prime} 30^{\prime \prime} \mathrm{N}$ & $38^{\circ} 35^{\prime} 58^{\prime \prime} \mathrm{N}$ & $41^{\circ} 03^{\prime} 53^{\prime \prime} \mathrm{N}$ \\
\hline Longitude & $115^{\circ} 26^{\prime} 46^{\prime \prime W}$ & $117^{\circ} 200^{\prime} 08^{\prime \prime} \mathrm{W}$ & $117^{\circ} 20^{\prime} 08^{\prime \prime W}$ & $119^{\circ} 16^{\prime} 52^{\prime \prime W}$ & $122^{\circ} 28^{\prime} 12^{\prime \prime W}$ & $121^{\circ} 3225^{\prime \prime W}$ & $121^{\circ} 27^{\prime} 16^{\prime \prime W}$ \\
\hline Samples for Element Study & $\begin{array}{l}\text { Gray Artic } \\
\text { concrete tile }\end{array}$ & $\begin{array}{c}\text { Gray Artic } \\
\text { concrete tile }\end{array}$ & $\begin{array}{l}\text { PVDF Metal } \\
\text { Charcoal Gray }\end{array}$ & $\begin{array}{l}\text { PVDF Metal } \\
\text { Rawhide }\end{array}$ & $\begin{array}{l}\text { PVDF Metal } \\
\text { Rawhide }\end{array}$ & $\begin{array}{l}\text { Gray Artic } \\
\text { concrete tile }\end{array}$ & $\begin{array}{l}\text { PVDF Metal } \\
\text { Rawhide }\end{array}$ \\
\hline Sample ID & 976 & 676 & $517,518,519$ & $\begin{array}{l}704,705 \\
706,707\end{array}$ & 404,406 & 378 & 805,806 \\
\hline Sample Area $\left(\mathrm{m}^{2}\right)$ & $7.903 \mathrm{E}-03$ & $7.903 \mathrm{E}-03$ & $2.371 \mathrm{E}-02$ & $3.161 \mathrm{E}-02$ & $1.581 \mathrm{E}-02$ & $7.903 \mathrm{E}-03$ & $1.581 \mathrm{E}-02$ \\
\hline SR initial & 0.265 & 0.252 & 0.308 & 0.571 & 0.569 & 0.269 & 0.570 \\
\hline SR after $1.63 \mathrm{yrs}$ & 0.275 & 0.233 & 0.297 & 0.524 & 0.545 & 0.248 & 0.547 \\
\hline Samples for Biomass Study & $\begin{array}{c}\text { PVDF Metal } \\
\text { Hartford Green }\end{array}$ & $\begin{array}{c}\text { PVDF Metal } \\
\text { Charcoal Gray }\end{array}$ & $\begin{array}{c}\text { Gray Artic } \\
\text { concrete tile }\end{array}$ & $\begin{array}{c}\text { Buff Blend } \\
\text { Clay tile }\end{array}$ & $\begin{array}{l}\text { PVDF Metal } \\
\text { Rawhide }\end{array}$ & $\begin{array}{l}\text { Brown Artic } \\
\text { concrete tile }\end{array}$ & $\begin{array}{l}\text { PVDF Metal } \\
\text { Rawhide }\end{array}$ \\
\hline Sample ID & $920,921,922,923$ & 616 & 576 & 779,780 & 405 & 372 & 804,807 \\
\hline Sample Area $\left(\mathrm{m}^{2}\right)$ & $3.161 \mathrm{E}-02$ & $7.903 \mathrm{E}-03$ & $7.903 \mathrm{E}-03$ & $1.581 \mathrm{E}-02$ & $7.903 \mathrm{E}-03$ & $7.903 \mathrm{E}-03$ & $1.581 \mathrm{E}-02$ \\
\hline SR aged & 0.272 & 0.309 & 0.246 & 0.527 & 0.569 & 0.261 & 0.571 \\
\hline SR after 1.63 yrs & 0.277 & 0.297 & 0.241 & 0.484 & 0.544 & 0.254 & 0.549 \\
\hline Samples for Element Study & $\begin{array}{l}\text { PVDF Metal Red } \\
\text { Brick }\end{array}$ & $\begin{array}{l}\text { PVDF Metal } \\
\text { Hartford Green }\end{array}$ & $\begin{array}{l}\text { PVDF Metal } \\
\text { Slate Blue }\end{array}$ & $\begin{array}{c}\text { MCA Clay Tile } \\
\text { White Buff }\end{array}$ & $\begin{array}{l}\text { PVDF Metal } \\
\text { Rawhide }\end{array}$ & $\begin{array}{l}\text { PVDF Metal } \\
\text { Charcoal Gray }\end{array}$ & $\begin{array}{c}\text { PVDF Metal Slate } \\
\text { Blue }\end{array}$ \\
\hline Sample ID & $912-915$ & $620-623$ & $508-511$ & $728-730$ & 407 & $316-319$ & $808-811$ \\
\hline Sample Area $\left(m^{2}\right)$ & $3.161 \mathrm{E}-02$ & $3.161 \mathrm{E}-02$ & $3.161 \mathrm{E}-02$ & $2.37 \mathrm{E}-02$ & $7.90 \mathrm{E}-03$ & $3.161 \mathrm{E}-02$ & $3.161 \mathrm{E}-02$ \\
\hline SR initial & 0.374 & 0.272 & 0.283 & 0.636 & 0.440 & 0.308 & 0.282 \\
\hline SR after $4.06 \mathrm{yrs}$ & 0.405 & 0.340 & 0.274 & 0.442 & 0.424 & 0.282 & 0.267 \\
\hline & Clay Apricot Buff & $\begin{array}{c}\text { Shepherd Gray } \\
\text { Artic }\end{array}$ & $\begin{array}{c}\text { MonierLife } \\
\text { Terracotta red }\end{array}$ & $\begin{array}{l}\text { Shepherd } \\
\text { Blue Artic }\end{array}$ & $\begin{array}{c}\text { MCA, Clay Tile } \\
\text { Weathered Green }\end{array}$ & $\begin{array}{l}\text { A.m Roof } \\
\text { Coatings }\end{array}$ & $\begin{array}{l}\text { MCA Clay Tile } \\
\text { Regency Blue }\end{array}$ \\
\hline Sample ID & $931-933$ & $677-678$ & $549-551,578$ & $764-766$ & $443-445$ & $381-386$ & $837-839$ \\
\hline Sample Area $\left(\mathrm{m}^{2}\right)$ & $2.37 \mathrm{E}-02$ & $1.58 \mathrm{E}-02$ & $3.16 \mathrm{E}-02$ & $2.37 \mathrm{E}-02$ & $2.37 \mathrm{E}-02$ & $4.74 \mathrm{E}-02$ & $2.37 \mathrm{E}-02$ \\
\hline SR initial & 0.608 & 0.247 & 0.199 & 0.236 & 0.415 & See Below ${ }^{2}$ & 0.420 \\
\hline SR after $4.06 \mathrm{yrs}$ & 0.493 & 0.304 & 0.222 & 0.252 & 0.354 & & 0.418 \\
\hline \multicolumn{8}{|c|}{${ }^{1} \mathrm{http} / /$ whwcimis.water.ca.gow/cimis/welcome.jsp } \\
\hline \multicolumn{8}{|c|}{${ }^{2}$ Solar reflectance for Am Rooftile Coatings exposed in Sacramento, CA } \\
\hline & & \multicolumn{2}{|c|}{ Time (yrs) } & & & & \\
\hline Sample & Code & 0 & 3.49 & & Area $\left(m^{2}\right)$ & & \\
\hline Ultra Marine & 381 & 0.392 & 0.392 & & $7.90 \mathrm{E}-03$ & & \\
\hline Chocolate & 382 & 0.41 & 0.381 & & $7.90 \mathrm{E}-03$ & & \\
\hline Camo Green & 383 & 0.463 & 0.357 & & $7.90 \mathrm{E}-03$ & & \\
\hline Light Gray & 384 & 0.433 & 0.417 & & 7.90E-03 & & \\
\hline Terracotta & 385 & 0.473 & 0.451 & & $7.90 \mathrm{E}-03$ & & \\
\hline Onyx & 386 & 0.417 & 0.431 & & $7.90 \mathrm{E}-03$ & & \\
\hline
\end{tabular}

\section{Instruments}

A Device and Services solar spectrum reflectometer was used to measure the solar reflectance (total hemispherical reflectance over spectrum of sun's energy) of the roof samples. The device uses a tungsten halogen lamp to diffusely illuminate a sample. Four detectors, each fitted with differently colored filters, measure the reflected light in different wavelength ranges. The four signals are weighted in appropriate proportions to yield the solar reflectance. The device was proven accurate to within \pm 0.003 units (Petrie et al. 2000) through validation against the ASTM E-903 method (ASTM 1996).

However, because the cool pigmented roof products exhibit high infrared reflectance, some of the field samples were measured at LBNL using their spectrophotometer to 
check the portable reflectometer. The average absolute difference between the Device and Services reflectometer and the spectrophotometer was about 0.02 points of reflectance with the spectrophotometer consistently reading lower than the reflectometer (as example, the reflectometer measured a solar reflectance of 0.741 for a IR painted metal while the spectrophotometer measured 0.73).

The impact of emittance on roof temperature is as important as that of reflectance. A portable Device and Services emissometer was used to measure the thermal emittance using the procedures in ASTM C-1371 (ASTM 1997). The device has a thermopile radiation detector, which is heated to $82.2^{\circ} \mathrm{C}\left(180^{\circ} \mathrm{F}\right)$. The detector has two high- $\varepsilon$ and two low- $\varepsilon$ elements and is designed to respond only to radiation heat transfer between itself and the sample. Because the device is comparative between the high- $\varepsilon$ and the low$\varepsilon$ elements, it must be calibrated in situ using two standards, one having an emittance of 0.89, the other having an emittance of 0.06. Kollie, Weaver, and McElroy (1990) verified the instrument's precision as \pm 0.008 units and its accuracy as \pm 0.014 units in controlled laboratory conditions.

\section{FIELD MEASUREMENTS}

Akbari and Konopacki (1998) and Miller et al. (2004) showed that in moderate to predominantly hot climates, an exterior roof surface with a high solar reflectance and high thermal emittance will reduce the exterior temperature and produce savings in comfort cooling. For predominantly heating-load climates, surfaces with moderate reflectance but low infrared emittance save in comfort heating. Determining the affects of climatic soiling on the solar reflectance and infrared emittance of cool color roofs is therefore very important for developing realistic claims of the net energy savings (cooling energy savings less heating penalty).

Coupons of concrete and clay tile and painted metal roof samples were exposed to the elements in six of California's sixteen climate zones. The tabulation of the solar reflectance data for the seven weathering sites is provided in Appendix A. Contaminant samples were collected after 1.6 and 4.1 years of exposure for the coupons identified in Table 2. The measures of solar reflectance and thermal emittance are reported herein to view the time dependence of climatic soiling and later, in the contaminants section, the impact of the various contaminants on the loss of solar reflectance.

\section{Effects of Soiling on Roof Samples in the Field}

The Regal white painted PVDF coupon steadily lost solar reflectance over the first year of exposure (Fig. 2). The loss varied from site to site with the least drop observed at McArthur (4\% after one year) and the worst occurring in the more desert-like areas of Colton and Meloland (23\% after one year). The exposure rack in Colton is roofmounted while the one in Meloland is ground mounted (Table 1), yet the change in solar reflectance after one year of exposure is very similar between the two sites. Visible inspection of the Regal white painted metal exposed at Shafter [medium sloped rack (4-in rise per 12-in run)] showed the sample was soiled with airborne debris after one year of exposure (Fig. 3). However, after an additional 8 months of weathering the samples at all sites regained most of their solar reflectance (average SR loss of only $6 \%$ from starting SR value). Meloland and Shafter had less than $1 / 2-$ in of rainfall from Aug 04 through 
April 05; however, McArthur, Corona, Colton, Sacramento and Richmond had two consecutive months in early 2005 with rains exceeding 5 -in per month. The average winds remained steady at about 4 to $5 \mathrm{mph}$ over the entire exposure period at all sites. Hence the results are showing that the loss of reflectance is remedied in part by the combination of precipitation and wind sweeping or simply wind sweeping in the drier climates of El Centro and Shafter.

The darker charcoal gray coupon did not show the same seasonal variations in solar reflectance as the lighter coupon because its solar reflectance is roughly half that of the white painted metal (Fig. 4). Dusts tend to lighten darker colors and the soiling of the charcoal gray coupon slightly increased solar reflectance. Coupons of the same color but having conventional pigments (labeled standard in Fig. 2 and 4) have lower solar reflectance than do the cool pigmented colors during the entire exposure period. The result is important because climatic soiling did not cause the cool pigmented colors to degrade more than that observed for the conventional pigmented colors. Therefore the cool pigmented painted metals performed as well as their counterparts. Further, the infrared reflective pigments boost the solar reflectance of a dark more aesthetically pleasing color to about 0.3 to 0.4 (view standard versus cool pigments at start of exposure Fig. 4) and results for the charcoal gray painted metal shows only about a 3\% drop in solar reflectance over about 4 years of exposure.

Climatic soiling had little effect on the solar reflectance of clay and concrete tile (Fig. 5). Dusts appear to lighten the darker Terra Cotta color. Results showed that both concrete and clay coupons lost less than 5\% of their original solar reflectance (Appendix A). Finally, the effect of roof slope becomes somewhat significant for coupons exceeding an initial solar reflectance of 0.50 , as observed for the Regal white painted metal coupons displayed in Fig. 6. As stated the coupons collect dust with the worst soiling occurring for samples exposed in Meloland, Colton, Corona and Shafter. The crisp and clear alpine climate of McArthur continues to show the lowest loss of reflectance (Fig. 6). The drop in solar reflectance diminishes slightly as roof slope increases for samples at Meloland and McArthur. Also the darker more aesthetically pleasing roof colors do not show the trend. The darker charcoal gray coupon shows slight increases in solar reflectance with time in El Centro and in Colton because of the accumulation of dusts that tend to lighten a darker color. Therefore the effect of roof slope appears more academic and its affect is secondary as compared to the soiling by airborne dust debris. It is also important to again point out that the cool pigmented colors maintain their solar reflectance as well as their conventional pigmented counterparts.

The thermal emittance of the painted metal, clay and concrete tile coupons has not changed much after 4 years of exposure in California (Table 3). Miller et al. (2004) and Wilkes et al. (2000) both observed little variation in the thermal emittance of painted and or coated surfaces. Consistent with reported findings, the thermal emittance did not vary from site-to-site nor did it change with time for these painted products. Thermal emittance of metals is strongly dependent on surface properties. Unpainted metals will over time oxidize; the metal oxide surface layer increases the thermal emittance (Miller and Kriner 2001). However, the paint finishes applied to PVDF metal and clay and concrete tile are very durable and there is therefore no adverse weathering effects observed for the thermal emittance of painted roof products. 
Table 3. Thermal Emittance measured for roof coupons at different sites over time of exposure.

\begin{tabular}{|r|c|c|c|c|c|c|c|c|}
\hline \multicolumn{2}{|c|}{ Roof Sample } & \multirow{2}{*}{ Site } & \multicolumn{7}{|c|}{ Thermal Emittance at Exposure Times (yrs) } \\
& & 0.000 & 0.748 & 0.962 & 1.630 & 2.493 & 3.592 & 4.047 \\
\hline \hline Charcoal Gray PVDF Metal & Corona & 0.83 & & & 0.82 & 0.84 & 0.84 & 0.83 \\
\hline & Richmond & 0.82 & 0.82 & 0.82 & & & & \\
\hline & & & & & & & & \\
\hline Rawhide PVDF Metal & Corona & 0.86 & & & 0.84 & 0.87 & 0.84 & 0.85 \\
\hline & Richmond & 0.83 & 0.84 & 0.84 & & & & \\
\hline Apricot Buff Clay Tile & Corona & 0.86 & 0.85 & 0.92 & 0.82 & 0.91 & 0.90 & 0.90 \\
\hline & Richmond & 0.86 & 0.83 & 0.83 & & & & \\
\hline & & & & & & & & \\
\hline Gray Artic Concrete Tile & Corona & & 0.84 & & & & & \\
\hline & Richmond & & 0.84 & 0.84 & & & & \\
\hline
\end{tabular}

\section{Contaminants measured in the field}

The contaminant study encompassed the identification of elements and carbons for characterizing the chemical profile of the particles soiling each roof sample. Coupons were analyzed after 1.63 years of exposure and a second set was analyzed after 4.1 years of exposure. The procedures used to detect and identify contaminants are reviewed to document the handling of samples and the analysis techniques used to identify particulates.

\section{Procedure for Measuring Elemental Contaminants}

Contaminants were swabbed from the concrete and painted metal coupons identified in Table 2. The samples from a single site were removed from the exposure racks, wrapped in aluminum foil, stored in a zip lock bag and sent airfreight back to ORNL.

Each sample was placed in a laboratory sonicating ${ }^{2}$ bath filled with $800 \mathrm{ml}$ of distilled water held at room temperature. After 20 minutes, the sample was removed from the bath using sterilized stainless steel forceps. The water suspension was then poured into a filtration system with vacuum applied to filter the suspended particulate onto the filters. The solution was divided into two $400-\mathrm{mL}$ aliquots. One $400-\mathrm{mL}$ sub-sample was filtered through a 47-mm diameter nylon filter (OSMONIC, Inc., $0.1 \mu \mathrm{m}$ pore size) that was subsequently analyzed for selected metal composition by a certified analytical lab. The other 400-mL sub-sample was passed through the same filtration system through a 47-mm diameter glass fiber filter (Whatman 934-GF). About $100 \mathrm{~mL}$ of additional deionized water was used to rinse off any particulate matter (PM) that remained on the samples. All the filters were placed in a laboratory desiccator and held overnight at room temperature before being analyzed. For quality control, $400 \mathrm{ml}$ of deionized water was filtered through a nylon filter to create an analytical blank of metal species. A glass fiber blank was created similarly for carbon analysis. The filtration apparatus was rinsed three times using deionized water in between different filtration runs.

Inductively Coupled Plasma (ICP) - Atomic Emission Spectrometry (AES) was used for analysis of the metal content on the filters. Metal concentrations in the deposited PM that exceeded those detected for blank values were reported. The carbon content was

\footnotetext{
${ }^{2}$ Sonicating agitates the bath using high-frequency sound waves.
} 
analyzed for total, elemental, and organic carbon by the Sunset Laboratory ${ }^{3}$, Inc., Portland, OR. Three samples, each 1-square cm, were punched out from a 47-mm diameter quartz filter and analyzed by the instrument, and the average of the triplicate was assigned as the carbon concentration for the sample. If the coefficient of variation of the triplicate concentration is greater than $\pm 5 \%$, the sample is considered as non-uniform deposition and the result may be discarded. In this study all the samples met the precision requirement and were retained in the subsequent data analysis.

\section{Chemical profile of roof particulates}

Figure 7 (data after 1.63 years of exposure) and Figure 8 (data after 4.1 years of exposure) display the concentration flux of elements and the variation of these elements across the weathering sites. At some sites only one sample was pulled, while at another site several samples were pulled just to obtain a sufficient quantity of contaminants (Table 2). All elements shown on the X-axis of each plot are those whose concentrations were higher than the method's detection limits and above the blank values.

Coupons pulled after 4.1 years of exposure (Fig. 8) and those pulled after only 1.6 years of exposure show similar contaminant flux concentrations (Fig. 7). Many of the metals analyzed for all sites are of crustal origins such as road dusts, soil, and or rock debris. Sulfur content in the roof samples was not large, which may be attributed to the absence of coal-fired power plants in California. Sulfur (S) was lowest at McArthur possibly because of its rural setting while at all other sites the concentration of $\mathrm{S}$ was about the same. Calcium is found to be in rather high abundance, except for the remote McArthur site in northeastern California. The elements aluminum, silicon, potassium, titanium, iron and barium ( $\mathrm{Al}, \mathrm{Si}, \mathrm{K}, \mathrm{Ti}, \mathrm{Fe}$ and $\mathrm{Ba}$ ) are typically associated with soil and dust and their respective concentrations are similar across all weathering sites. Greater variations are observed with anthropogenic elements such as vanadium, chromium, nickel, zinc, and lead (V, Cr, Ni, Zn, and $\mathrm{Pb}$ ). Generally the clear alpine climate of McArthur yielded the lowest or near lowest concentration of these elements emanating from man-made emissions.

OC values are higher than EC values for all sites. The McArthur site that is located in an alpine climate rather than the industrial and or urban environments of the other sites had the least amount of EC per unit area of pulled sample. Plants and vegetations are excellent sources of emission of organic compounds that could be detected as $\mathrm{OC}$, if the compounds or their reaction products were found on particulate matter. On the other hand, elemental carbons (e.g., soot) emanate from combustion source emissions such as vehicle engine exhausts. We thus attributed the observed higher EC values in Shafter, Richmond and Sacramento to potential contributions by traffic and vehicle emissions at the sites. The traffic volume around the McArthur site area is much less than other areas because of its rural setting, but McArthur is in a forest area where biogenic emissions might be significant. This resulted in higher OC than EC, and the data reported here support this understanding.

To further study the sources of carbon content in aerosol particles, we computed the ratios of EC to OC for the seven sites based on the data shown in Figs 7 and 8. The

\footnotetext{
${ }^{3}$ The Sunset instrument is capable of analyzing carbon content of a filter sample using the temperature and oxidation profiles of particulate carbonaceous species to define organic vs. elemental carbon (i.e., OC vs. EC). The total sum of OC and EC is called the total carbon of a sample.
} 
EC/OC ratio has been successfully used by Appel et al., 1976, Turpin and Huntzicker, 1995, and Strader et al., 1999 to identify whether the carbon in aerosol was primary or secondary in content. If the $\mathrm{EC} / \mathrm{OC}$ ratio is low and correlation between $\mathrm{OC}$ and $\mathrm{EC}$ is high, the carbon likely emanates from direct emissions. Average EC/OC value reported by Appel et al., 1976, Turpin and Huntzicker, 1995, and Strader et al., 1999 is about 0.48 in winter, 0.32 in spring, and 0.18 in summer. The EC/OC ratios computed for the seven sites were all smaller than 0.18 , much smaller than 0.48 . These results suggest averaged over the 1.6 and 4.1 year exposure periods, the carbon contents found on PM deposited at these sites were driven primarily by sources such as biogenic emissions and or forest or local brush fire rather than photochemical conversion.

\section{Effect of particulate matter on roof materials}

The results presented in Figs 7 and 8 indicate two major contributors of particulate matter: crustal sources and traffic activities. Miller et al. (2006) conducted linear regression analysis to determine the important chemical elements that contributed to the loss of roof reflectance; however, only the 1.6 year exposure data was available from the $\mathrm{CA}$ weathering sites. Results showed statistically that $\mathrm{Cr}, \mathrm{Cu}, \mathrm{Mn}, \mathrm{Mg}, \mathrm{Ni}, \mathrm{Na}$, $\mathrm{S}, \mathrm{V}$, and $\mathrm{EC}$ had little contribution to the change of solar reflectance. Al and OC contributed to the increase of solar reflectance values found at the sites, and $\mathrm{Ca}, \mathrm{Fe}, \mathrm{K}, \mathrm{Si}$, and $\mathrm{Zn}$ could contribute to the degradation of solar reflectance measured on the roof samples. Aluminum oxide has a refractive index of about 1.7, and its particles can thus be reflective in the visible to infrared region. Organic carbon, OC, is a highly complex mixture of materials containing carbon that can be detected in the form of $\mathrm{CO}_{2}$ when burned. OC is well-known to be a reflective component of aerosol particles (see Novakov and Penner, 1993 in http://eetd.lbl.gov/newsletter/nl17/blackcarbon.html, for example) due to its ability to scatter light. OC absorbs at short wavelengths (UV and blue), but is reflective at longer wavelengths. EC is commonly referred to as black carbon or soot and is believed to be a significant factor in the loss of a roof's solar reflectance (Berdahl et al., 2002).

The second set of elemental contaminants collected after 4 years of exposure (2008 data) were statistically analyzed with and without the contaminant data collected after just 1.6 years of exposure (2005 data). A principal component analysis (PCA) test identified the parameters that best describe the solar reflectance of the roof samples. Both the 2005 and the 2008 data show two components resolved by PCA. One is related to dust characterized by the chemical species $\mathrm{Al}, \mathrm{Ca}, \mathrm{Fe}, \mathrm{K}, \mathrm{Si}, \mathrm{OC} 4$ (organic carbon). $\mathrm{Br}$ is also observed; however, it is not thought to be a soil ingredient. Possibly its presence comes from sea salt. The other principal component is of anthropogenic origin and was identified as $\mathrm{Cu}, \mathrm{Sb}$, and $\mathrm{Zn}$. Overall, a Scree test verified that the two data sets (2005 and 2008) can be correlated using two variables and explained $87 \%$ of the variation in the data. Dust appears a dominant factor contributing to the data variation in California. Corona showed the greatest amounts of anthropogenic contaminants possibly because of new industrial activities in that region from 2005 to 2008.

\footnotetext{
${ }^{4}$ Organic carbon (OC) was defined by any carbonaceous compounds that can be burned below about $400^{\circ} \mathrm{C}$. Any carbon that was not $\mathrm{OC}$ was operationally attributed to EC.
} 


\section{Effects of Carbon Soot on roof materials}

The role of elemental carbon (i.e., soot) if in significant content in aerosols has dramatic effects on the loss of solar reflectance. Berdahl (2006) shows the expected solar reflectance and visible reflectance as a function of soot concentration. The OC and EC amounts measured in mg per unit area in centimeter squared at these seven sites are shown in Table 4. The largest EC per unit area for coupons exposed for 1.63 years was

Table 4. Derived OC and EC Amounts per Unit Area on the Roof Samples Collected at the CA Sites (Detection Limit of Carbon is $0.2 \mu \mathrm{g}$ )

\begin{tabular}{|c|c|c|c|c|}
\hline \multirow{2}{*}{ Site ID } & \multicolumn{2}{|c|}{ Organic Carbon (mg/m²) } & \multicolumn{2}{|c|}{ Elemental Carbon $\left(\mathrm{mg} / \mathrm{m}^{2}\right)$} \\
\hline & $\begin{array}{c}1.63 \text { yr } \\
\text { exposure }\end{array}$ & $\begin{array}{c}4.1 \mathrm{yr} \\
\text { exposure }\end{array}$ & $\begin{array}{c}1.63 \text { yr } \\
\text { exposure }\end{array}$ & $\begin{array}{c}4.1 \mathrm{yr} \\
\text { exposure }\end{array}$ \\
\hline El Centro & 8.312 & NA & 0.237 & NA \\
\hline Corona & 5.361 & 52.226 & 0.240 & 0.987 \\
\hline Colton & 6.146 & 54.565 & 0.165 & 2.833 \\
\hline Shafter & 5.591 & 41.835 & 0.404 & 3.555 \\
\hline Richmond & 11.090 & 8.745 & 1.344 & 0.569 \\
\hline Sacramento & 4.461 & NA & 0.221 & NA \\
\hline McArthur & 1.315 & 88.902 & 0.018 & 0.796 \\
\hline
\end{tabular}

found at Richmond; its blank filter had virtually no EC. Note that the detection limit for carbon is $0.2 \mu \mathrm{g}$. However, for the samples exposed for 4.06 years, all sites with exception of Richmond had increased deposition of EC. Previous reporting by Miller et al. (2006) stated that EC was found in too small concentrations to be a significant contributor in reducing surface reflectance at all seven sites in California. The more recent data shows that EC may indeed affect the solar reflectance of the roof samples and can be used to describe the subsequent losses. It also suggests that losses in solar reflectance due to soiling occur after at least 2 to 3 years of exposure.

\section{A SIMPLE MODEL FOR A SOILED SUBSTRATE}

An increase in solar reflectance requires the addition of light-scattering particles. For example, a white powder increases the reflectance of a black or gray substrate. The ability of a particle to scatter light is proportional to the difference in refractive index of a particle and that of the surrounding medium as described by $\left(n_{p l}-n_{o}\right)^{2}$ where $n_{p l}$ is the real refractive index of the particle and $\mathrm{n}_{\mathrm{o}}$ is the refractive index of the surrounding medium. As example, many minerals and organic substances have refractive indices in the range of [1.3 to 1.8$]$ and therefore in air $\left(\mathrm{n}_{\mathrm{o}}=1\right)$ cause light scattering.

Suppose there is a soil layer with absorptance $a$, reflectance $r$, and transmittance $t$ on a substrate with a clean reflectance denoted Ro and one wishes to compute the soiled substrate reflectance R (see Fig. 9). A photon interacts with the soiled substrate in one of three ways. In the first process the photon can be reflected directly by the soil; the photon 
can be transmitted by the soil, reflected by the substrate, and transmitted again by the soil (Process 2); or the photon can be transmitted twice, reflected from the substrate twice, and reflected by the underside of the soil (Process 3 ). Therefore summing the different ways a photon can be reflected as demonstrated in Figure 9 yields a formulation for the reflectance of the soiled substrate as:

$$
\mathrm{R}=\mathrm{r}+\mathrm{t}^{2} \mathrm{R}_{\mathrm{O}}+\mathrm{t}^{2} \mathrm{R}_{\mathrm{O}}^{2} \mathrm{r}+\cdots
$$

Since an incident photon must be absorbed, reflected, or transmitted, we know that $a+r$ $+\mathrm{t}=1$. We can therefore eliminate $t$ in our equation in favor of $a$ and $r$. This assumes the soil layer is thin ( $a$ and $r$ are small compared to unity) so quadratic and higher powers of $a$ and $r$ are small and can be discarded ${ }^{5}$. It follows then that the change in reflectance $\mathrm{R}$ of the soiled substrate is given, to first order in $a$ and $r$, by:

$$
\mathrm{R}-\mathrm{R}_{\mathrm{O}}=-2 \mathrm{R}_{\mathrm{O}} \mathrm{a}+\left(1-\mathrm{R}_{\mathrm{O}}\right)^{2} \mathrm{r}
$$

Thus increasing the soil absorptance $a$ reduces the reflectance $\mathrm{R}$ of the soiled substrate while increasing the soil reflectance $r$ increases $\mathrm{R}$. The importance of $a$ diminishes if Ro is small and $r$ will be less important if Ro is close to unity.

\section{Model Limitations}

The proposed model neglects the angular distributions of the radiant energy. A two-stream approximation was assumed, keeping track only of whether the radiation is traveling up or down. Physically, radiation traveling normal to the soil layer has a shorter path length than radiation traveling obliquely. If one associates the absorptance $a$ with a measured Lambert-Beer's law absorptance ${ }^{6}$, there is an ambiguity as to the correct path length and a corresponding ambiguity in $a$ by about a factor of 2 .

The model also neglects the spectral distributions of the radiant energy. Spectral components of the absorption are likely to be larger at short wavelengths, since most materials absorb more strongly in the visible and UV compared with the near infrared. Thus the parameters $a$ and $r$ should be understood as average values over the solar spectrum. Note that for $a=0.2$, the spectral value of $a$ may still be rather large at short wavelengths, invalidating our approximation that $a<<1$.

The simple model assumes a uniform layer of soil. In principal, it may need to describe fluctuations in the thickness of the soil layer.

\section{Computed a and $r$ for soiled substrates}

Despite the above-mentioned limitations in the model of a soiled substrate, the method's strength stems from its simplicity. Based on Eq. (2), if we have measured values of both $\mathrm{R}$ and $\mathrm{R}_{0}$ for two samples with differing $\mathrm{R}_{0}$ but the same soil layer, then we can compute values for $a$ and $r$. Now in most cases, we have measurements with a dozen or more samples with the same soil layer, so we can refine the determination of $a$ and $r$ by least squares fitting, as specified in more detail below.

\footnotetext{
${ }^{5}$ If the soil layer is not thin, it can be divided into thin sublayers and the current method can be used recursively, leading to more complex equations.

${ }^{6}$ The Lambert-Beer law assumes a logarithmic dependence between the transmission of light through a soiled substrate and the product of the path length of light with the absorption coefficient of the substrate.
} 
The results for the $a$ and $r$ coefficients of polyvinylidene-fluoride (PVDF) painted metal roof samples at all slopes are listed in Table 5 and clay roofs at all slopes are listed in Table 6. Computations were made for all CA sites and all times where solar reflectance measurements were collected in the field and passed the Grubb's statistical ${ }^{7}$ test for outliers. Appendix A tabulates all the reflectance field measurements used.

\begin{tabular}{|c|c|c|c|c|c|c|c|c|c|}
\hline \multirow[b]{2}{*}{ Site } & \multicolumn{3}{|c|}{ Year $[.564, .764]$} & \multicolumn{3}{|c|}{ Year [.959,.962] } & \multicolumn{3}{|c|}{ Year $[1.625,1.644]$} \\
\hline & $\mathbf{a}$ & $r$ & sse & $\mathbf{a}$ & $r$ & sse & $\mathbf{a}$ & $r$ & sse \\
\hline Colton & 0.061 & 0.054 & 0.001216 & 0.148 & 0.181 & 0.005634 & 0.043 & 0.013 & 0.000912 \\
\hline Corona & 0.032 & 0.025 & 0.000432 & 0.092 & 0.102 & 0.008962 & 0.044 & 0.021 & 0.001362 \\
\hline Meloland & 0.039 & 0.065 & 0.00241 & 0.092 & 0.165 & 0.014618 & 0.008 & 0.014 & 0.000926 \\
\hline McArthur & 0.019 & 0.001 & 0.000481 & 0.026 & 0.031 & 0.001087 & 0.017 & 0.001 & 0.000712 \\
\hline Richmond & 0.077 & 0.047 & 0.001244 & 0.077 & 0.047 & 0.001244 & 0.021 & 0.001 & 0.000489 \\
\hline Sacramento & 0.03 & 0.001 & 0.000334 & 0.064 & 0.07 & 0.001536 & 0.034 & 0.005 & 0.000648 \\
\hline \multirow[t]{2}{*}{ Shafter } & 0.103 & 0.102 & 0.00626 & 0.121 & 0.119 & 0.006853 & 0.036 & 0.001 & 0.004755 \\
\hline & \multicolumn{3}{|c|}{ Year $[2.488,2.501]$} & \multicolumn{3}{|c|}{ Year $[3.589,3.592]$} & \multicolumn{3}{|c|}{ Year $[4.041,4.060]$} \\
\hline Colton & 0.062 & 0.059 & 0.002212 & 0.055 & 0.047 & 0.001818 & 0.161 & 0.164 & 0.116969 \\
\hline Corona & 0.082 & 0.095 & 0.004187 & 0.06 & 0.077 & 0.003193 & 0.204 & 0.33 & 0.003711 \\
\hline Meloland & 0.077 & 0.158 & 0.004812 & 0.066 & 0.142 & 0.006415 & 0.097 & 0.212 & 0.008285 \\
\hline McArthur & 0.01 & 0.02 & 0.000864 & 0.008 & 0.011 & 0.000616 & 0.025 & 0.03 & 0.001516 \\
\hline Richmond & 0.013 & 0.015 & 0.000914 & 0.023 & 0.022 & 0.002894 & 0.058 & 0.043 & 0.018385 \\
\hline Sacramento & 0.037 & 0.029 & 0.001216 & 0.06 & 0.034 & 0.004133 & 0.09 & 0.079 & 0.004985 \\
\hline Shafter & 0.083 & 0.057 & 0.005592 & 0.065 & 0.055 & 0.001923 & 0.121 & 0.106 & 0.013985 \\
\hline
\end{tabular}

To show the quality of the fits, plots of the absolute change in reflectance of the coupons (Fig. 10) are computed using Equation 2 with the $a$ and $r$ coefficients in Table 5 and superimposed on the reduced field data for coupons exposed at the various sites over the span of approximately four years. The optimal values for the $a$ and $r$ terms (Table 5) were calculated using least squares fitting routines for coupon reflectance data measured at a respective time, Fig. 10. On the y-axis is plotted the coupon's solar reflectance R, less the new coupon's initial solar reflectance Ro, as a function of Ro. Dark samples (small Ro) have an increased reflectance and light samples (large Ro) have a decreased reflectance, Fig. 10. The ordinate at $\mathrm{R}-\mathrm{Ro}=0$ marks zero reflectance change, and the curve intersects this line at $\mathrm{Ro}=0.32$. Thus a sample with $\mathrm{Ro}=0.32$ will be unchanged in reflectance by added dust. This critical value for Ro is actually a function of $a / r$. Larger $a$ leads to a darker surface, while a smaller $a$ yields a lighter surface. In summary, in the fitting process, both parameters $a$ and $r$ are determined by minimizing the mean square deviation of $\mathrm{R}-\mathrm{R}_{0}$ from the fitted line.

\footnotetext{
${ }^{7}$ Grubbs' test was used to detect and eliminate outliers in the data set.
} 


\begin{tabular}{|c|c|c|c|c|c|c|c|c|c|}
\hline \multicolumn{10}{|c|}{ Table 6. Model Fitting for Clay Roofs at All Slopes } \\
\hline & \multicolumn{3}{|c|}{ Year $[.564, .764]$} & \multicolumn{3}{|c|}{ Year $[.959, .962]$} & \multicolumn{3}{|c|}{ Year $[1.625,1.644]$} \\
\hline Site & $\mathbf{a}$ & $r$ & sse & $\mathbf{a}$ & $r$ & sse & $\mathbf{a}$ & $r$ & sse \\
\hline Colton & 0.071 & 0.04 & 0.004508 & 0.139 & 0.145 & 0.004016 & 0.058 & 0.001 & 0.004636 \\
\hline Corona & 0.053 & 0.047 & 0.003442 & 0.101 & 0.11 & 0.009918 & 0.08 & 0.057 & .003316 \\
\hline Meloland & 0.07 & 0.126 & 0.003075 & 0.084 & 0.183 & 0.003666 & 0.054 & 0.104 & 0.003461 \\
\hline McArthur & 0.021 & 0.001 & 0.003289 & 0.024 & 0.031 & 0.002662 & 0.021 & 0.001 & 0.002655 \\
\hline Richmond & 0.059 & 0.027 & 0.003189 & 0.059 & 0.027 & 0.003189 & 0.046 & 0.001 & 0.003457 \\
\hline Sacramento & 0.039 & 0.005 & 0.003295 & 0.058 & 0.074 & 0.00382 & 0.056 & 0.026 & 0.00425 \\
\hline \multirow[t]{2}{*}{ Shafter } & 0.13 & 0.143 & 0.007475 & 0.144 & 0.178 & 0.010309 & 0.084 & 0.043 & 0.00525 \\
\hline & \multicolumn{3}{|c|}{ Year $[2.488,2.501]$} & \multicolumn{3}{|c|}{ Year $[3.589,3.592]$} & \multicolumn{3}{|c|}{ Year $[4.041,4.060]$} \\
\hline Colton & 0.099 & 0.065 & 0.003863 & 0.097 & 0.063 & 0.00382 & 0.197 & 0.201 & 0.021605 \\
\hline Corona & 0.133 & 0.159 & 0.006643 & 0.128 & 0.129 & 0.014209 & 0.205 & 0.3 & 0.004796 \\
\hline Meloland & 0.094 & 0.2 & 0.00332 & 0.107 & 0.241 & 0.00205 & 0.127 & 0.282 & 0.003917 \\
\hline McArthur & 0.016 & 0.027 & 0.00205 & 0.018 & 0.012 & 0.002661 & 0.014 & 0.014 & 0.003671 \\
\hline Richmond & 0.049 & 0.026 & 0.003458 & 0.069 & 0.031 & 0.00292 & 0.085 & 0.045 & 0.005079 \\
\hline Sacramento & 0.055 & 0.048 & 0.006556 & 0.111 & 0.084 & 0.006986 & 0.131 & 0.127 & 0.010294 \\
\hline Shafter & 0.139 & 0.109 & 0.004212 & 0.11 & 0.092 & 0.004973 & 0.178 & 0.193 & 0.004302 \\
\hline
\end{tabular}

It should be noted that clay roofs averaged 34\% higher soil absorption " $a$ " coefficient than yielded by the PVDF-painted metal roofs, highlighting material-specific soiling dynamics. Likewise, compared to average low-slope soil absorption, mid-slope had an $11 \%$ reduction and steep-slope had a $16 \%$ reduction. The observation helps again confirm that there is some enhanced washing of the coupons at steeper slopes resulting in higher reflectivity over time.

\section{STATISTICAL ANALYSIS OF PARTICULATE MATTER'S EFFECT ON SOLAR REFLECTANCE}

Additional statistical techniques were used to investigate the contribution of individual elements or combinations of elements on solar reflectance. First, principal component analysis was used to indicate combinations of elements that account for the variability of the contaminant concentration data as well as correlation to soil aborptance and reflectance. Second, linear fits were utilized to determine which elements or combination of elements is best for predicting soil absorptance and reflectance. Each analysis is discussed in more detail below, and are based upon the contaminant data shared among the 5 sites and between the 2 time periods whenever concentrations exceeded the detection threshold, Table 7 


\begin{tabular}{|c|c|c|c|c|c|c|c|c|c|c|c|c|}
\hline & & & & m & & & & & & & & \\
\hline & & & & & 1.6 Years & & & & & 4 YEARS & & \\
\hline & & Site \# & RS02 & RS03 & RS04 & RS05 & RS07 & RS02 & RS03 & RS04 & RS05 & RS07 \\
\hline & & ite Name & Corona & Colton & Shafter & $\begin{array}{c}\text { Richmo } \\
\text { nd }\end{array}$ & $\begin{array}{c}\text { McArthu } \\
r\end{array}$ & Corona & Colton & Shafter & $\begin{array}{c}\text { Richmo } \\
\text { nd }\end{array}$ & $\begin{array}{c}\text { McArthu } \\
r\end{array}$ \\
\hline & & Lat,Lon & $\begin{array}{c}33.88 \mathrm{~N} \\
117.56 \mathrm{~W} \\
\end{array}$ & $\begin{array}{c}34.07 \mathrm{~N} \\
117.31 \mathrm{~W}\end{array}$ & $\begin{array}{c}35.5 \mathrm{~N} \\
119.27 \mathrm{~W}\end{array}$ & $\begin{array}{c}37.94 \mathrm{~N}, \\
122.34 \mathrm{~W}\end{array}$ & $\begin{array}{c}41.02 \mathrm{~N} \\
121.65 \mathrm{~W}\end{array}$ & $\begin{array}{c}33.88 \mathrm{~N} \\
117.56 \mathrm{~W} \\
\end{array}$ & $\begin{array}{c}34.07 \mathrm{~N} \\
117.31 \mathrm{~W}\end{array}$ & $\begin{array}{c}35.5 \mathrm{~N} \\
119.27 \mathrm{~W}\end{array}$ & $\begin{array}{c}37.94 \mathrm{~N}, \\
122.34 \mathrm{~W}\end{array}$ & $\begin{array}{c}41.02 \mathrm{~N} \\
121.65 \mathrm{~W}\end{array}$ \\
\hline & Soil $t$ & Absortance a & 0.06 & 0.053 & 0.058 & 0.034 & 0.019 & 0.206 & 0.177 & 0.147 & 0.075 & 0.02 \\
\hline & Soil F & Reflectance $r$ & 0.03 & 0.014 & 0.012 & 0.001 & 0.001 & 0.315 & 0.173 & 0.128 & 0.049 & 0.026 \\
\hline Element & Abbr. & Unit & & & & & & & & & & \\
\hline Aluminum & Al & $\mathrm{mg} / \mathrm{m}^{2}$ & 40.996 & 39.0559 & 16.449 & 26.698 & 5.34593 & 27.4173 & 9.91161 & 14.4418 & 12.3775 & 8.07376 \\
\hline Barium & $\mathrm{Ba}$ & $\mathrm{mg} / \mathrm{m}^{2}$ & 0.7149 & 0.52299 & 0.47765 & 0.25939 & 0.23218 & 0.52492 & 0 & 0.32614 & 0.4722 & 0.26626 \\
\hline Calcium & $\mathrm{Ca}$ & $\mathrm{mg} / \mathrm{m}^{2}$ & 55.294 & 95.7417 & 17.3347 & 146.143 & 1.01225 & 30.8752 & 39.893 & 42.5148 & 8.63617 & 4.01016 \\
\hline Chromium & $\mathrm{Cr}$ & $\mathrm{mg} / \mathrm{m}^{2}$ & 0.63392 & 0.74231 & 1.30327 & 0.80347 & 0.68959 & 5.71021 & 4.38469 & 2.64347 & 0.9512 & 0.32149 \\
\hline Copper & $\mathrm{Cu}$ & $\mathrm{mg} / \mathrm{m}^{2}$ & 1.44245 & 1.13034 & 0.75286 & 0.93633 & 0.29292 & 0.26227 & 0.10092 & 0.23544 & 0.181 & 0.15487 \\
\hline Iron & $\mathrm{Fe}$ & $\mathrm{mg} / \mathrm{m}^{2}$ & 67.441 & 67.0614 & 31.6327 & 43.9695 & 4.95368 & 51.0933 & 23.539 & 28.6455 & 29.5619 & 9.53303 \\
\hline Lead & $\mathbf{P b}$ & $\mathrm{mg} / \mathrm{m}^{2}$ & 0.35682 & 0.47238 & 0.09047 & 0 & 0 & 0.14498 & 0.09372 & 0.05638 & 0.1422 & 0.03344 \\
\hline Magnesium & Mn & $\mathrm{mg} / \mathrm{m}^{2}$ & 19.7388 & 19.781 & 9.01532 & 15.5 & 0.51372 & 1.41036 & 0.23482 & 1.43171 & 0.45519 & 0.12374 \\
\hline Nickel & $\mathrm{Ni}$ & $\mathrm{mg} / \mathrm{m}^{2}$ & 0 & 0.28596 & 0.09363 & 0.20118 & 0 & 0.07084 & 0 & 1.53129 & 0.13177 & 0.01827 \\
\hline Potassium & $\mathbf{K}$ & $\mathrm{mg} / \mathrm{m}^{2}$ & 10.2617 & 9.65852 & 3.22654 & 0 & 0 & 9.48552 & 5.07768 & 7.62809 & 5.88121 & 2.11845 \\
\hline Silicon & Si & $\mathrm{mg} / \mathrm{m}^{2}$ & 19.1062 & 13.7075 & 6.83267 & 9.67961 & 2.32817 & 39.3214 & 20.2937 & 28.4377 & 36.336 & 18.8037 \\
\hline Strontium & $\mathrm{Sr}$ & $\mathrm{mg} / \mathrm{m}^{2}$ & 0.48841 & 0.16618 & 0.63582 & 0.20941 & 0.18474 & 0.24904 & 0.20506 & 0.18347 & 0.1581 & 0.08049 \\
\hline Sulfur & $\mathbf{S}$ & $\mathrm{mg} / \mathrm{m}^{2}$ & 1.79674 & 1.72926 & 1.35388 & 1.74613 & 0 & 0 & 0.46313 & 0.53701 & 0.46568 & \begin{tabular}{|l|l|}
3 & 0.04987 \\
\end{tabular} \\
\hline Titanium & $\mathrm{Ti}$ & $\mathrm{mg} / \mathrm{m}^{2}$ & 4.11225 & 3.28137 & 0.95531 & 2.30919 & 0.20055 & 2.31091 & 1.60139 & 1.75199 & 2.50667 & 1.68116 \\
\hline Zinc & $\mathrm{Zn}$ & $\mathrm{mg} / \mathrm{m}^{2}$ & 4.37797 & 1.34544 & 7.27552 & 1.12612 & 3.17592 & 0.97047 & 0.47021 & 0.81893 & 0.47503 & 0.15613 \\
\hline Organic Carbon & OC & $\mathrm{mg} / \mathrm{m}^{2}$ & 5.361 & 6.14583 & 5.59065 & 11.0905 & 1.31528 & 52.226 & 54.565 & 41.8346 & 8.74498 & 88.9018 \\
\hline Elemental Carbon & EC & $\mathrm{mg} / \mathrm{m}^{2}$ & 0.24016 & 0.16529 & 0.40417 & 1.34414 & 0.01778 & 0.98688 & 2.83329 & 3.55499 & 0.56905 & 0.79599 \\
\hline
\end{tabular}

\section{Principal Component Analysis}

Principal component analysis (PCA) using Matlab functions was performed on the covariance matrix of the mean-centered raw contaminant data and the first three eigenvectors accounted for $97.3 \%$ of the variability. The main contributors, in order of decreasing loading factors for the first three eigenvectors, are: $\mathrm{Ca}, \mathrm{Fe}, \mathrm{OC}, \mathrm{Al}$, and $\mathrm{Si}$. To move beyond variance and into correlation, three successively more sophisticated techniques were utilized.

First, the soil absorption $a$ and the soil reflectance $r$, were included in a correlation matrix (rather than a covariance matrix) and again analyzed using principal component analysis. This effectively treats $a$ and $r$ as variables in the same manner as the included chemical contaminants. The first three eigenvectors accounted for $78.3 \%$ of the correlation with $a$ and $78.5 \%$ of the correlation with $r$; the per-element loadings for each eigenvector are shown in Table 8 . These loadings are indicative of the relative importance of each elemental contaminant in mathematically accounting for the correlation to $a$ or $r$ with decreasing importance for subsequent eigenvectors. The $1^{\text {st }}$ eigenvector for a contaminant in Table 8 helps one view whether the contaminant positively or negatively affects a change in the soil absorption $a$ and/or soil reflectance $r$.

Second, the varimax variant of principal component analysis was utilized to increase the contribution of the a and $r$ parameters to the final eigenvectors. This limits contributions from elements which exhibit only minor influences on the correlation. In the case of both a and r, the elements with the highest loading factors were: Al, Sr, Ni, and $\mathrm{Ca}$.

Third, an orthonormal basis vector was derived and utilized for varimax PCA in order to align eigenvectors precisely with $a$ or $r$. This maximizes the correlation of a given contaminant element directly with $a$ or $r$. The major eigenvectors for both $a$ and $r$ 
had per-element loading factors in the following order: $\mathrm{Fe}, \mathrm{OC}, \mathrm{Ca}, \mathrm{Si}, \mathrm{Al}$, and $\mathrm{Mn}$. These eigenvector loadings correspond well to the elements with the largest concentrations present in the soil.

\begin{tabular}{|c|c|c|c|c|c|c|c|}
\hline \multicolumn{4}{|c|}{ PCA for soil absorptance a } & \multicolumn{4}{|c|}{ PCA for soil reflectance $r$} \\
\hline & $1^{1^{\text {st }} \text { Eigenvec }}$ & $2^{2^{\text {nd }}}$ & $3^{\text {rd }}$ & & $1^{\text {st }}$ & $2^{\text {nd }}$ & $3^{\text {rd }}$ \\
\hline $\mathbf{a}$ & 0.1027 & 0.402 & -0.1472 & $r$ & 0.126 & 0.3916 & -0.1837 \\
\hline Al & -0.3274 & 0.163 & 0.0506 & Al & -0.3246 & 0.1731 & 0.045 \\
\hline $\mathrm{Ba}$ & -0.2688 & 0.087 & -0.3186 & $\mathrm{Ba}$ & -0.2657 & 0.1046 & -0.3165 \\
\hline $\mathrm{Ca}$ & -0.1985 & 0.0514 & 0.5092 & $\mathrm{Ca}$ & -0.1987 & 0.0447 & 0.4984 \\
\hline $\mathrm{Cr}$ & 0.1273 & 0.3418 & -0.1677 & $\mathrm{Cr}$ & 0.1305 & 0.3392 & -0.1535 \\
\hline $\mathrm{Cu}$ & -0.3454 & -0.0751 & 0.0735 & $\mathrm{Cu}$ & -0.3453 & -0.0718 & 0.0651 \\
\hline $\mathrm{Fe}$ & -0.3142 & 0.2195 & 0.0158 & $\mathrm{Fe}$ & -0.3115 & 0.2258 & 0.0172 \\
\hline $\mathbf{P b}$ & -0.2812 & 0.1679 & -0.0775 & $\mathrm{~Pb}$ & -0.2794 & 0.1748 & -0.0735 \\
\hline Mn & -0.341 & -0.0484 & 0.1744 & $\mathrm{Mn}$ & -0.341 & -0.0467 & 0.165 \\
\hline $\mathrm{Ni}$ & 0.0523 & 0.184 & 0.2298 & $\mathrm{Ni}$ & 0.0503 & 0.1601 & 0.2662 \\
\hline $\mathrm{K}$ & -0.1683 & 0.3839 & -0.2003 & K & -0.165 & 0.387 & -0.1774 \\
\hline Si & 0.0707 & 0.413 & -0.1573 & Si & 0.0744 & 0.4201 & -0.1389 \\
\hline Sr & -0.1801 & -0.1195 & -0.3929 & Sr & -0.1808 & -0.126 & -0.3806 \\
\hline $\mathbf{s}$ & -0.3155 & -0.0685 & 0.2033 & $S$ & -0.3171 & -0.0783 & 0.2041 \\
\hline $\mathrm{Ti}$ & -0.2673 & 0.25 & 0.0859 & $\mathrm{Ti}$ & -0.2647 & 0.2591 & 0.0872 \\
\hline $\mathrm{Zn}$ & -0.1551 & -0.2621 & -0.3834 & $\mathrm{Zn}$ & -0.1567 & -0.2664 & -0.3785 \\
\hline OC & 0.2194 & 0.1925 & 0.0547 & OC & 0.2215 & 0.2002 & 0.0535 \\
\hline EC & 0.1715 & 0.2476 & 0.2722 & EC & 0.1696 & 0.2185 & 0.3052 \\
\hline
\end{tabular}

\section{Linear Regression}

Linear regression was again utilized to accurately model the soil absorptance $a$ and reflectance $r$ as a function of all possible combinations of all contaminants measured from the soil. Fits were generated for one, two, and three contaminants to determine which combinations best predicted $a$ or $r$, Table 9 (e.g. the best 1-element prediction for $r$ is to multiply the $\mathrm{mg} / \mathrm{m}^{2}$ concentration of $\mathrm{Cr}$ by $.053 \ldots$ and subtract $.02815 \ldots$ ).

\begin{tabular}{|c|c|c|c|c|c|c|c|c|}
\hline \multicolumn{9}{|c|}{ Table 9. Best Models for Predicting $a$ and $r$} \\
\hline & \multicolumn{2}{|c|}{$1.6+4 y$} & \multicolumn{2}{|c|}{ 1-element } & \multicolumn{2}{|c|}{ 2-elements } & \multicolumn{2}{|c|}{ 3-elements } \\
\hline Abbr. & a & $\mathbf{r}$ & a & $\mathbf{r}$ & a & $\mathbf{r}$ & a & $\mathbf{r}$ \\
\hline b & 0 & 0 & 0.01328 & -0.02815 & 0.00158 & 0.002083 & 0.0013 & -0.07316 \\
\hline Al & 0.00245 & -0.0586 & 0 & 0 & 0 & 0 & 0 & 0 \\
\hline $\mathbf{B a}$ & -0.00026 & 0.00717 & 0 & 0 & 0 & 0 & 0 & 0 \\
\hline $\mathbf{C a}$ & 0 & 0 & 0 & 0 & 0 & 0 & 0 & 0 \\
\hline $\mathrm{Cr}$ & 8.5E-05 & -0.0003 & 0.03499 & 0.05398 & -0.00669 & -0.054394 & -0.0091 & -0.02139 \\
\hline $\mathrm{Cu}$ & 0.03188 & 0.03196 & 0 & 0 & 0 & 0 & 0 & 0 \\
\hline $\mathrm{Fe}$ & 0 & 0 & 0 & 0 & 0 & 0 & 0 & 0.03949 \\
\hline $\mathbf{P b}$ & -0.00156 & 0.00303 & 0 & 0 & 0 & 0 & 0 & 0 \\
\hline Mn & 0 & 0 & 0 & 0 & 0 & 0 & 0 & 0 \\
\hline $\mathrm{Ni}$ & 0.00271 & -0.01538 & 0 & 0 & 0 & 0 & 0 & 0 \\
\hline K & 0 & 0 & 0 & 0 & 0 & 0 & 0.02888 & 0 \\
\hline Si & 0.0052 & -0.00898 & 0 & 0 & 0.02899 & 0.046095 & 0.00152 & 0 \\
\hline $\mathrm{Sr}$ & 0.00173 & -0.00119 & 0 & 0 & 0 & 0 & 0 & 0 \\
\hline $\mathbf{S}$ & 0 & 0 & 0 & 0 & 0 & 0 & 0 & 0.00221 \\
\hline $\mathrm{Ti}$ & 0 & 0 & 0 & 0 & 0 & 0 & 0 & 0 \\
\hline Zn & 0 & 0 & 0 & 0 & 0 & 0 & 0 & 0 \\
\hline OC & -0.00082 & -0.00168 & 0 & 0 & 0 & 0 & 0 & 0 \\
\hline EC & -0.00017 & 0.00039 & 0 & 0 & 0 & 0 & 0 & 0 \\
\hline
\end{tabular}


As another example, the best 2-element prediction for the soil absorptance $a$ and reflectance $r$ is given in Table 9 by the following two fits:

$$
\mathrm{a}=0.00158-0.00669[\mathrm{Cr}]+0.02899[\mathrm{Si}]
$$

and

$$
\mathrm{r}=0.00208-0.05439[\mathrm{Cr}]+0.04609[\mathrm{Si}]
$$

where

[Cr] represents the $\mathrm{mg} / \mathrm{m}^{2}$ concentration of $\mathrm{Cr}$, and

[Si] represents the $\mathrm{mg} / \mathrm{m}^{2}$ concentration of $\mathrm{Si}$.

\section{Statistical Summary}

Several variants of principal component analysis have been used to show which elements account for the variability of the raw data as well as the correlation of that data to soil absorptance $a$ and soil reflectance $r$. Linear regression and exhaustive search of all possible k-element contributions was used to find the optimal linear combination of elements for $a$ and $r$ in our data.

It is very important to point out that the confidence in the results of the statistical analyses is very limited as chemical concentration was measured at only 5 sites at 2 times (1.6 and 4 years) resulting in only 10 data points. Any conclusions drawn from these statistical analyses must include a physical chemistry-based interpretation of elemental contaminant effects on reflectivity of soiled roofs.

\section{Physical Interpretation of Elemental Contribution}

As reported earlier, crustal element and carbon concentrations soiling the coupons were collected in coordination with solar reflectance measurements made after 1.63 years and 4.1 years of exposure. The relatively abundant transition metals $\mathrm{Fe}, \mathrm{Mn}, \mathrm{Cu}, \mathrm{Cr}$, have colored or black oxides which reduce roof reflectance. Of these elements, iron was the most abundant contaminant found on the soiled coupons. The presence of iron in mineral dust is expected to be accompanied by a reddish (hematite) or brownish tint (FeOOH). Hematite is a strong absorber of the short wavelength part of the solar spectrum (300 to $550 \mathrm{~nm}$ ) with a coefficient of about $4 \mathrm{~m}^{2} / \mathrm{gm}$ (Levinson, Berdahl and Akbari, 2005). Thus such a hematite layer could absorb a measurable portion $(\sim 20 \%)$ of the short wavelength component. Of course, most of the iron present is not likely to be in the form of pure iron oxides, but rather the iron is in mineral particles containing other oxides like $\mathrm{Si}, \mathrm{Al}, \mathrm{Ca}$, etc. as well.

Plotting iron concentration against the soiled absorptance $a$ for data measured after 4.1 years of exposure revealed a potential correlation between the optical absorptance $a$ and the iron concentration, Fig. 11a. Here the elemental compositions and the $a$-values are from Table 7. The estimation of $a$ was improved by including the effect of chromium compounds, Fig. 11b. Note that the inclusion of a term proportional to chromium concentration reduced the best (least-squares) fit coefficient for iron. Finally, a three-term fit for soil absorptance $a$ was used to incorporate elemental carbon [C] 
concentration as well. This final fit allows us to use the three concentrations [Fe], [Cr], and [C] to estimate soil absorptance with an rms deviation of only $\Delta a=0.008$.

A simple interpretation of the results is that the coefficients in the equation for estimating $a$ are the absorption strengths of iron (minerals), chromium (minerals/compounds), and elemental carbon. The units, expressed as for aerosols, can be given in $\mathrm{m}^{2} \mathrm{~g}^{-1}: 1.52$ for $\mathrm{Fe}, 19.9$ for $\mathrm{Cr}$, and 15.8 for C. Some caution, however, is in order. If we had not found the relationships with $\mathrm{Cr}$ and $\mathrm{C}$, the larger coefficient of 4.2 (upper panel) would have been found for iron. Likewise, if there are other unknown absorbers present that are correlated with iron, then the 1.52 figure might still be too large. Also, due to experimental errors and the use of a very limited number of data points, the coefficients that we derive are uncertain by about a factor of 2 . Furthermore, it is known that the absorption coefficient depends on the detailed chemical environment of the absorbing atoms, and that atoms deep inside absorbing particles have reduced absorption efficiency. However, a simple interpretation will be used here. The mass of a $\mathrm{Cr}$ atom is 52, whereas the mass of $\mathrm{Fe}$ is almost the same at 56. Therefore, we see that $\mathrm{Cr}$ atoms are roughly 13 times as effective as Fe atoms at causing absorption. Thus the $\mathrm{Cr}$-absorption is comparable to the Fe-absorption even though less $\mathrm{Cr}$ is present. The earth's crust contains about $5 \% \mathrm{Fe}$ by weight, and $0.01 \% \mathrm{Cr}$. The ratio $[\mathrm{Cr}] /[\mathrm{Fe}]$ might be expected to be $\sim 0.002$ whereas Table 7 shows that at 4.1 yr this ratio is $0.03-0.2$. We infer that most of the chromium is of anthropogenic origin.

It is not known a priori what the size of the absorption coefficients should be for $\mathrm{Fe}$ and $\mathrm{Cr}$. However, we expect the elemental carbon should be present in the form of soot with optical properties that are approximately known. Kirchstetter et al. (2004) reported that the absorptance of soot is about $14 \mathrm{~m}^{2} \mathrm{~g}^{-1}$ at $550 \mathrm{~nm}$. The absorption coefficient is roughly proportional to the inverse of wavelength. At $700 \mathrm{~nm}$, the energy center of the solar spectrum, the Kirchstetter value extrapolates to $11 \mathrm{~m}^{2} \mathrm{~g}^{-1}$, which is not far from our value. Berdahl, Akbari and Rose (2002) estimate about $8 \mathrm{~m}^{2} \mathrm{~g}^{-1}$. The relative closeness of our new coefficient for carbon to that of published values of soot reinforces the interpretation that soot is indeed the cause.

Babin and Stramsky (2004) studied light absorption by mineral particles suspended in water. They identified iron compounds as quite important and found that the absorption at $440 \mathrm{~nm}$ was in the range of 1 to $4 \mathrm{~m}^{2}$ per gram of iron. This absorption was even stronger in the ultraviolet and disappeared near $600 \mathrm{~nm}$. A derived rough estimate for the solar-spectrum-averaged value of Fe absorption is $0.2-1.0 \mathrm{~m}^{2} \mathrm{~g}^{-1}$. Table 10 summarizes the status of the absorption coefficients.

\begin{tabular}{|l|l|l|}
\hline \multicolumn{3}{|l|}{ Table 10. Comparison of measurements with literature data. } \\
\hline Absorbing Species & $\begin{array}{l}\text { Absorption coefficient } \\
\text { from our data }\left(\mathrm{m}^{2} \mathrm{~g}^{-1}\right)\end{array}$ & $\begin{array}{l}\text { Absorption coefficient, estimate is } \\
\text { from literature }\left(\mathrm{m}^{2} \mathrm{~g}^{-1}\right)\end{array}$ \\
\hline $\mathrm{Fe}$ & 1.5 & $0.2-1.0$ \\
\hline $\mathrm{Cr}$ & 20. & - \\
\hline Elemental C & 16 & 8,11 \\
\hline
\end{tabular}

The site with the largest iron concentration is Corona with $51.1 \mathrm{mg} / \mathrm{m}^{2}$. The corresponding contribution to $a$ is 0.08 . The site with the largest elemental carbon concentration is Shafter with $3.55 \mathrm{mg} / \mathrm{m}^{2}$. The contribution to $a$ is 0.06 . The site with 
the largest chromium concentration is Corona with $5.71 \mathrm{mg} / \mathrm{m}^{2}$, and contribution to $a$ of 0.11. Thus, it appears that chromium ranks first, iron ranks second, and elemental carbon ranks third in importance to soil absorptance in our data at 4.1 years.

\section{CONCLUSIONS}

Seven sites were selected for exposing painted PVDF metal, clay and concrete tile coupons with and without cool pigmented colors in the arid, alpine, urban populated and also the cool, humid climates of California. The losses in solar reflectance varied from site to site and also varied at a given site based on the color of the coupon. The least drop in reflectance was observed in the alpine climate of McArthur while the largest drop occurred in sites near urban development. Visible inspection of the Regal white PVDF metal exposed at Shafter showed the sample was soiled with airborne debris and had lost $24 \%$ of it initial solar reflectance after just one year of exposure. The darker color coupons did not show the same seasonal variations in solar reflectance as observed for the lighter colors. However, after an additional 8 months of exposure the samples at all sites regained most of their solar reflectance due to rain washing. Field data show the loss of reflectance is cyclical with the onset of seasons having more rainfall. Solar reflectance of the cool pigmented coupons always exceeded that of the conventional pigmented coupons. Climatic soiling did not cause the cool pigmented roof coupons to lose any more solar reflectance than their conventional pigmented counterparts. The effect of roof slope appears to have more of an effect on lighter color roofs whose solar reflectance exceeds at least 0.5 and visually shows the accumulation of airborne contaminants. However, precipitation and or wind sweeping helps restore most of the initial solar reflectance. The thermal emittance remained invariant with time and location and was therefore not affected by climatic soiling.

The roof samples collected at seven California sites after 1.6 years and 4.1 years of exposure have been analyzed for elements and carbons. The chemical profile of the particles collected by each roof sample was obtained and reported for the seven sites. Analysis of cross-correlation of the seven chemical profiles shows a clear separation between the rural and urban/industrial sites and correlation among sites in a region; e.g., Southern California. Many of the contaminants were of crustal origin such as road dusts, soil and or rock debris and the concentration flux of the contaminants were about the same after 1.6- and 4.1-years of exposure. Iron was the most abundant contaminant found on the soiled coupons. Higher elemental carbon concentrations were observed after 4.1 years of exposure than observed for 1.63 years.

Principal Component Analysis (PCA) showed that the loss of solar reflectance of the field samples is explainable by two independent parameters. Dust and anthropogenic contaminants explain over $85 \%$ of the data variation. We also attempted to identify the elements that contribute to the loss or enhancement of solar reflectance by performing a least-square fit to the data. We successfully developed an approximate and preliminary correlation using chromium, iron and elemental carbon concentrations that simulates the solar reflectance of soiled samples exposed to the elements for 4.1 years.

\section{ACKNOWLEDGEMENTS}

Funding for this project was provided by the California Energy Commission's Public Interest Energy Research program through the U. S. Department of Energy under 
contract DE-AC03-76SF00098. The authors acknowledge Doh-Won Lee of Oak Ridge Associated Universities for assistance in analyzing the filter samples for carbon content. The elemental composition of particles was analyzed by the analytical chemistry services at the DOE Y12 complex using ICP-AES instrument. Oak Ridge National Laboratory is managed by UT-Battelle, LLC, for the U.S. Dept. of Energy under contract DE-AC0500OR22725. The submitted manuscript has been authored by a contractor of the U.S. Government under contract DE-AC05-00OR22725. Accordingly, the U.S. Government retains a nonexclusive, royalty-free license to publish or reproduce the published form of this contribution, or allow others to do so, for U.S. Government purposes.

\section{DISCLAIMERS}

Mention of the trade names, instrument model and model number, and any commercial products in the manuscript does not represent the endorsement of the authors nor their employer, the Oak Ridge National Laboratory or the US Department of Energy.

\section{NOMENCLATURE}

\begin{tabular}{|l|l|}
\hline CIMIS & California Irrigation Management Information System \\
\hline CMRC & Cool Metal Roof Coalition \\
\hline AISI & American Institute of Steel Industries \\
\hline NamZac & Galvalume Sheet Producers of North America \\
\hline MBMA & Metal Building Manufacturers Association \\
\hline MCA & Metal Construction Association \\
\hline NCCA & National Coil Coaters Association \\
\hline PVC & polyvinylchloride thermoplastic membranes \\
\hline SR & solar reflectance \\
\hline TE & thermal emittance \\
\hline PM & particulate matter \\
\hline
\end{tabular}

\section{REFERENCES}

Akbari,H., P. Berdahl, R. Levinson, R. Wiel, A. Desjarlais, W. Miller, N. Jenkins, A. Rosenfeld, C. Scruton (2004) Cool Colored Materials for Roofs, ACEEE Summer Study on Energy Efficiency in Buildings. Proceedings of American Council for an Energy Efficient Economy, Asilomar Conference Center in Pacific Grove, CA, August.

Akbari, H., Konopacki, S.J. 1998. "The Impact of Reflectivity and Emissivity of Roofs on Building Cooling and Heating Energy Use," in Thermal Performance of the Exterior Envelopes of Buildings, VII, proceedings of ASHRAE THERM VIII, Clearwater, FL., Dec. 1998.

ASTM. 1997. Designation C 1371-97: Standard Test Method for Determination of Emittance of Materials Near Room Temperature Using Portable Emissometers. American Society for Testing and Materials, West Conshohocken, PA.

1996. Designation E903-96: Standard Test Method for Solar Absorption, Reflectance, and Transmittance of Materials Using Integrating Spheres. American Society for Testing and Materials, West Conshohocken, PA.

Appel, B. R., P. Colodny, and J. J. Wesolowski (1976) Analysis of Carbonaceous Materials in Southern California Atmospheric Aerosols, Environ. Sci. Technol., 10: 359-363.

Babin, M., and D. Stramsky, Variations in the mass-specific absorption coefficient of mineral particles suspended in water (2004), Limnol. Oceanogr., 49(3), 2004, 756-767. 
Berdahl, P., H. Akbari, and L. S. Rose (2002) Aging of Reflective Roofs: Soot Deposition, Appl. Opt., April 2002 Vol. 41, No. 12, 2355-2360.

Berdahl, P., H. Akbari, R. Levinson, and W. A. Miller (2008) Weathering of Roofing Materials-An Overview, Construction and Building Materials, Vol 22: 423 - 433.

Kirchstetter TW, Novakov T, Hobbs PV. Evidence that the spectral dependence of light absorption by aerosols is affected by organic carbon. J Geophys Res-Atmos 109(d21): D21208; 12 November 2004.

Kollie, T. G., F.J. Weaver, D.L. McElroy. 1990. "Evaluation of a Commercial, Portable, AmbientTemperature Emissometer.” Rev. Sci. Instrum., Vol. 61, 1509-1517.

Levinson, R, P. Berdahl, and H. Akbari (2005) Solar spectral optical properties of pigments - part II: survey of common colorants, Sol. Energy Mater. Sol. Cells 89, 351-389 (2005), Fig. 1, Film R03.

Miller, W.A., Cheng., M.D., Pfiffner, S., Akbari, A., Berdahl, P. and Levinson, R. (2006) Composition and Effects of Atmospheric Particles on the Performance of Steep-Slope Roofing Materials, Task Report to the California Energy Commission.

Miller, W.A., A. Desjarlais, D.S. Parker and S. Kriner (2004) Cool Metal Roofing Tested for Energy Efficiency and Sustainability, Proceedings of CIB World Building Congress, Toronto, Ontario, May 17, 2004.

Miller, W. and B. Rudolph (2003), Exposure Testing of Painted PVDF Metal Roofing, Report prepared for the Cool Metal Roof Coalition.

Miller, W.A., Cheng, M-D., Pfiffner, S., and Byars, N. (2002) The Field Performance of High-Reflectance Single-Ply Membranes Exposed to Three Years of Weathering in Various U.S. Climates, Final Report to SPRI, Inc., Aug., 2002.

Miller, W. A., and Kriner, S. 2001. "The Thermal Performance of Painted and Unpainted Structural Standing Seam Metal Roofing Systems Exposed to One Year of Weathering," in Thermal Performance of the Exterior Envelopes of Buildings, VIII, proceedings of ASHRAE THERM VIII, Clearwater, FL., Dec. 2001.

Novakov, T. and Penner, J.E. (1993) Large Contribution of Organic Aerosols to Cloud-CondensationNuclei Concentrations, Nature, 365, 823- 826.

Petrie, T. W., A.O. Desjarlais, R.H. Robertson and D.S. Parker. 2000. Comparison of techniques for in-situ, non-damaging measurement of solar reflectance of low-slope roof membrane. Presented at the $14^{\text {th }}$ Symposium on Thermophysical Properties and under review for publication in International Journal of Thermophysics, Boulder, CO; National Institute of Standards and Technology.

Strader, R., P. Lurmann, and S. P. Pandis (1999) Evaluation of Secondary Organic Aerosol Formation in Winter, Atmos. Environ., 33: 4849-4863.

Turprin, B. J. and J. J. Huntzicker (1995) Identification of Secondary Organic Aerosol Episodes and Quantitation of Primary and Secondary Organic Aerosol Concentrations during SCAQS, Atmos. Environ., 29: 3527-3544.

White DC, Davis WM, Nickels JS, King JD, Bobbie RJ. 1979. Determination of the sedimentary microbial biodensity by extractable lipid phosphate. Oecologia 40: 51-62.

Wilkes, K. E., Petrie, T. W., Atchley, J. A., and Childs, P. W. (2000) Roof Heating and Cooling Loads in Various Climates for the Range of Solar Reflectances and Infrared Emittances Observed for Weathered Coatings, pp. 3.361-3.372, Proceedings, 2000 Summer Study on Energy Efficiency in Buildings. Washington, D.C.: American Council for an Energy-Efficient Economy. 


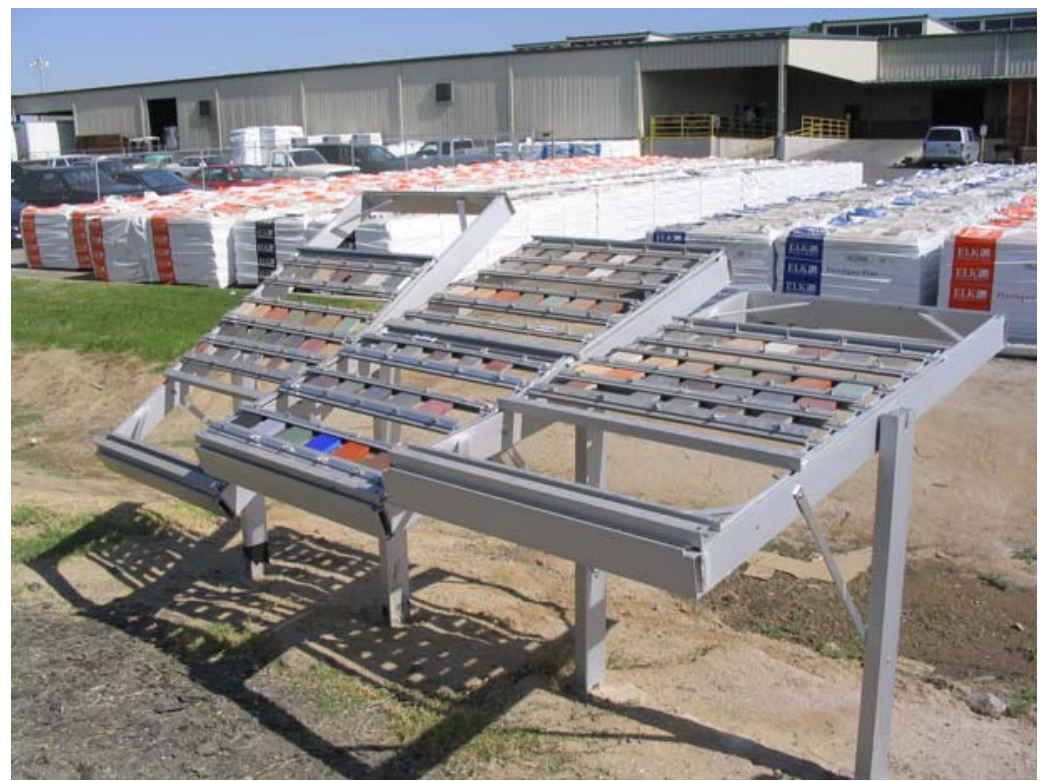

Fig. 1. Assembly used for natural exposure testing of roof samples in seven California climatic zones; site shown is the GAF/Elk Manufacturing facility in Shafter, CA.

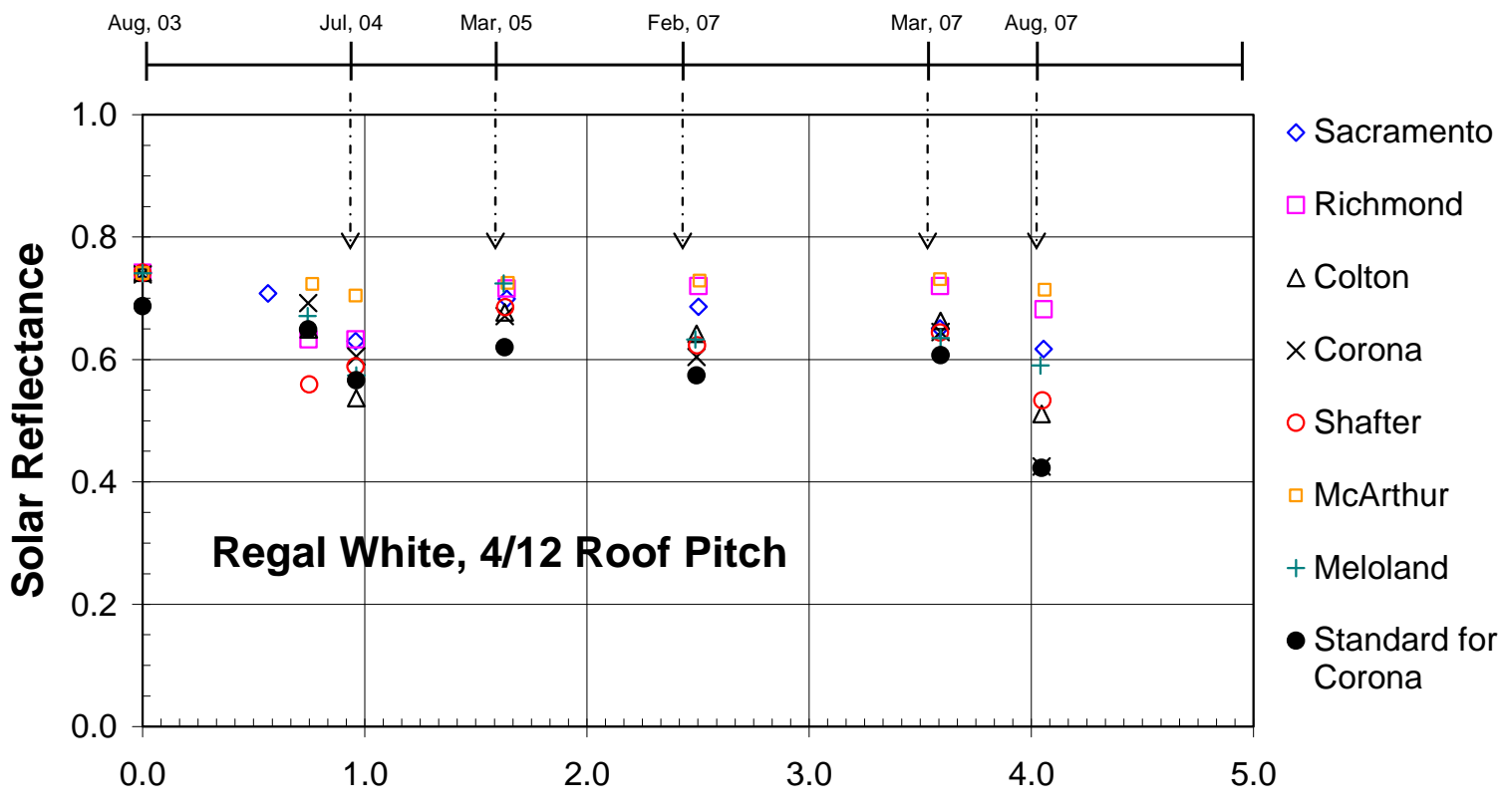

\section{Exposure Time (yrs)}

Fig. 2. Solar reflectance of PVDF metal (white color) at the seven CA weathering sites. 


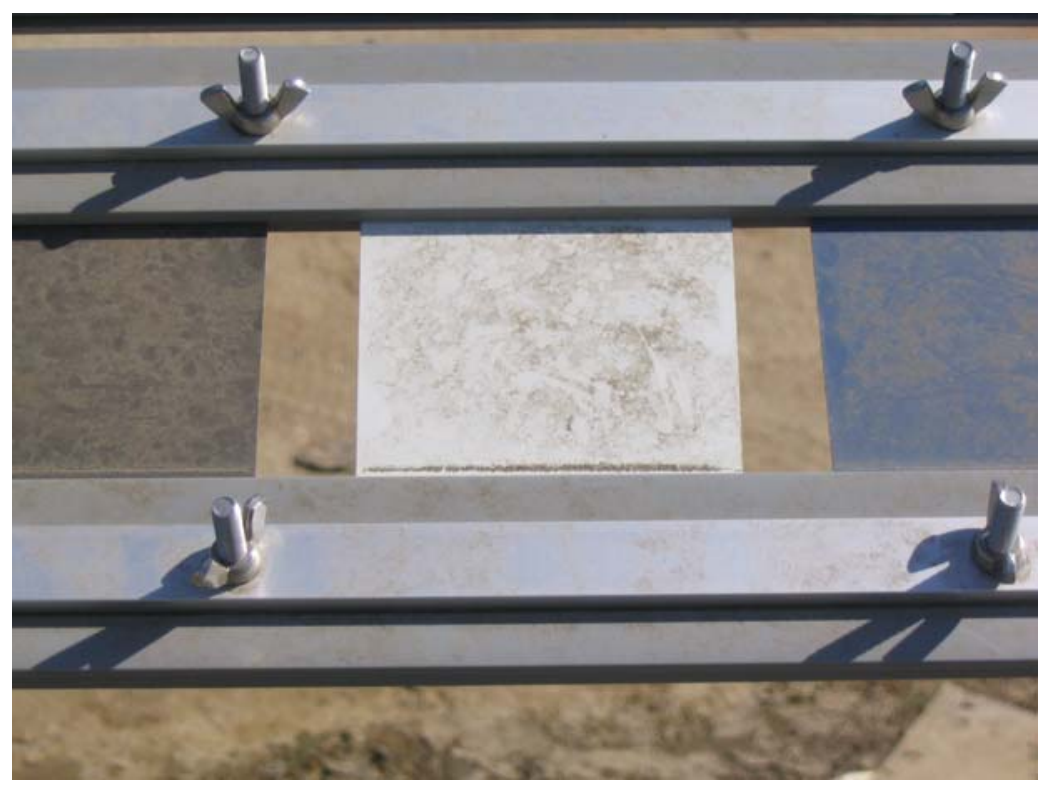

Fig. 3. Painted PVDF metal coupon soiled at the Shafter site after 1 full year of exposure.

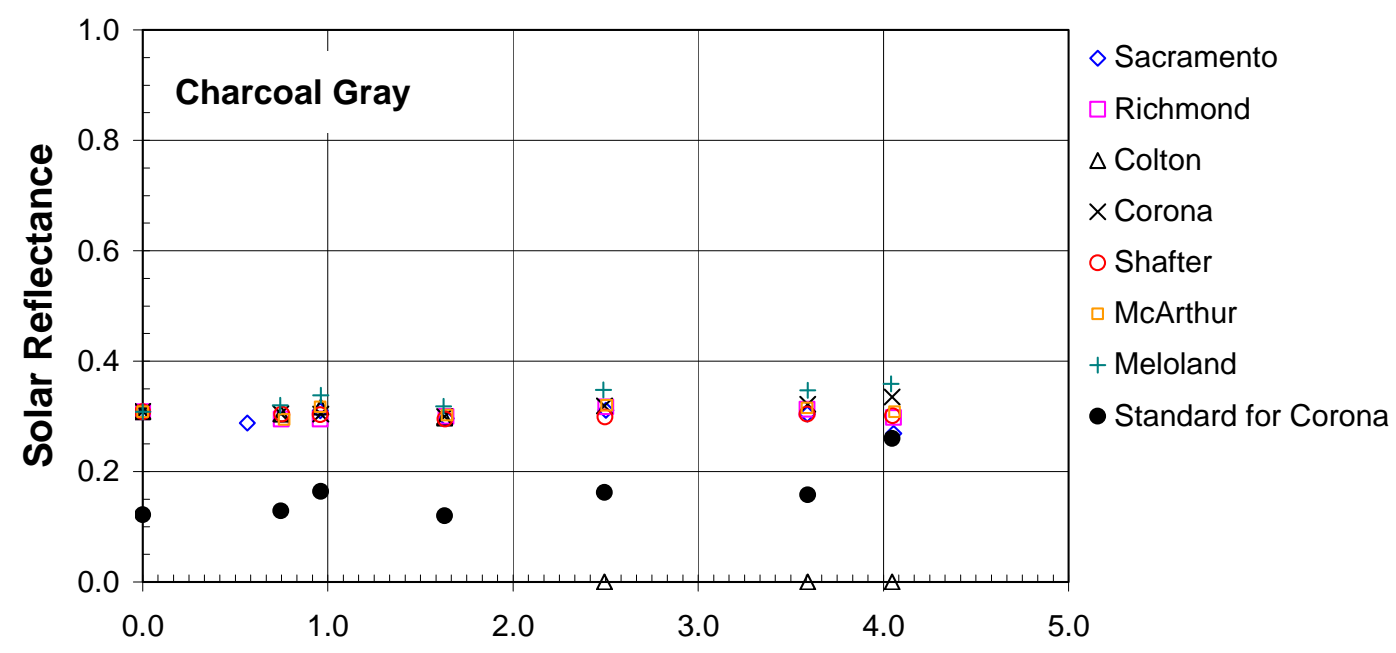

Exposure Time (yrs)

Fig. 4. Solar reflectance of a painted PVDF metal coupon (charcoal gray color) at the seven CA weathering sites. 
Terra Cotta Red

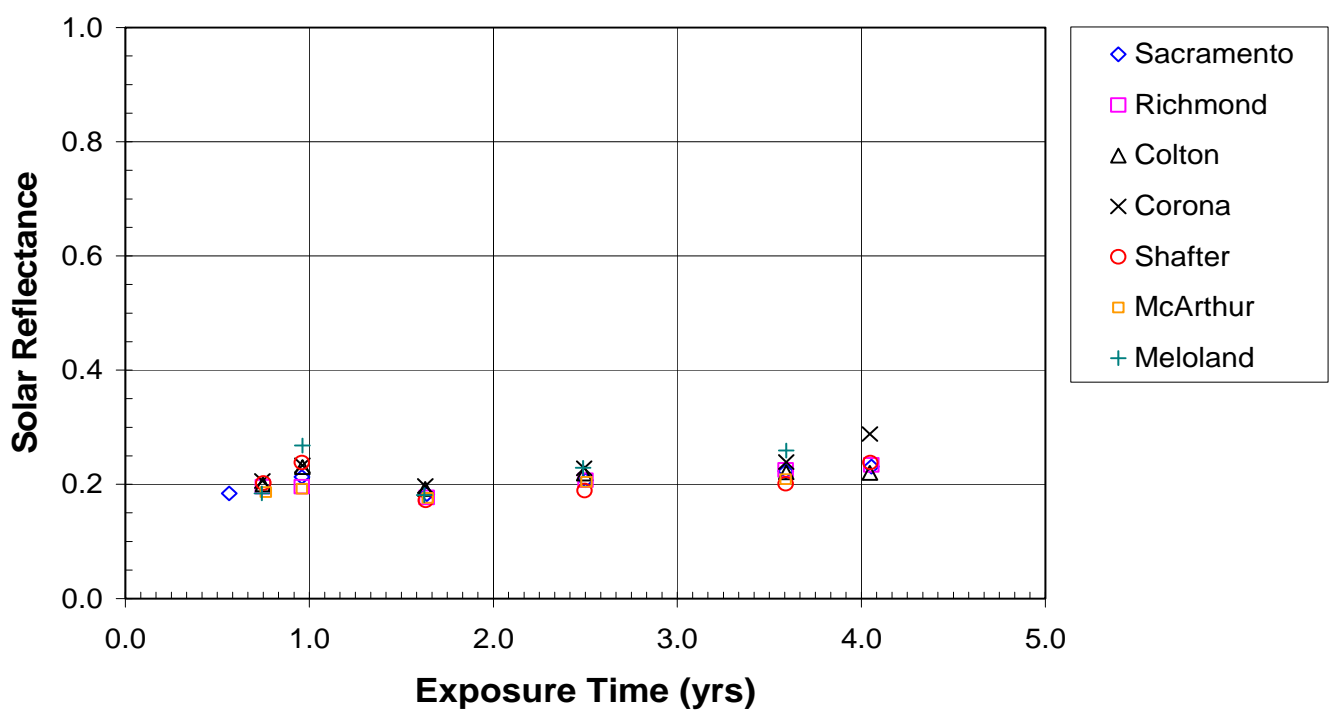

Fig. 5. Solar reflectance of a concrete tile coupon (Terra Cotta Red color) at the CA sites.

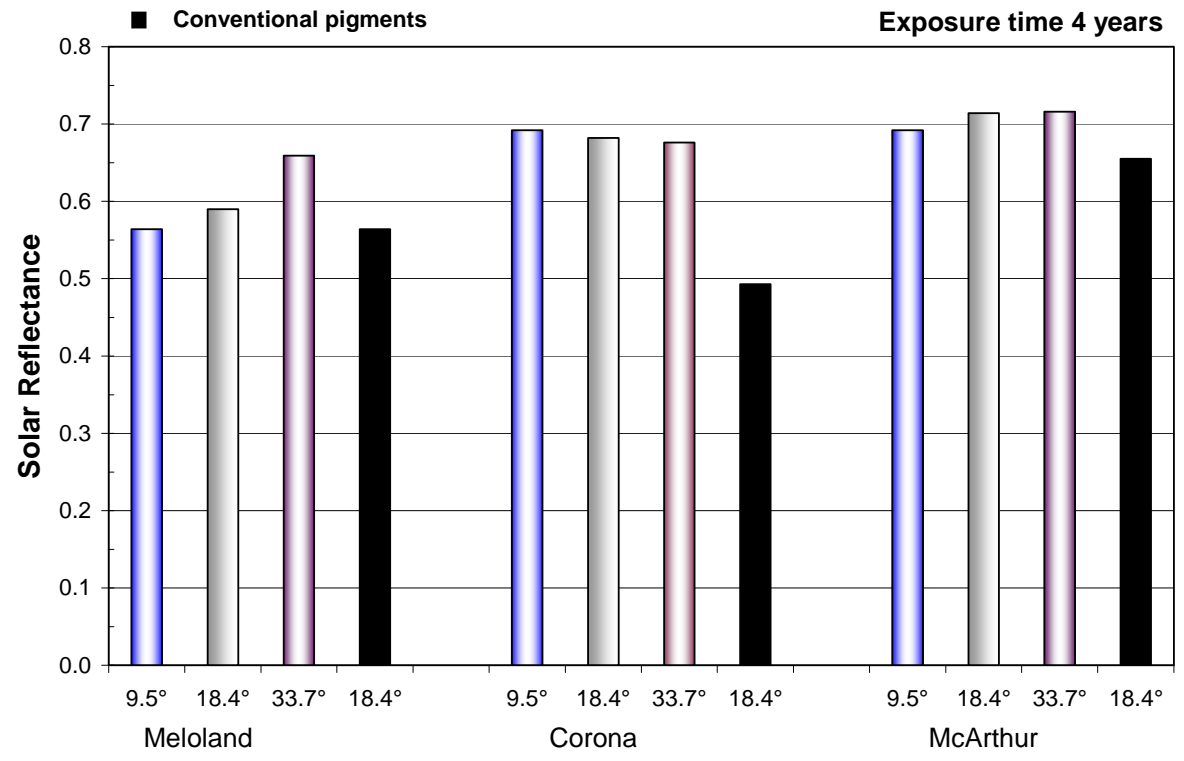

Fig. 6. Regal white painted metal with and without cool pigments. The slopes of $9.5^{\circ}$, $18.4^{\circ}$ and $33.7^{\circ}$ represent respective exposure settings of 2 -in, 4 -in and 8 -in of rise per 12-in of run. 


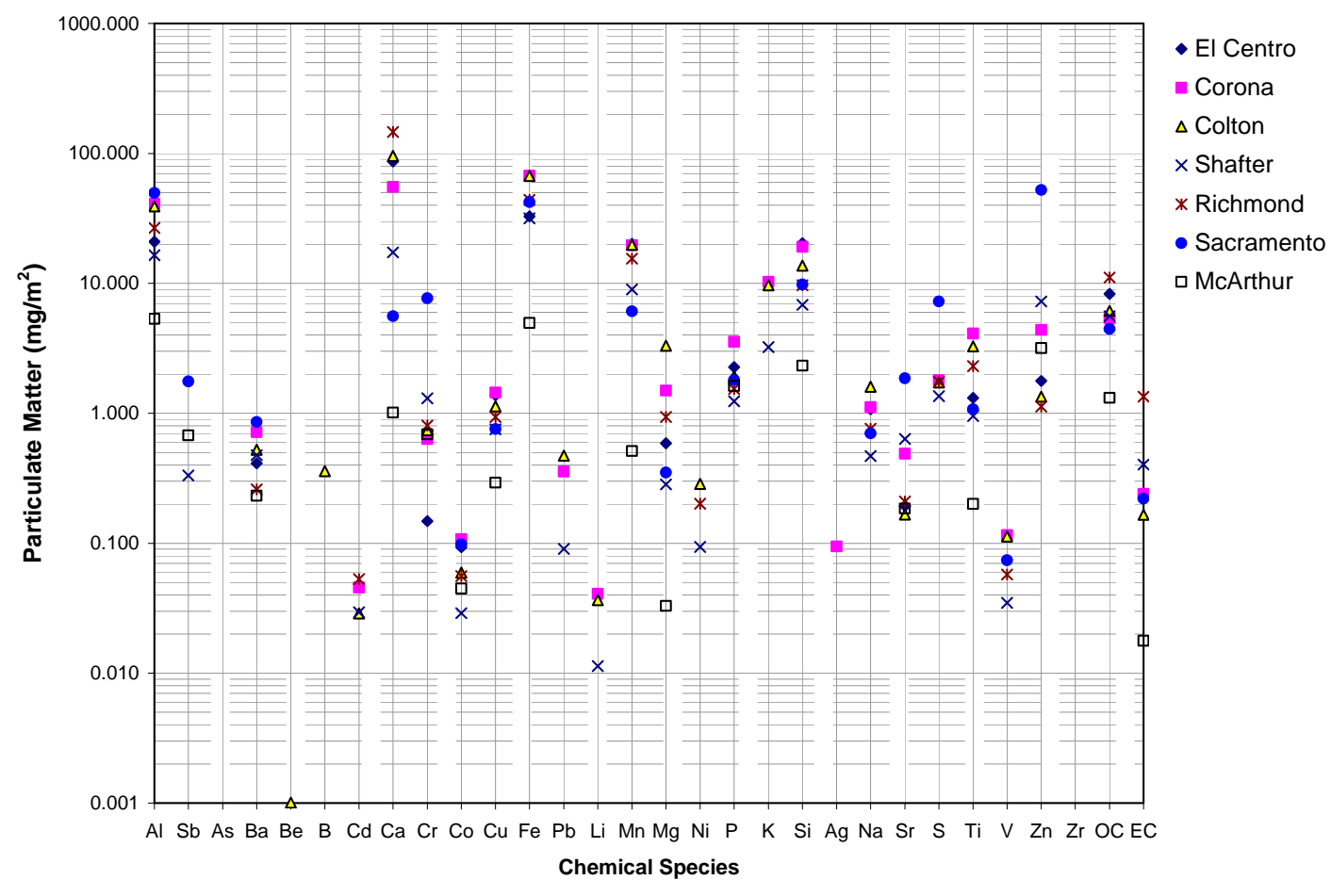

Fig. 7. Elemental compositions and carbon contents of particulate matter extracted from roof samples during March 2005. Samples exposed for 1.63 years.

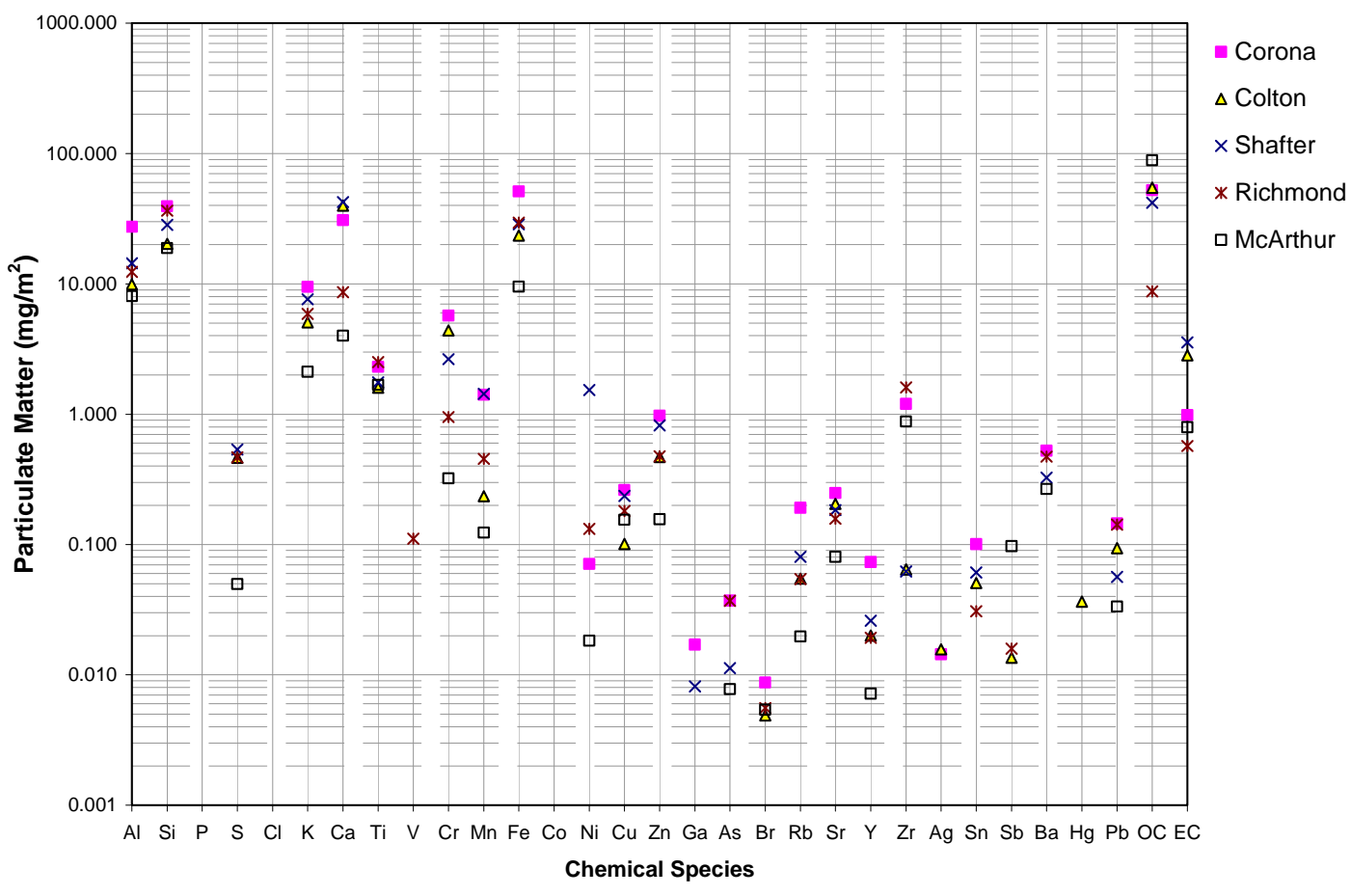

Fig. 8. Elemental compositions and carbon contents of particulate matter extracted from roof samples during August 2007. Samples exposed for 4.06 years. 


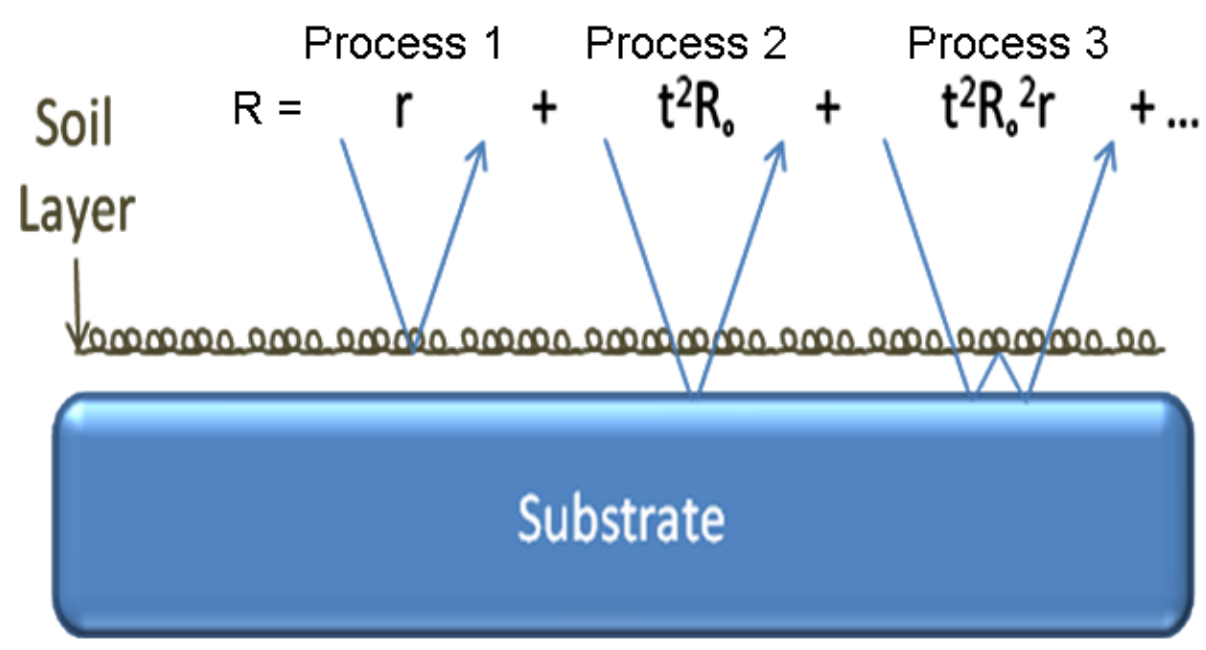

Fig. 9. Diagram showing photon behavior for retained terms in the expansion for the soiled substrate reflectance R.
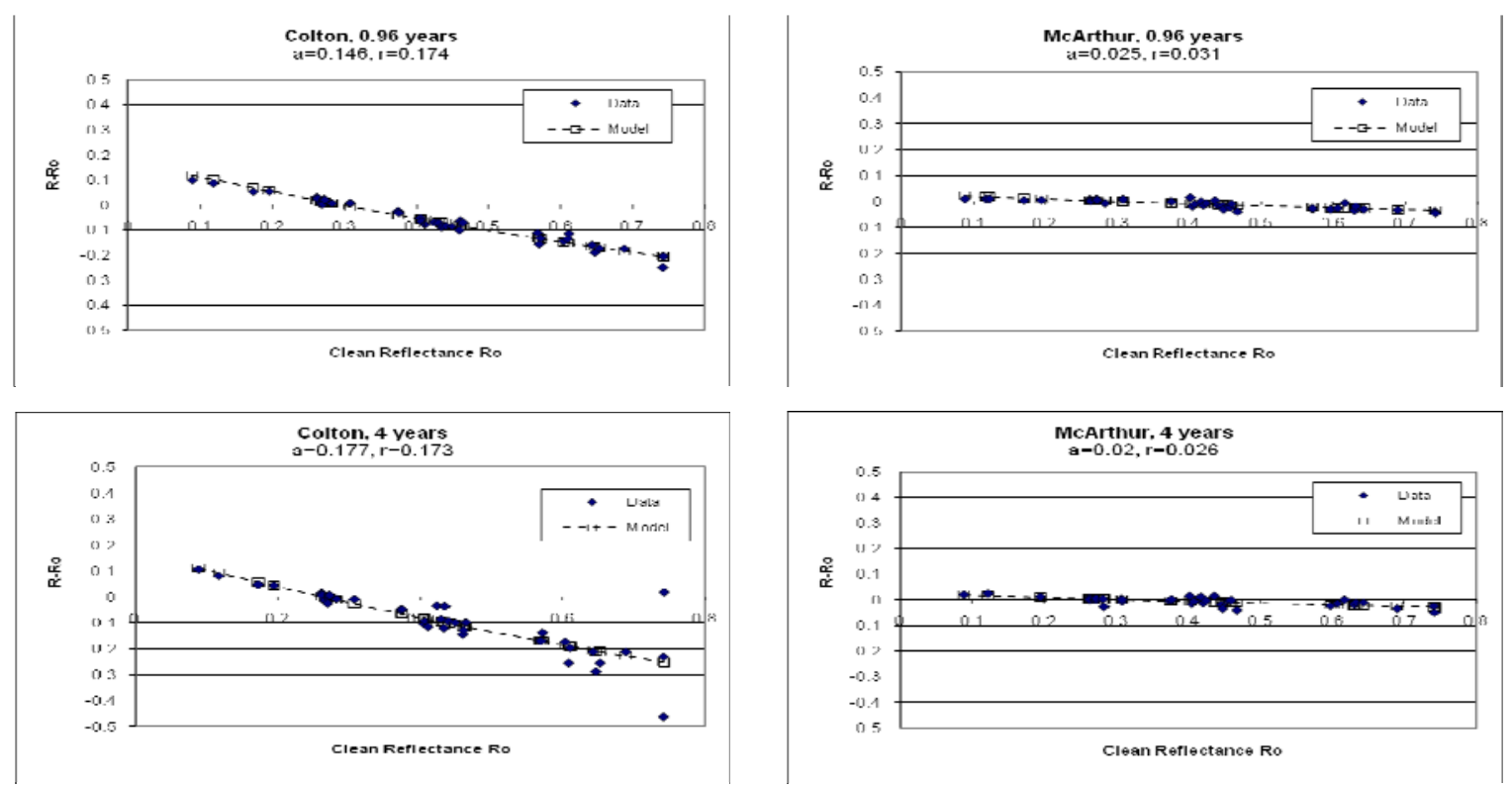

Fig. 10. The measured solar reflectance $\mathrm{R}$ is compared to the modeled $\mathrm{R}$ as computed from linear regression of the $a$ and $r$ terms (Eq. 2). 
Estimation of a with iron concentration alone (units for [Fe] $\mathrm{mg} / \mathrm{m}^{2}$ )

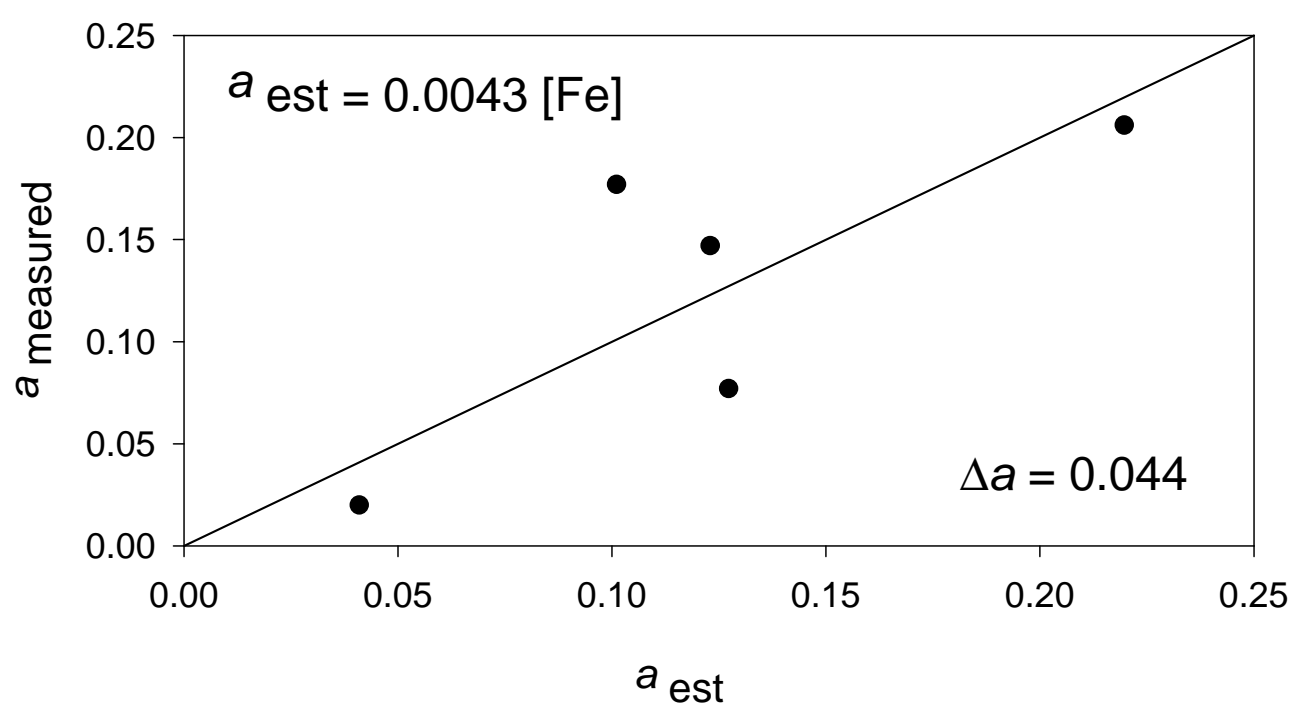

Fig. 11(a)

\section{Estimation of a using concentrations of iron and chromium (concentration units, $\mathrm{mg} / \mathrm{m}^{2}$ )}

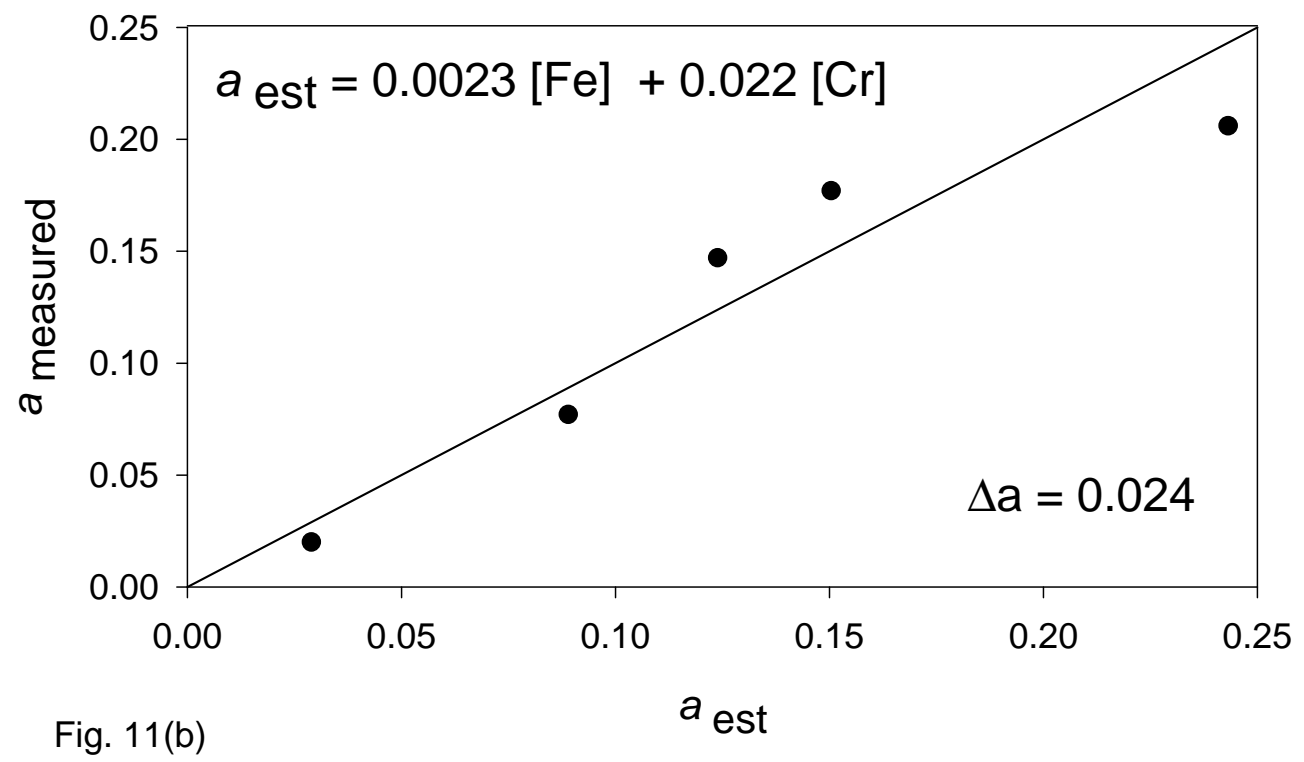




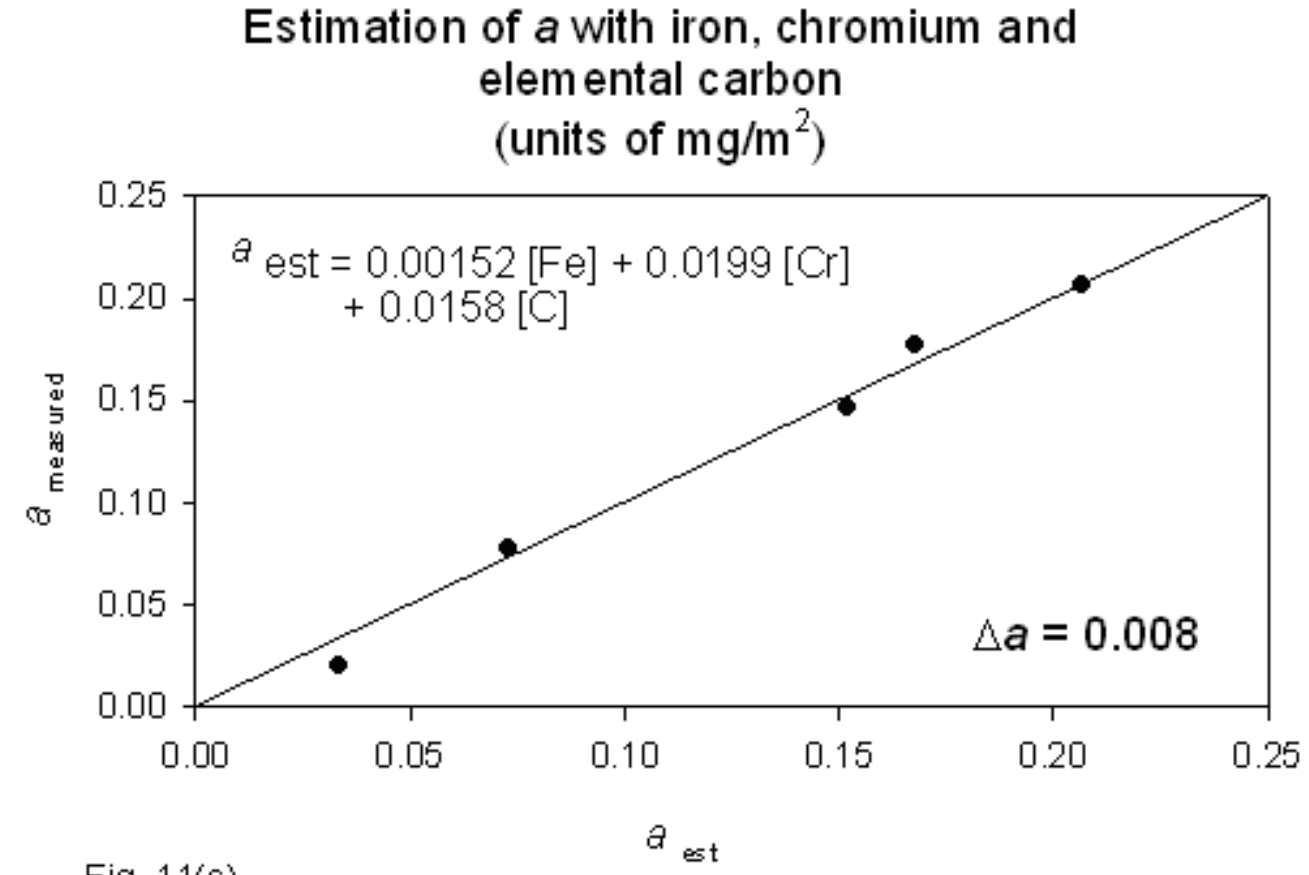

Fig. 11(c)

Fig. 11. Estimation of soil absorptance $a$ based on absorber concentrations. Data from Table 7 for 4 yr. Fit lines are required to pass through the origin. Parameters of the linear relationships were selected by minimizing the root mean square deviation $\Delta a$ of the points from the line. In part (a) only iron concentration [Fe] was considered, in part (b) $\mathrm{Fe}$ and $\mathrm{Cr}$, and in part (c) $\mathrm{Fe}, \mathrm{Cr}$, and elemental carbon $\mathrm{C}$ were all considered. 


\section{Appendix A}

\section{El Centro Exposure Site (RS01)}

Painted metal, clay and concrete tile roof products with and without cool color pigments were placed at ground level at the Davis University Agricultural Extension office located in El Centro, CA. Coupons of the roof products were installed in exposure rack assemblies, which are 5.5-ft high by 9 -ft long, and divided into three sub-frames having respective slopes of 2-, 4- and 8-in of rise for 12-in of run (i.e., slopes of $9.5^{\circ}$, $18.4^{\circ}$ and $33.7^{\circ}$ ). Each sub-frame can hold two "Sure-Grip" sub-assemblies, which are designed to have 6 rows of samples with 34 -in of usable space in each row. Sample size is 3.5 -in by 3.5 -in. Orientation of the racks was set at $260^{\circ} \mathrm{CCW}$ and faced south, southwest into the sun. A CIMIS weather station (CIMIS \# 87) is adjacent the exposure rack.

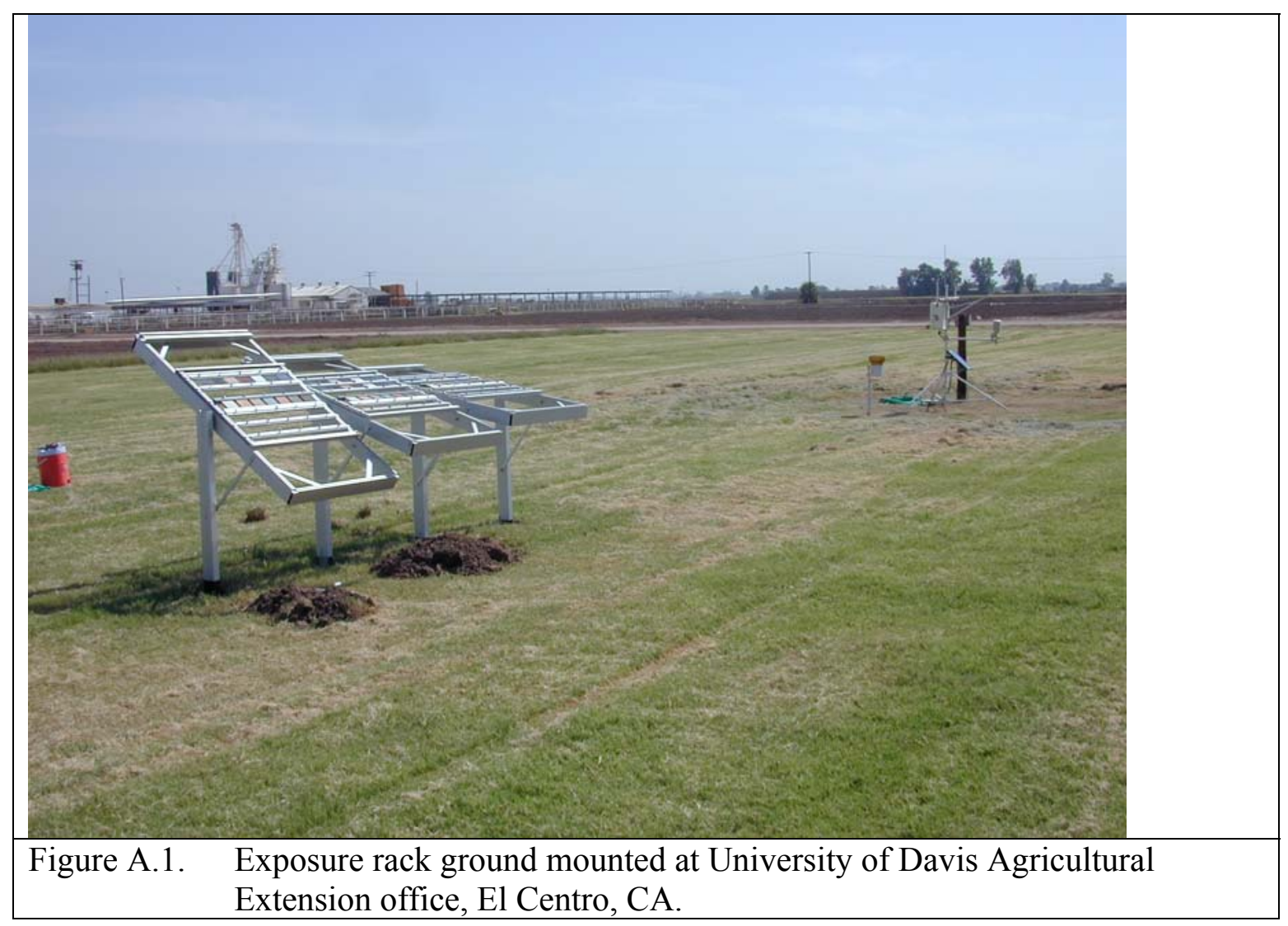




\section{El Centro, CA Solar Reflectance Field Data}

Table A.1

\begin{tabular}{|c|c|c|c|c|c|c|c|c|c|c|}
\hline & & & & \multicolumn{7}{|c|}{ EXPOSURE TIME (YRS) } \\
\hline & Identifier & Code & Slope & 0.000 & 0.742 & 0.962 & 1.625 & 2.488 & 3.592 & 4.041 \\
\hline \multicolumn{11}{|c|}{ BASF PVDF Painted Metal } \\
\hline \multirow[t]{4}{*}{ Regal White } & $872 W 2$ & 900 & 2 in 12 & 0.74 & 0.664 & 0.551 & 0.724 & 0.609 & 0.615 & 0.564 \\
\hline & $872 W 2$ & 901 & 4 in 12 & 0.741 & 0.671 & 0.574 & 0.724 & 0.633 & 0.635 & 0.590 \\
\hline & $872 W 2$ & 902 & 8 in 12 & 0.74 & 0.697 & 0.653 & 0.722 & 0.647 & 0.661 & 0.659 \\
\hline & $815 W 98$ & 903 & 4 in 12 & 0.685 & 0.639 & 0.558 & 0.673 & 0.571 & 0.605 & 0.564 \\
\hline \multirow[t]{4}{*}{ Rawhide } & $872 T 6$ & 904 & 2 in 12 & 0.566 & 0.545 & 0.519 & 0.56 & 0.513 & 0.525 & 0.490 \\
\hline & $872 T 6$ & 905 & 4 in 12 & 0.566 & 0.534 & 0.497 & 0.564 & 0.521 & 0.532 & 0.497 \\
\hline & $872 T 6$ & 906 & 8 in 12 & 0.566 & 0.539 & 0.528 & 0.562 & 0.525 & 0.535 & 0.502 \\
\hline & $836 T 223$ & 907 & 4 in 12 & 0.439 & 0.422 & 0.412 & 0.43 & 0.410 & 0.410 & 0.414 \\
\hline \multirow[t]{4}{*}{ Slate Blue } & $872 \mathrm{~B} 7$ & 908 & 2 in 12 & 0.282 & 0.296 & 0.311 & 0.276 & 0.319 & 0.322 & 0.334 \\
\hline & $872 \mathrm{~B} 7$ & 909 & 4 in 12 & 0.282 & 0.297 & 0.321 & 0.276 & 0.308 & 0.298 & 0.332 \\
\hline & $872 \mathrm{~B} 7$ & 910 & 8 in 12 & 0.282 & 0.286 & 0.312 & 0.277 & 0.305 & 0.297 & 0.326 \\
\hline & 815B49 & 911 & 4 in 12 & 0.169 & 0.192 & 0.243 & 0.173 & 0.240 & 0.225 & 0.272 \\
\hline \multirow[t]{4}{*}{ Brick Red } & $872 \mathrm{R} 10$ & 912 & 2 in 12 & 0.374 & 0.379 & 0.384 & 0.382 & 0.400 & 0.404 & 0.412 \\
\hline & 872R10 & 913 & 4 in 12 & 0.375 & 0.379 & 0.389 & 0.381 & 0.295 & 0.396 & 0.402 \\
\hline & 872R10 & 914 & 8 in 12 & 0.373 & 0.38 & 0.389 & 0.383 & 0.397 & 0.395 & 0.400 \\
\hline & $815 R 71$ & 915 & 4 in 12 & 0.195 & 0.22 & 0.254 & 0.197 & 0.257 & 0.240 & 0.293 \\
\hline \multirow[t]{4}{*}{ Charcoal Gray } & $872 D 6$ & 916 & 2 in 12 & 0.308 & 0.32 & 0.342 & 0.316 & 0.358 & 0.354 & 0.374 \\
\hline & 872D6 & 917 & 4 in 12 & 0.308 & 0.32 & 0.338 & 0.318 & 0.348 & 0.347 & 0.359 \\
\hline & $872 \mathrm{D} 6$ & 918 & 8 in 12 & 0.308 & 0.325 & 0.333 & 0.317 & 0.347 & 0.339 & 0.356 \\
\hline & 815D119 & 919 & 4 in 12 & 0.123 & 0.138 & 0.193 & 0.127 & 0.211 & 0.210 & 0.242 \\
\hline \multirow[t]{4}{*}{ Hartford Green } & $872 \mathrm{G} 16$ & 920 & 2 in 12 & 0.27 & 0.288 & 0.318 & 0.276 & Pulled & & \\
\hline & $872 \mathrm{G} 16$ & 921 & 4 in 12 & 0.272 & 0.29 & 0.319 & 0.276 & Pulled & & \\
\hline & $872 \mathrm{G} 16$ & 922 & 8 in 12 & 0.274 & 0.295 & 0.29 & 0.28 & Pulled & & \\
\hline & $815 G 37$ & 923 & 4 in 12 & 0.088 & 0.134 & 0.176 & 0.094 & Pulled & & \\
\hline \multirow[t]{4}{*}{ Slate Bronze } & 872 T3 & 924 & 2 in 12 & 0.263 & 0.277 & 0.312 & 0.27 & 0.321 & 0.313 & 0.340 \\
\hline & $872 T 3$ & 925 & 4 in 12 & 0.262 & 0.283 & 0.304 & 0.27 & 0.315 & 0.328 & 0.328 \\
\hline & 872 T3 & 926 & 8 in 12 & 0.262 & 0.278 & 0.314 & 0.269 & 0.310 & 0.302 & 0.318 \\
\hline & 815T119 & 927 & 4 in 12 & 0.118 & 0.155 & 0.25 & 0.123 & 0.211 & 0.213 & 0.246 \\
\hline \multicolumn{11}{|l|}{ MCA Clay Tile } \\
\hline \multirow[t]{3}{*}{ White Buff } & $2 \mathrm{~F} 44$ & 928 & 2 in 12 & 0.644 & 0.574 & 0.555 & 0.596 & 0.544 & 0.531 & 0.513 \\
\hline & $2 \mathrm{~F} 44$ & 929 & 4 in 12 & 0.638 & 0.567 & 0.554 & 0.581 & 0.539 & 0.533 & 0.504 \\
\hline & $2 \mathrm{~F} 44$ & 930 & 8 in 12 & 0.651 & 0.593 & 0.56 & 0.592 & 0.551 & 0.540 & 0.519 \\
\hline \multirow[t]{3}{*}{ Apricot Buff } & CF50 & 931 & 2 in 12 & 0.62 & 0.515 & 0.507 & 0.543 & 0.508 & 0.512 & 0.475 \\
\hline & CF50 & 932 & 4 in 12 & 0.598 & 0.546 & 0.545 & 0.574 & 0.543 & 0.514 & 0.509 \\
\hline & CF50 & 933 & 8 in 12 & 0.607 & 0.518 & 0.521 & 0.539 & 0.508 & 0.510 & 0.495 \\
\hline \multirow[t]{3}{*}{ Adobe Gray } & $2 \mathrm{~F} 71$ & 934 & 2 in 12 & 0.424 & 0.406 & 0.412 & 0.41 & 0.412 & 0.410 & 0.418 \\
\hline & $2 \mathrm{~F} 71$ & 935 & 4 in 12 & 0.421 & 0.409 & 0.414 & 0.419 & 0.414 & 0.420 & 0.413 \\
\hline & $2 \mathrm{~F} 71$ & 936 & 8 in 12 & 0.412 & 0.415 & 0.432 & 0.429 & 0.427 & 0.430 & 0.420 \\
\hline \multirow[t]{3}{*}{ Regency Blue } & $2 \mathrm{~F} 52$ & 937 & 2 in 12 & 0.411 & 0.395 & 0.398 & 0.395 & 0.395 & 0.397 & 0.396 \\
\hline & $2 \mathrm{~F} 52$ & 938 & 4 in 12 & 0.424 & 0.404 & 0.413 & 0.401 & 0.400 & 0.406 & 0.406 \\
\hline & $2 \mathrm{~F} 52$ & 939 & 8 in 12 & 0.422 & 0.402 & 0.409 & 0.392 & 0.401 & 0.400 & 0.396 \\
\hline
\end{tabular}




\section{El Centro, CA Solar Reflectance Field Data}

Table A.1

\begin{tabular}{|c|c|c|c|c|c|c|c|c|c|c|}
\hline & & & & \multicolumn{7}{|c|}{ EXPOSURE TIME (YRS) } \\
\hline & Identifier & Code & Slope & 0.000 & 0.742 & 0.962 & 1.625 & 2.488 & 3.592 & 4.041 \\
\hline \multirow[t]{3}{*}{ Natural Red } & $\mathrm{F} 40$ & 940 & 2 in 12 & 0.466 & 0.441 & 0.46 & 0.457 & 0.450 & 0.442 & 0.438 \\
\hline & $\mathrm{F} 40$ & 941 & 4 in 12 & 0.468 & 0.439 & 0.45 & & 0.446 & 0.439 & 0.437 \\
\hline & F40 & 942 & 8 in 12 & 0.464 & 0.445 & 0.451 & 0.458 & 0.453 & 0.445 & 0.442 \\
\hline \multirow[t]{3}{*}{$\begin{array}{r}\text { Weathered } \\
\text { Green }\end{array}$} & B305 & 943 & 2 in 12 & 0.412 & 0.4 & 0.413 & 0.407 & 0.404 & 0.409 & 0.420 \\
\hline & B305 & 944 & 4 in 12 & 0.4 & 0.397 & 0.401 & 0.397 & 0.400 & 0.402 & 0.418 \\
\hline & B305 & 945 & 8 in 12 & 0.41 & 0.402 & 0.413 & 0.409 & 0.409 & 0.415 & 0.410 \\
\hline \multirow[t]{3}{*}{ Ironwood } & $2 \mathrm{~F} 19$ & 946 & 2 in 12 & 0.268 & 0.287 & 0.313 & 0.292 & 0.321 & 0.339 & 0.336 \\
\hline & 2F19 & 947 & 4 in 12 & 0.271 & 0.3 & 0.315 & 0.296 & 0.321 & 0.351 & 0.372 \\
\hline & 2F19 & 948 & 8 in 12 & 0.261 & 0.285 & 0.3 & 0.278 & 0.306 & 0.312 & 0.319 \\
\hline \multicolumn{3}{|l|}{ US Clay Tile } & & & & & & & & \\
\hline Buff Blend & & 979 & 2 in 12 & & 0.568 & 0.543 & 0.568 & 0.549 & 0.521 & 0.504 \\
\hline Bermuda Blend & & 980 & 2 in 12 & & 0.499 & 0.503 & 0.508 & 0.486 & 0.470 & 0.477 \\
\hline \multicolumn{3}{|c|}{ Monierlife Concrete Tile } & & & & & & & & \\
\hline \multirow[t]{4}{*}{ Terra Cotta Red } & 6978 & 949 & 2 in 12 & & 0.184 & 0.268 & 0.181 & 0.229 & 0.259 & 0.286 \\
\hline & 6978 & 950 & 4 in 12 & & & & & & & \\
\hline & 6978 & 951 & 8 in 12 & & & & & & & \\
\hline & & & & & & & & & & \\
\hline \multirow[t]{3}{*}{ Hearthside } & 3083 & 952 & 2 in 12 & & 0.122 & 0.192 & 0.145 & 0.202 & 0.228 & 0.260 \\
\hline & 3083 & 953 & 4 in 12 & & 0.135 & 0.219 & 0.156 & 0.204 & 0.220 & 0.258 \\
\hline & 3083 & 954 & 8 in 12 & & 0.141 & 0.226 & 0.158 & 0.200 & 0.225 & 0.252 \\
\hline \multirow[t]{3}{*}{ Riversidepebble } & 3080 & 955 & 2 in 12 & & 0.164 & 0.225 & 0.166 & 0.214 & 0.242 & 0.263 \\
\hline & 3080 & 956 & 4 in 12 & & 0.131 & 0.202 & 0.14 & 0.189 & 0.211 & 0.258 \\
\hline & 3080 & 957 & 8 in 12 & & 0.136 & 0.219 & 0.154 & 0.200 & 0.210 & 0.252 \\
\hline \multirow[t]{3}{*}{ Ebony } & 5047 & 958 & 2 in 12 & & 0.133 & 0.257 & 0.13 & 0.188 & 0.229 & 0.230 \\
\hline & 5047 & 959 & 4 in 12 & & 0.136 & 0.242 & 0.156 & 0.187 & 0.220 & 0.242 \\
\hline & 5047 & 960 & 8 in 12 & & 0.134 & 0.219 & 0.129 & 0.177 & 0.207 & 0.232 \\
\hline & & & & & & & & & & \\
\hline \multirow[t]{3}{*}{ Lincoln Green } & 4087 & 961 & 2 in 12 & & 0.185 & 0.263 & 0.181 & 0.239 & 0.265 & 0.320 \\
\hline & 4087 & 962 & 4 in 12 & & 0.174 & 0.233 & 0.185 & 0.224 & 0.240 & 0.277 \\
\hline & 4087 & 963 & 8 in 12 & & 0.174 & 0.235 & 0.179 & 0.217 & 0.230 & 0.264 \\
\hline \multicolumn{3}{|c|}{ Shepherd Artic Match } & & & & & & & & \\
\hline \multirow[t]{3}{*}{ Blue Artic } & & 964 & 2 in 12 & & 0.226 & 0.285 & 0.237 & 0.285 & 0.294 & 0.298 \\
\hline & & 965 & 4 in 12 & & 0.234 & 0.295 & 0.243 & 0.277 & 0.280 & 0.279 \\
\hline & & 966 & 8 in 12 & & 0.225 & 0.299 & 0.235 & 0.269 & 0.272 & 0.296 \\
\hline \multirow[t]{3}{*}{ Red Artic } & & 967 & 2 in 12 & & 0.267 & 0.317 & 0.279 & 0.316 & 0.312 & 0.317 \\
\hline & & 968 & 4 in 12 & & 0.266 & 0.318 & 0.283 & 0.316 & 0.314 & 0.317 \\
\hline & & 969 & 8 in 12 & & 0.309 & 0.339 & 0.306 & 0.338 & 0.338 & 0.334 \\
\hline & & & & & & & & & & \\
\hline \multirow[t]{4}{*}{ Brown Artic } & & 970 & 2 in 12 & & 0.261 & 0.315 & 0.283 & 0.320 & 0.332 & 0.334 \\
\hline & & 971 & 4 in 12 & & 0.26 & 0.315 & 0.283 & 0.313 & 0.320 & 0.319 \\
\hline & & 972 & 8 in 12 & & 0.251 & 0.315 & 0.283 & & 0.299 & \\
\hline & & & & & & & & & & \\
\hline
\end{tabular}




\section{Appendix A}

\section{Corona Exposure Site (RS02)}

Painted metal, clay and concrete tile roof products with and without cool color pigments were placed at ground level adjacent the clay tile manufacturing facility of Maruhachi Ceramics of America, Inc. located in Corona, CA. Coupons of the roof products were installed in exposure rack assemblies, which are 5.5-ft high by 9 -ft long, and divided into three sub-frames having respective slopes of 2-, 4- and 8-in of rise for 12 -in of run (i.e., slopes of $9.5^{\circ}, 18.4^{\circ}$ and $33.7^{\circ}$ ). Each sub-frame can hold two "SureGrip" sub-assemblies, which are designed to have 6 rows of samples with 34 -in of usable space in each row. Sample size is 3.5 -in by 3.5 -in. Orientation of the racks is $310^{\circ} \mathrm{CCW}$ from the east and faces south south-east.

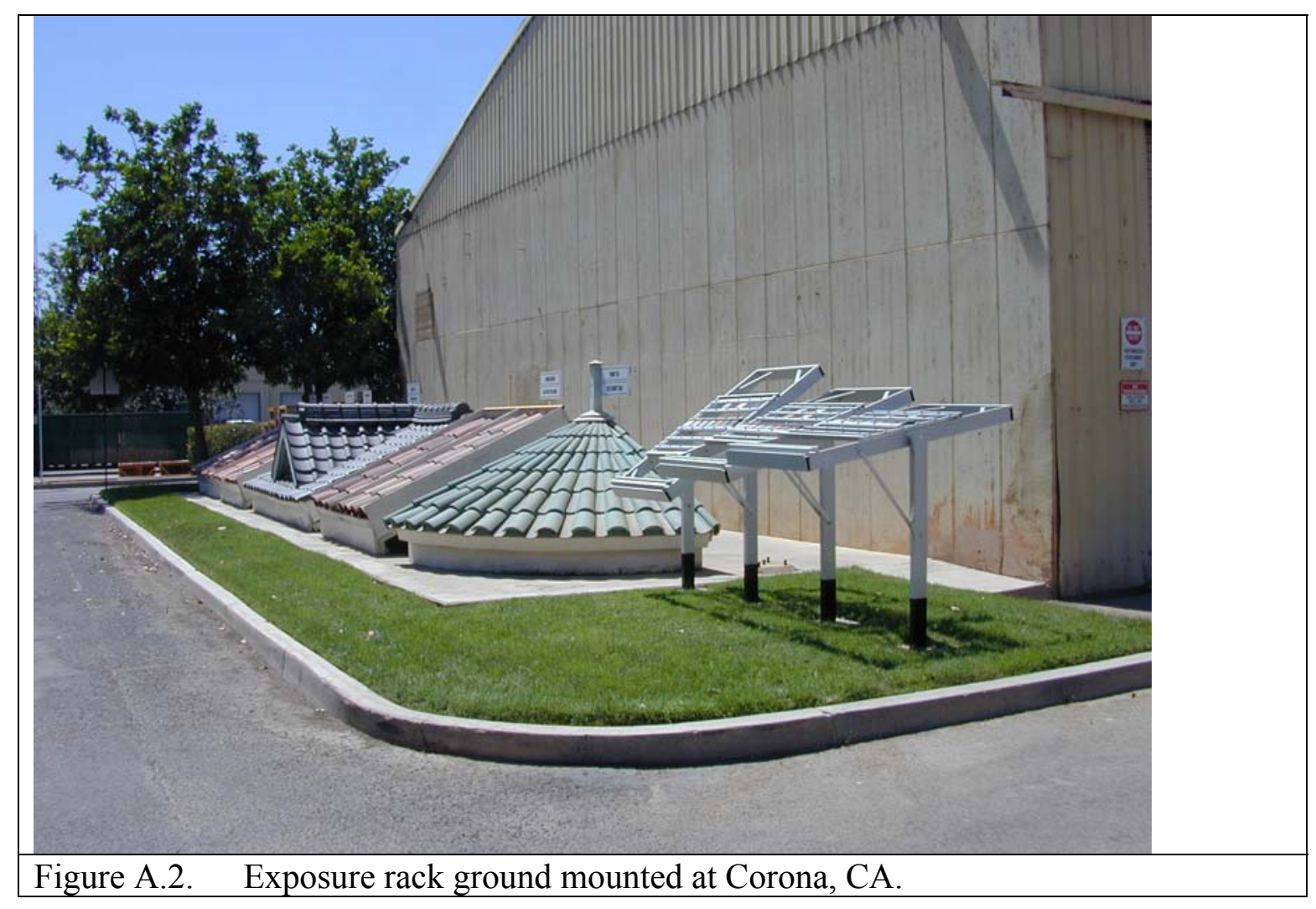




\section{Corona, CA Solar Reflectance Field Data}

Table A.2

\begin{tabular}{|c|c|c|c|c|c|c|c|c|c|c|}
\hline & & & & \multicolumn{7}{|c|}{ EXPOSURE TIME (YRS) } \\
\hline & Identifier & Code & Slope & 0.000 & 0.750 & 0.962 & 1.630 & 2.493 & 3.592 & 4.047 \\
\hline \multicolumn{11}{|c|}{ BASF PVDF Painted Metal } \\
\hline \multirow[t]{4}{*}{ Regal White } & $872 W 2$ & 600 & 2 in 12 & 0.74 & 0.691 & 0.542 & 0.675 & 0.604 & 0.628 & 0.468 \\
\hline & $872 W 2$ & 601 & 4 in 12 & 0.739 & 0.692 & 0.605 & 0.671 & 0.604 & 0.645 & 0.425 \\
\hline & $872 W 2$ & 602 & 8 in 12 & 0.74 & 0.693 & 0.651 & 0.688 & 0.634 & 0.664 & 0.472 \\
\hline & $815 W 98$ & 603 & 4 in 12 & 0.687 & 0.649 & 0.566 & 0.62 & 0.574 & 0.607 & 0.423 \\
\hline \multirow[t]{4}{*}{ Rawhide } & $872 T 6$ & 604 & 2 in 12 & 0.573 & 0.532 & 0.468 & 0.518 & 0.489 & 0.522 & 0.423 \\
\hline & $872 T 6$ & 605 & 4 in 12 & 0.573 & 0.534 & 0.496 & 0.522 & 0.503 & 0.521 & 0.415 \\
\hline & $872 T 6$ & 606 & 8 in 12 & 0.569 & 0.535 & 0.498 & 0.524 & 0.508 & 0.524 & 0.404 \\
\hline & $836 \mathrm{~T} 223$ & 607 & 4 in 12 & 0.44 & 0.417 & 0.386 & 0.395 & 0.384 & 0.407 & 0.373 \\
\hline \multirow[t]{4}{*}{ Slate Blue } & $872 \mathrm{~B} 7$ & 608 & 2 in 12 & 0.282 & 0.278 & 0.282 & 0.259 & 0.278 & 0.280 & 0.322 \\
\hline & $872 \mathrm{~B} 7$ & 609 & 4 in 12 & 0.281 & 0.278 & 0.285 & 0.259 & 0.278 & 0.283 & 0.316 \\
\hline & $872 B 7$ & 610 & 8 in 12 & 0.282 & 0.279 & 0.279 & 0.262 & 0.277 & 0.279 & 0.314 \\
\hline & 815B49 & 611 & 4 in 12 & 0.172 & 0.175 & 0.202 & 0.165 & 0.197 & 0.195 & 0.277 \\
\hline \multirow[t]{4}{*}{ Brick Red } & $872 \mathrm{R} 10$ & 612 & 2 in 12 & 0.372 & 0.363 & 0.358 & 0.356 & 0.365 & 0.378 & 0.367 \\
\hline & $872 \mathrm{R} 10$ & 613 & 4 in 12 & 0.374 & 0.364 & 0.36 & 0.358 & 0.368 & 0.377 & 0.366 \\
\hline & $872 R 10$ & 614 & 8 in 12 & 0.375 & 0.363 & 0.363 & 0.359 & 0.370 & 0.375 & 0.360 \\
\hline & $815 R 71$ & 615 & 4 in 12 & 0.195 & 0.198 & 0.222 & 0.19 & 0.223 & 0.220 & 0.305 \\
\hline \multirow[t]{4}{*}{ Charcoal Gray } & $872 \mathrm{D} 6$ & 616 & 2 in 12 & 0.309 & 0.305 & 0.314 & 0.297 & Pulled & & \\
\hline & $872 \mathrm{D} 6$ & 617 & 4 in 12 & 0.309 & 0.305 & 0.304 & 0.3 & 0.319 & 0.322 & 0.335 \\
\hline & $872 \mathrm{D} 6$ & 618 & 8 in 12 & 0.308 & 0.304 & 0.305 & 0.3 & 0.318 & 0.317 & 0.338 \\
\hline & $815 \mathrm{D} 119$ & 619 & 4 in 12 & 0.122 & 0.129 & 0.164 & 0.12 & 0.162 & 0.158 & 0.260 \\
\hline \multirow[t]{4}{*}{ Hartford Green } & $872 \mathrm{G} 16$ & 620 & 2 in 12 & 0.271 & 0.271 & 0.289 & 0.263 & 0.286 & 0.286 & 0.336 \\
\hline & $872 \mathrm{G} 16$ & 621 & 4 in 12 & 0.272 & 0.271 & 0.28 & 0.266 & 0.288 & 0.291 & 0.370 \\
\hline & $872 G 16$ & 622 & 8 in 12 & 0.272 & 0.268 & 0.274 & 0.263 & 0.279 & 0.281 & 0.314 \\
\hline & $815 G 37$ & 623 & 4 in 12 & 0.089 & 0.097 & 0.142 & 0.095 & 0.137 & 0.131 & 0.277 \\
\hline & & & & & & & & & & \\
\hline \multirow[t]{4}{*}{ Slate Bronze } & $872 \mathrm{~T} 3$ & 624 & 2 in 12 & 0.262 & 0.261 & 0.28 & 0.253 & 0.278 & 0.278 & 0.323 \\
\hline & $872 T 3$ & 625 & 4 in 12 & 0.263 & 0.263 & 0.276 & 0.256 & 0.280 & 0.282 & 0.320 \\
\hline & $872 T 3$ & 626 & 8 in 12 & 0.262 & 0.262 & 0.266 & 0.257 & 0.278 & 0.269 & 0.311 \\
\hline & $815 T 119$ & 627 & 4 in 12 & 0.118 & 0.124 & 0.167 & 0.119 & 0.161 & 0.152 & 0.269 \\
\hline \multicolumn{11}{|l|}{ MCA Clay Tile } \\
\hline \multirow[t]{3}{*}{ White Buff } & $2 \mathrm{~F} 44$ & 628 & 2 in 12 & 0.64 & 0.56 & 0.482 & 0.526 & 0.458 & 0.448 & 0.385 \\
\hline & $2 \mathrm{~F} 44$ & 629 & 4 in 12 & 0.651 & 0.568 & 0.503 & 0.536 & 0.484 & 0.505 & 0.407 \\
\hline & $2 \mathrm{~F} 44$ & 630 & 8 in 12 & 0.632 & 0.584 & 0.538 & 0.55 & 0.514 & 0.527 & 0.425 \\
\hline \multirow[t]{3}{*}{ Apricot Buff } & CF50 & 631 & 2 in 12 & 0.601 & 0.547 & 0.482 & 0.514 & 0.433 & 0.413 & 0.381 \\
\hline & CF50 & 632 & 4 in 12 & 0.595 & 0.539 & 0.477 & 0.51 & 0.469 & 0.470 & 0.407 \\
\hline & CF50 & 633 & 8 in 12 & 0.619 & 0.549 & 0.558 & 0.527 & 0.497 & 0.504 & 0.418 \\
\hline & & & & & & & & & & \\
\hline \multirow[t]{3}{*}{ Adobe Gray } & $2 \mathrm{~F} 71$ & 634 & 2 in 12 & 0.426 & 0.414 & 0.385 & 0.393 & 0.366 & 0.333 & 0.347 \\
\hline & $2 \mathrm{~F} 71$ & 635 & 4 in 12 & 0.418 & 0.42 & 0.387 & 0.395 & 0.383 & 0.391 & 0.372 \\
\hline & $2 \mathrm{~F} 71$ & 636 & 8 in 12 & 0.42 & 0.4 & 0.392 & 0.389 & 0.380 & 0.371 & 0.360 \\
\hline \multirow[t]{3}{*}{ Regency Blue } & $2 \mathrm{~F} 52$ & 637 & 2 in 12 & 0.42 & 0.395 & 0.368 & 0.365 & 0.338 & 0.333 & 0.343 \\
\hline & $2 \mathrm{~F} 52$ & 638 & 4 in 12 & 0.412 & 0.388 & 0.366 & 0.355 & 0.350 & 0.356 & 0.353 \\
\hline & $2 \mathrm{~F} 52$ & 639 & 8 in 12 & 0.406 & 0.396 & 0.377 & 0.371 & 0.361 & 0.363 & 0.347 \\
\hline
\end{tabular}




\section{Corona, CA Solar Reflectance Field Data}

Table A.2

\begin{tabular}{|c|c|c|c|c|c|c|c|c|c|c|}
\hline & & & & \multicolumn{7}{|c|}{ EXPOSURE TIME (YRS) } \\
\hline & Identifier & Code & Slope & 0.000 & 0.750 & 0.962 & 1.630 & 2.493 & 3.592 & 4.047 \\
\hline \multirow[t]{3}{*}{ Natural Red } & F40 & 640 & 2 in 12 & 0.449 & 0.415 & 0.393 & 0.395 & & 0.364 & 0.354 \\
\hline & $\mathrm{F} 40$ & 641 & 4 in 12 & 0.462 & 0.43 & 0.415 & 0.408 & 0.394 & 0.408 & 0.376 \\
\hline & F40 & 642 & 8 in 12 & 0.459 & 0.423 & 0.43 & 0.415 & 0.407 & 0.418 & 0.394 \\
\hline \multirow[t]{3}{*}{$\begin{array}{r}\text { Weathered } \\
\text { Green }\end{array}$} & B305 & 643 & 2 in 12 & 0.411 & 0.386 & 0.346 & 0.357 & & 0.319 & 0.337 \\
\hline & B305 & 644 & 4 in 12 & 0.419 & 0.378 & 0.348 & 0.357 & 0.340 & 0.338 & 0.338 \\
\hline & B305 & 645 & 8 in 12 & 0.409 & 0.39 & 0.385 & 0.378 & 0.372 & 0.360 & 0.352 \\
\hline \multirow[t]{3}{*}{ Ironwood } & $2 \mathrm{~F} 19$ & 646 & 2 in 12 & 0.267 & 0.253 & 0.264 & 0.24 & & 0.253 & 0.305 \\
\hline & $2 \mathrm{~F} 19$ & 647 & 4 in 12 & 0.273 & 0.252 & 0.267 & 0.245 & 0.272 & 0.269 & 0.313 \\
\hline & $2 \mathrm{~F} 19$ & 648 & 8 in 12 & 0.27 & 0.253 & 0.255 & 0.257 & 0.275 & 0.272 & 0.308 \\
\hline \multicolumn{3}{|l|}{ US Clay Tile } & & & & & & & & \\
\hline Buff Blend & & 679 & 2 in 12 & & 0.536 & 0.272 & 0.492 & 0.436 & 0.391 & 0.312 \\
\hline Bermuda Blend & & 680 & 2 in 12 & & 0.456 & 0.278 & 0.411 & 0.396 & 0.390 & 0.361 \\
\hline \multicolumn{3}{|c|}{ Monierlife Concrete Tile } & & & & & & & & \\
\hline \multirow[t]{3}{*}{ Terra Cotta Red } & 6978 & 649 & 2 in 12 & & 0.206 & 0.233 & 0.197 & 0.228 & 0.239 & 0.288 \\
\hline & 6978 & 650 & 4 in 12 & & 0.207 & 0.209 & 0.195 & 0.235 & 0.248 & 0.293 \\
\hline & 6978 & 651 & 8 in 12 & & 0.178 & 0.182 & 0.165 & 0.212 & 0.249 & 0.273 \\
\hline \multirow[t]{3}{*}{ Hearthside } & 3083 & 652 & 2 in 12 & & 0.143 & 0.186 & 0.158 & 0.196 & 0.224 & 0.273 \\
\hline & 3083 & 653 & 4 in 12 & & 0.131 & 0.134 & 0.166 & 0.217 & 0.230 & 0.268 \\
\hline & 3083 & 654 & 8 in 12 & & 0.125 & 0.138 & 0.164 & 0.207 & 0.230 & 0.271 \\
\hline \multirow[t]{3}{*}{ Riversidepebble } & 3080 & 655 & 2 in 12 & & 0.146 & 0.171 & 0.164 & 0.215 & 0.245 & 0.280 \\
\hline & 3080 & 656 & 4 in 12 & & 0.151 & 0.142 & 0.199 & 0.222 & 0.253 & 0.279 \\
\hline & 3080 & 657 & 8 in 12 & & 0.151 & 0.141 & 0.156 & 0.200 & 0.230 & 0.266 \\
\hline \multirow[t]{3}{*}{ Ebony } & 5047 & 658 & 2 in 12 & & 0.14 & 0.186 & 0.141 & 0.192 & 0.210 & 0.275 \\
\hline & 5047 & 659 & 4 in 12 & & 0.131 & 0.13 & 0.128 & 0.176 & 0.198 & 0.271 \\
\hline & 5047 & 660 & 8 in 12 & & 0.137 & 0.135 & 0.125 & 0.172 & 0.194 & 0.271 \\
\hline \multirow{3}{*}{ Lincoln Green } & & & & & & & & & & \\
\hline & $\frac{4087}{4087}$ & $\frac{661}{662}$ & $\frac{2 \text { in } 12}{4 \text { in } 12}$ & & $\begin{array}{l}0.169 \\
0.161\end{array}$ & $\frac{0.211}{0.14}$ & $\begin{array}{l}0.178 \\
0.174\end{array}$ & $\begin{array}{l}0.227 \\
0.217\end{array}$ & $\begin{array}{l}0.255 \\
0.241\end{array}$ & $\begin{array}{l}0.295 \\
0.287\end{array}$ \\
\hline & 4087 & 663 & 8 in 12 & & 0.165 & 0.164 & 0.171 & 0.203 & 0.235 & 0.286 \\
\hline \multicolumn{3}{|c|}{ Shepherd Artic Match } & & & & & & & & \\
\hline \multirow[t]{3}{*}{ Blue Artic } & & 664 & 2 in 12 & & 0.255 & 0.27 & 0.251 & 0.257 & 0.238 & 0.304 \\
\hline & & 665 & 4 in 12 & & 0.258 & 0.273 & 0.249 & 0.265 & 0.256 & 0.298 \\
\hline & & 666 & 8 in 12 & & 0.25 & 0.262 & 0.238 & 0.250 & 0.253 & 0.282 \\
\hline & & & & & & & & & & \\
\hline \multirow[t]{3}{*}{ Red Artic } & & 667 & 2 in 12 & & 0.273 & 0.283 & 0.261 & 0.269 & 0.255 & 0.296 \\
\hline & & 668 & 4 in 12 & & 0.27 & & 0.266 & 0.281 & 0.275 & 0.317 \\
\hline & & 669 & 8 in 12 & & 0.276 & 0.287 & 0.262 & 0.279 & 0.283 & 0.312 \\
\hline \multirow[t]{3}{*}{ Brown Artic } & & 670 & 2 in 12 & & 0.255 & 0.282 & 0.253 & 0.262 & 0.241 & 0.289 \\
\hline & & 671 & 4 in 12 & & 0.244 & 0.268 & 0.247 & 0.263 & 0.251 & 0.300 \\
\hline & & 672 & 8 in 12 & & 0.258 & 0.277 & 0.266 & 0.278 & 0.274 & \\
\hline & & & & & & & & & & \\
\hline
\end{tabular}




\section{Appendix A}

\section{Colton Exposure Site (RS03)}

Painted metal, clay and concrete tile roof products with and without cool color pigments were placed on top of the low-slope roof at BASF's Research plant in Colton, CA. Coupons of the roof products were installed in exposure rack assemblies, which are 5.5-ft high by 9 -ft long, and divided into three sub-frames having respective slopes of 2-, 4- and 8-in of rise for 12-in of run (i.e., slopes of $9.5^{\circ}, 18.4^{\circ}$ and $33.7^{\circ}$ ). Each sub-frame can hold two "Sure-Grip" sub-assemblies, which are designed to have 6 rows of samples with 34-in of usable space in each row. Sample size is 3.5-in by 3.5-in. Orientation of the racks was set at $270^{\circ} \mathrm{CCW}$ from the east, so the roof coupons faced directly south to receive full solar exposure.

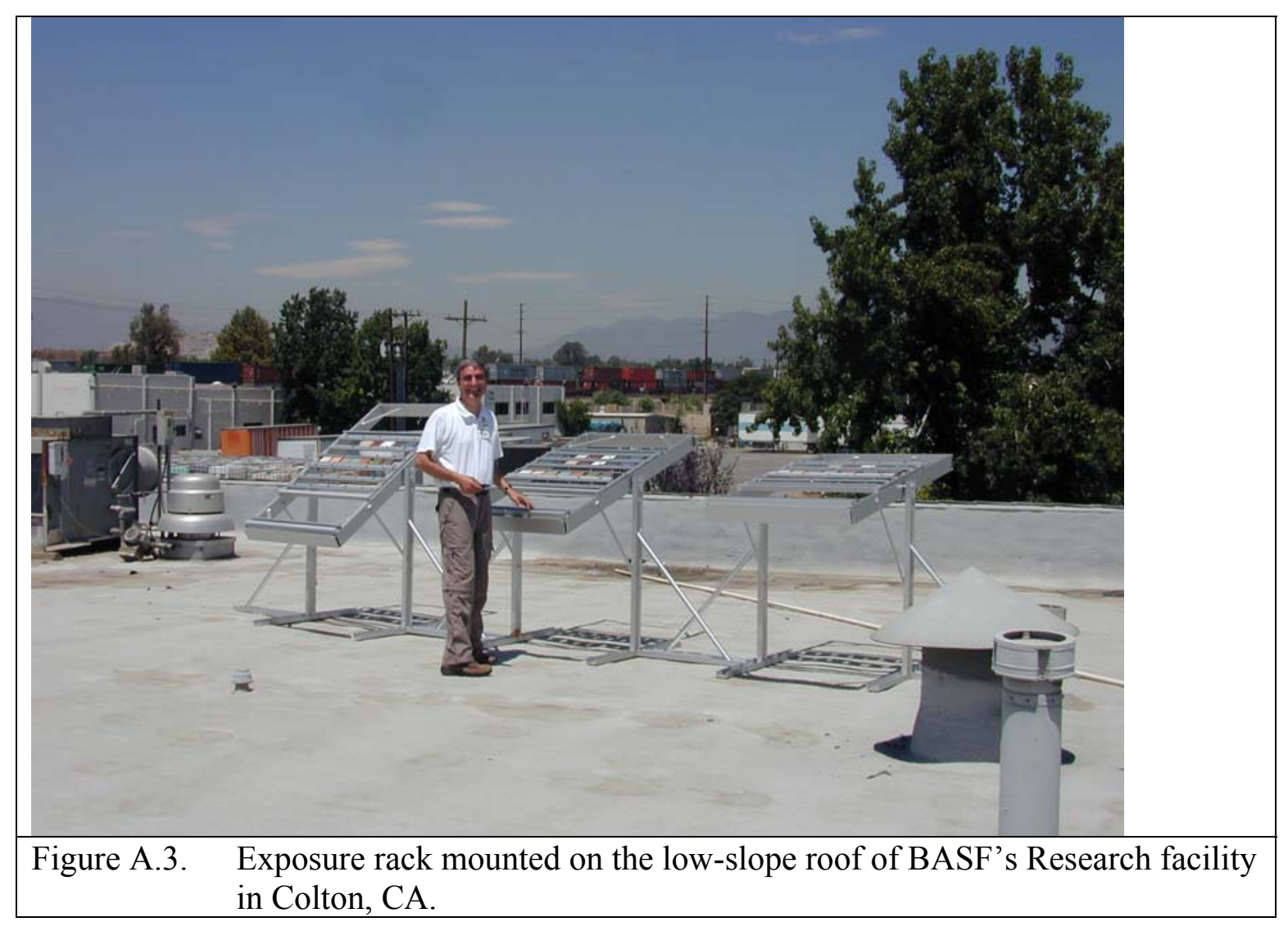




\section{Colton, CA Solar Reflectance Field Data}

Table A.3

\begin{tabular}{|c|c|c|c|c|c|c|c|c|c|c|}
\hline & & & & \multicolumn{7}{|c|}{ EXPOSURE TIME (YRS) } \\
\hline & Identifier & Code & Slope & 0.000 & 0.748 & 0.962 & 1.630 & 2.493 & 3.592 & 4.047 \\
\hline \multicolumn{11}{|c|}{ BASF PVDF Painted Metal } \\
\hline \multirow[t]{4}{*}{ Regal White } & $872 W 2$ & 500 & 2.628 in 12 & 0.742 & 0.646 & 0.491 & 0.673 & 0.639 & 0.639 & 0.279 \\
\hline & $872 W 2$ & 501 & 4.628 in 12 & 0.742 & 0.649 & 0.537 & 0.677 & 0.642 & 0.663 & 0.511 \\
\hline & $872 W 2$ & 502 & 8.628 in 12 & 0.743 & 0.663 & 0.537 & 0.681 & 0.658 & 0.669 & 0.760 \\
\hline & $815 W 98$ & 503 & 4.628 in 12 & 0.689 & 0.602 & 0.513 & 0.625 & 0.602 & 0.614 & 0.477 \\
\hline \multirow[t]{4}{*}{ Rawhide } & $872 T 6$ & 504 & 2.628 in 12 & 0.57 & 0.503 & 0.413 & 0.521 & 0.504 & 0.513 & 0.400 \\
\hline & 872 T6 & 505 & 4.628 in 12 & 0.572 & 0.509 & 0.438 & 0.52 & 0.515 & 0.520 & 0.433 \\
\hline & $872 T 6$ & 506 & 8.628 in 12 & 0.568 & 0.515 & 0.456 & 0.528 & 0.524 & 0.528 & 0.398 \\
\hline & $836 T 223$ & 507 & 4.628 in 12 & 0.44 & 0.4 & 0.356 & 0.4 & 0.399 & 0.409 & 0.345 \\
\hline \multirow[t]{4}{*}{ Slate Blue } & $872 B 7$ & 508 & 2.628 in 12 & 0.283 & 0.276 & 0.289 & 0.257 & 0.272 & 0.268 & 0.275 \\
\hline & $872 \mathrm{~B} 7$ & 509 & 4.628 in 12 & 0.282 & 0.278 & 0.29 & 0.258 & 0.271 & 0.270 & 0.273 \\
\hline & $872 \mathrm{~B} 7$ & 510 & 8.628 in 12 & 0.283 & 0.278 & 0.29 & 0.257 & 0.271 & 0.270 & 0.274 \\
\hline & 815B49 & 511 & 4.628 in 12 & 0.173 & 0.185 & 0.227 & 0.162 & 0.181 & 0.180 & 0.220 \\
\hline \multirow[t]{4}{*}{ Brick Red } & 872R10 & 512 & 2.628 in 12 & 0.375 & 0.354 & 0.343 & 0.353 & 0.363 & 0.358 & 0.326 \\
\hline & 872R10 & 513 & 4.628 in 12 & 0.374 & 0.355 & 0.349 & 0.353 & 0.365 & 0.360 & 0.327 \\
\hline & 872R10 & 514 & 8.628 in 12 & 0.374 & 0.358 & 0.349 & 0.355 & 0.362 & 0.364 & 0.320 \\
\hline & $815 R 71$ & 515 & 4.628 in 12 & 0.195 & 0.205 & 0.25 & 0.186 & 0.206 & 0.197 & 0.238 \\
\hline \multirow[t]{4}{*}{ Charcoal Gray } & 872D6 & 516 & 2.628 in 12 & 0.308 & 0.304 & 0.314 & 0.297 & 0.312 & 0.306 & 0.298 \\
\hline & 872D6 & 517 & 4.628 in 12 & 0.308 & 0.304 & 0.317 & 0.297 & Pulled & & \\
\hline & $872 D 6$ & 518 & 8.628 in 12 & 0.308 & 0.305 & 0.316 & 0.297 & Pulled & & \\
\hline & 815D119 & 519 & 4.628 in 12 & 0.122 & 0.13 & 0.203 & 0.117 & Pulled & & \\
\hline \multirow[t]{4}{*}{ Hartford Green } & $872 \mathrm{G} 16$ & 520 & 2.628 in 12 & 0.272 & 0.271 & 0.296 & 0.254 & 0.276 & 0.270 & 0.272 \\
\hline & $872 \mathrm{G} 16$ & 521 & 4.628 in 12 & 0.272 & 0.273 & 0.294 & 0.26 & 0.277 & 0.274 & 0.278 \\
\hline & $872 \mathrm{G} 16$ & 522 & 8.628 in 12 & 0.273 & 0.271 & 0.294 & 0.26 & 0.275 & 0.274 & 0.278 \\
\hline & $815 G 37$ & 523 & 4.628 in 12 & 0.089 & 0.116 & 0.189 & 0.088 & 0.113 & 0.108 & 0.194 \\
\hline \multirow[t]{4}{*}{ Slate Bronze } & 872 T3 & 524 & 2.628 in 12 & 0.262 & 0.263 & 0.293 & 0.251 & 0.268 & 0.524 & 0.275 \\
\hline & $872 T 3$ & 525 & 4.628 in 12 & 0.263 & 0.264 & 0.29 & 0.252 & 0.270 & 0.267 & 0.268 \\
\hline & $872 T 3$ & 526 & 8.628 in 12 & 0.262 & 0.264 & 0.287 & 0.249 & 0.268 & 0.267 & 0.271 \\
\hline & 815T119 & 527 & 4.628 in 12 & 0.118 & 0.14 & 0.206 & 0.115 & 0.139 & 0.133 & 0.198 \\
\hline \multicolumn{3}{|l|}{ MCA Clay Tile } & & & & & & & & \\
\hline \multirow[t]{3}{*}{ White Buff } & $2 \mathrm{~F} 44$ & 528 & 2.628 in 12 & 0.647 & 0.543 & 0.456 & 0.559 & 0.509 & 0.513 & 0.358 \\
\hline & $2 \mathrm{~F} 44$ & 529 & 4.628 in 12 & 0.653 & 0.554 & 0.479 & 0.565 & 0.523 & 0.524 & 0.398 \\
\hline & $2 \mathrm{~F} 44$ & 530 & 8.628 in 12 & 0.643 & 0.555 & 0.482 & 0.568 & 0.541 & 0.551 & 0.431 \\
\hline \multirow[t]{3}{*}{ Apricot Buff } & CF50 & 531 & 2.628 in 12 & 0.609 & 0.555 & 0.472 & 0.56 & 0.491 & 0.490 & 0.354 \\
\hline & CF50 & 532 & 4.628 in 12 & 0.611 & 0.563 & 0.496 & 0.576 & 0.505 & 0.507 & 0.414 \\
\hline & CF50 & 533 & 8.628 in 12 & 0.604 & 0.519 & 0.459 & 0.536 & 0.506 & 0.500 & 0.430 \\
\hline \multirow[t]{3}{*}{ Adobe Gray } & $2 \mathrm{~F} 71$ & 534 & 2.628 in 12 & 0.434 & 0.361 & 0.344 & 0.364 & 0.352 & 0.351 & 0.313 \\
\hline & $2 \mathrm{~F} 71$ & 535 & 4.628 in 12 & 0.46 & 0.378 & 0.359 & 0.38 & 0.369 & 0.370 & 0.314 \\
\hline & $2 \mathrm{~F} 71$ & 536 & 8.628 in 12 & 0.449 & 0.384 & 0.363 & 0.386 & 0.383 & 0.393 & 0.349 \\
\hline \multirow[t]{3}{*}{ Regency Blue } & $2 \mathrm{~F} 52$ & 537 & 2.628 in 12 & 0.435 & 0.379 & 0.351 & 0.367 & 0.351 & 0.393 & 0.398 \\
\hline & $2 \mathrm{~F} 52$ & 538 & 4.628 in 12 & 0.424 & 0.38 & 0.355 & 0.368 & 0.357 & 0.360 & 0.389 \\
\hline & 2 F52 & 539 & 8.628 in 12 & 0.43 & 0.381 & 0.359 & 0.369 & 0.368 & 0.359 & 0.343 \\
\hline
\end{tabular}




\section{Colton, CA Solar Reflectance Field Data}

Table A.3

\begin{tabular}{|c|c|c|c|c|c|c|c|c|c|c|}
\hline & & & & \multicolumn{7}{|c|}{ EXPOSURE TIME (YRS) } \\
\hline & Identifier & Code & Slope & 0.000 & 0.748 & 0.962 & 1.630 & 2.493 & 3.592 & 4.047 \\
\hline \multirow[t]{3}{*}{ Natural Red } & $\mathrm{F} 40$ & 540 & 2.628 in 12 & 0.461 & 0.421 & 0.397 & 0.423 & 0.413 & 0.410 & 0.332 \\
\hline & $\mathrm{F} 40$ & 541 & 4.628 in 12 & 0.463 & 0.416 & 0.389 & 0.412 & 0.405 & 0.405 & 0.363 \\
\hline & $\mathrm{F} 40$ & 542 & 8.628 in 12 & 0.465 & 0.418 & 0.395 & 0.419 & 0.417 & 0.401 & 0.366 \\
\hline \multirow[t]{3}{*}{$\begin{array}{r}\text { Weathered } \\
\text { Green } \\
\end{array}$} & B305 & 543 & 2.628 in 12 & 0.405 & 0.377 & 0.352 & 0.377 & 0.353 & 0.351 & 0.300 \\
\hline & B305 & 544 & 4.628 in 12 & 0.406 & 0.363 & 0.341 & 0.36 & 0.337 & 0.350 & 0.313 \\
\hline & B305 & 545 & 8.628 in 12 & 0.411 & 0.358 & 0.332 & 0.353 & 0.336 & 0.330 & 0.295 \\
\hline \multirow[t]{3}{*}{ Ironwood } & $2 \mathrm{~F} 19$ & 546 & 2.628 in 12 & 0.27 & 0.254 & 0.273 & 0.24 & 0.252 & 0.255 & 0.244 \\
\hline & 2F19 & 547 & 4.628 in 12 & 0.268 & 0.253 & 0.272 & 0.24 & 0.252 & 0.253 & 0.249 \\
\hline & 2F19 & 548 & 8.628 in 12 & 0.267 & 0.258 & 0.271 & 0.244 & 0.256 & 0.243 & 0.256 \\
\hline \multicolumn{11}{|l|}{ US Clay Tile } \\
\hline Buff Blend & & 579 & 2.628 in 12 & & 0.514 & 0.465 & 0.489 & 0.471 & 0.463 & 0.387 \\
\hline Bermuda Blend & & 580 & 2.628 in 12 & & 0.481 & 0.455 & 0.472 & 0.468 & 0.448 & 0.368 \\
\hline \multicolumn{3}{|c|}{ Monierlife Concrete Tile } & & & & & & & & \\
\hline \multirow[t]{3}{*}{ Terra Cotta Red } & 6978 & 549 & 2.628 in 12 & & 0.2 & 0.23 & 0.192 & 0.219 & 0.221 & 0.220 \\
\hline & 6978 & 550 & 4.628 in 12 & & 0.195 & 0.222 & 0.181 & 0.210 & 0.209 & 0.239 \\
\hline & 6978 & 551 & 8.628 in 12 & & 0.202 & 0.226 & 0.176 & 0.206 & 0.206 & 0.206 \\
\hline \multirow[t]{3}{*}{ Hearthside } & 3083 & 552 & 2.628 in 12 & & 0.149 & 0.202 & 0.178 & 0.207 & 0.209 & 0.218 \\
\hline & 3083 & 553 & 4.628 in 12 & & 0.138 & 0.2 & 0.158 & 0.193 & 0.195 & 0.233 \\
\hline & 3083 & 554 & 8.628 in 12 & & 0.135 & 0.207 & 0.161 & 0.190 & 0.180 & 0.221 \\
\hline \multirow[t]{3}{*}{ Riversidepebble } & 3080 & 555 & 2.628 in 12 & & 0.141 & 0.195 & 0.171 & 0.197 & 0.198 & 0.223 \\
\hline & 3080 & 556 & 4.628 in 12 & & 0.141 & 0.201 & 0.172 & 0.199 & 0.201 & 0.201 \\
\hline & 3080 & 557 & 8.628 in 12 & & 0.154 & 0.196 & 0.148 & 0.186 & 0.183 & 0.215 \\
\hline \multirow[t]{3}{*}{ Ebony } & 5047 & 558 & 2.628 in 12 & & 0.139 & 0.187 & 0.134 & 0.167 & 0.169 & 0.213 \\
\hline & 5047 & 559 & 4.628 in 12 & & 0.13 & 0.189 & 0.131 & 0.160 & 0.159 & 0.201 \\
\hline & 5047 & 560 & 8.628 in 12 & & 0.143 & 0.193 & 0.125 & 0.155 & 0.151 & 0.201 \\
\hline \multirow[t]{3}{*}{ Lincoln Green } & 4087 & 561 & 2.628 in 12 & & 0.18 & 0.226 & 0.172 & 0.197 & 0.199 & 0.227 \\
\hline & 4087 & 562 & 4.628 in 12 & & 0.153 & 0.204 & 0.152 & & 0.203 & 0.230 \\
\hline & 4087 & 563 & 8.628 in 12 & & 0.175 & 0.211 & 0.169 & 0.203 & 0.216 & 0.229 \\
\hline \multicolumn{3}{|c|}{ Shepherd Artic Match } & & & & & & & & \\
\hline \multirow[t]{3}{*}{ Blue Artic } & & 564 & 2.628 in 12 & & 0.234 & 0.26 & 0.222 & 0.232 & 0.229 & 0.239 \\
\hline & & 565 & 4.628 in 12 & & 0.242 & 0.27 & 0.229 & 0.238 & 0.235 & 0.243 \\
\hline & & 566 & 8.628 in 12 & & 0.25 & 0.276 & 0.242 & 0.263 & 0.256 & 0.264 \\
\hline \multirow[t]{3}{*}{ Red Artic } & & 567 & 2.628 in 12 & & 0.265 & 0.279 & 0.256 & 0.254 & 0.254 & 0.236 \\
\hline & & 568 & 4.628 in 12 & & 0.276 & 0.287 & 0.263 & 0.264 & 0.260 & 0.257 \\
\hline & & 569 & 8.628 in 12 & & 0.311 & 0.302 & 0.273 & 0.289 & 0.293 & 0.276 \\
\hline \multirow[t]{3}{*}{ Brown Artic } & & 570 & 2.628 in 12 & & 0.25 & 0.281 & 0.26 & 0.263 & 0.260 & 0.251 \\
\hline & & 571 & 4.628 in 12 & & 0.265 & 0.29 & 0.258 & 0.266 & 0.269 & 0.255 \\
\hline & & 572 & 8.628 in 12 & & 0.266 & 0.283 & 0.266 & 0.276 & 0.269 & 0.268 \\
\hline
\end{tabular}




\section{Appendix A}

\section{Shafter Exposure Site (RS04)}

Painted metal, clay and concrete tile roof products with and without cool color pigments were placed at ground level on the premises of Elk Corp.'s manufacturing facility in Shafter, CA. Coupons of the roof products were installed in exposure rack assemblies, which are 5.5-ft high by 9 -ft long, and divided into three sub-frames having respective slopes of 2-, 4- and 8-in of rise for 12-in of run (i.e., slopes of $9.5^{\circ}, 18.4^{\circ}$ and $33.7^{\circ}$ ). Each sub-frame can hold two "Sure-Grip" sub-assemblies, which are designed to have 6 rows of samples with 34-in of usable space in each row. Sample size is 3.5-in by 3.5 -in. Orientation of the racks was set at $270^{\circ} \mathrm{CCW}$ from the east, so the roof coupons faced directly south to receive full solar exposure.

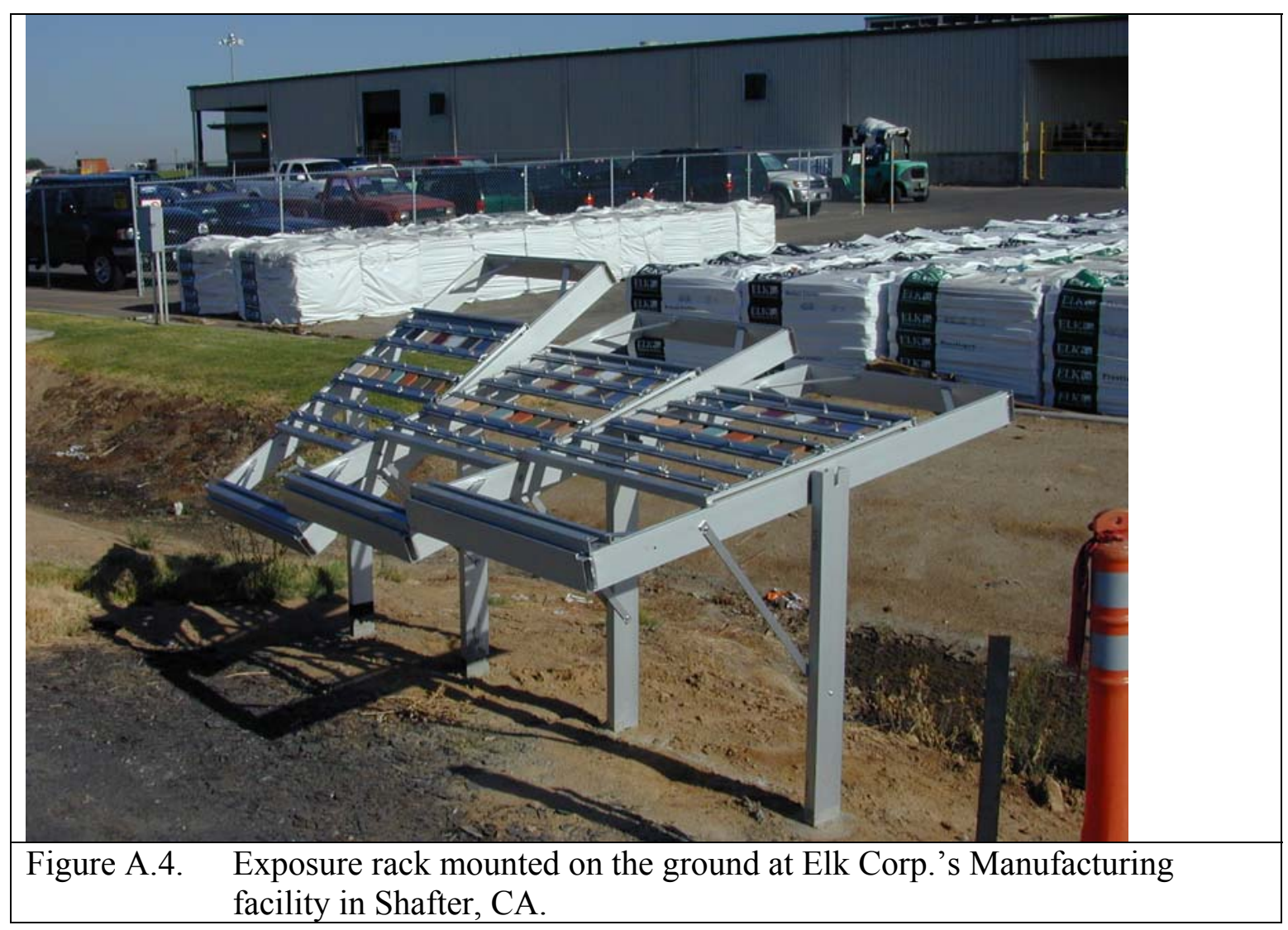




\section{Shafter, CA Solar Reflectance Field Data}

Table A.4

\begin{tabular}{|c|c|c|c|c|c|c|c|c|c|c|}
\hline & & & & \multicolumn{7}{|c|}{ EXPOSURE TIME (YRS) } \\
\hline & Identifier & Code & Slope & 0.000 & 0.751 & 0.959 & 1.633 & 2.496 & 3.589 & 4.049 \\
\hline \multicolumn{11}{|c|}{ BASF PVDF Painted Metal } \\
\hline \multirow[t]{4}{*}{ Regal White } & $872 W 2$ & 700 & 2 in 12 & 0.739 & 0.613 & 0.529 & 0.687 & 0.596 & 0.635 & 0.539 \\
\hline & $872 W 2$ & 701 & 4 in 12 & 0.742 & 0.559 & 0.589 & 0.685 & 0.623 & 0.644 & 0.533 \\
\hline & $872 W 2$ & 702 & 8 in 12 & 0.737 & 0.591 & 0.558 & 0.689 & 0.617 & 0.664 & 0.589 \\
\hline & 815 W98 & 703 & 4 in 12 & 0.688 & 0.551 & 0.545 & 0.638 & 0.574 & 0.588 & 0.525 \\
\hline \multirow[t]{4}{*}{ Rawhide } & $872 T 6$ & 704 & 2 in 12 & 0.570 & 0.490 & 0.443 & 0.524 & Pulled & & \\
\hline & $872 T 6$ & 705 & 4 in 12 & 0.569 & 0.456 & 0.457 & 0.523 & Pulled & & \\
\hline & 872 T6 & 706 & 8 in 12 & 0.574 & 0.469 & 0.437 & 0.525 & Pulled & & \\
\hline & 836 T223 & 707 & 4 in 12 & 0.441 & 0.378 & 0.369 & 0.405 & Pulled & & \\
\hline \multirow[t]{4}{*}{ Slate Blue } & $872 B 7$ & 708 & 2 in 12 & 0.282 & 0.278 & 0.277 & 0.256 & 0.256 & 0.259 & 0.277 \\
\hline & $872 \mathrm{~B} 7$ & 709 & 4 in 12 & 0.283 & 0.279 & 0.278 & 0.258 & 0.261 & 0.265 & 0.278 \\
\hline & 872B7 & 710 & 8 in 12 & 0.282 & 0.278 & 0.280 & 0.258 & 0.262 & 0.267 & 0.279 \\
\hline & 815B49 & 711 & 4 in 12 & 0.172 & 0.199 & 0.204 & 0.158 & 0.176 & 0.178 & 0.199 \\
\hline \multirow[t]{4}{*}{ Brick Red } & 872R10 & 712 & 2 in 12 & 0.375 & 0.350 & 0.340 & 0.353 & 0.339 & 0.347 & 0.347 \\
\hline & 872R10 & 713 & 4 in 12 & 0.375 & 0.344 & 0.347 & 0.354 & 0.348 & 0.353 & 0.304 \\
\hline & $872 \mathrm{R} 10$ & 714 & 8 in 12 & 0.375 & 0.340 & 0.338 & 0.353 & 0.350 & 0.360 & 0.343 \\
\hline & $815 R 71$ & 715 & 4 in 12 & 0.195 & 0.220 & 0.218 & 0.184 & 0.200 & 0.202 & 0.229 \\
\hline \multirow[t]{4}{*}{ Charcoal Gray } & $872 D 6$ & 716 & 2 in 12 & 0.308 & 0.303 & 0.307 & 0.295 & 0.296 & 0.303 & 0.302 \\
\hline & $872 D 6$ & 717 & 4 in 12 & 0.308 & 0.304 & 0.303 & 0.295 & 0.299 & 0.304 & 0.301 \\
\hline & 872D6 & 718 & 8 in 12 & 0.308 & 0.304 & 0.305 & 0.297 & 0.301 & 0.306 & 0.305 \\
\hline & 815D119 & 719 & 4 in 12 & 0.122 & 0.175 & 0.163 & 0.116 & 0.141 & 0.143 & 0.173 \\
\hline \multirow[t]{4}{*}{ Hartford Green } & $872 \mathrm{G} 16$ & 720 & 2 in 12 & 0.270 & 0.276 & 0.279 & 0.258 & 0.262 & 0.264 & 0.279 \\
\hline & $872 \mathrm{G} 16$ & 721 & 4 in 12 & 0.272 & 0.278 & 0.279 & 0.260 & 0.267 & 0.271 & 0.282 \\
\hline & $872 \mathrm{G} 16$ & 722 & 8 in 12 & 0.271 & 0.273 & 0.279 & 0.260 & 0.266 & 0.272 & 0.280 \\
\hline & $815 G 37$ & 723 & 4 in 12 & 0.088 & 0.154 & 0.151 & 0.086 & 0.114 & 0.116 & 0.087 \\
\hline \multirow[t]{4}{*}{ Slate Bronze } & $872 T 3$ & 724 & 2 in 12 & 0.262 & 0.269 & 0.273 & 0.250 & 0.258 & 0.263 & 0.277 \\
\hline & $872 T 3$ & 725 & 4 in 12 & 0.263 & 0.269 & 0.273 & 0.250 & 0.258 & 0.264 & 0.271 \\
\hline & 872 T3 & 726 & 8 in 12 & 0.262 & 0.270 & 0.277 & 0.250 & 0.257 & 0.261 & 0.238 \\
\hline & 815T119 & 727 & 4 in 12 & 0.188 & 0.161 & 0.180 & 0.113 & 0.137 & & 0.168 \\
\hline \multicolumn{3}{|l|}{ MCA Clay Tile } & & & & & & & & \\
\hline \multirow[t]{3}{*}{ White Buff } & $2 \mathrm{~F} 44$ & 728 & 2 in 12 & 0.626 & 0.503 & 0.482 & 0.541 & 0.476 & 0.513 & 0.462 \\
\hline & $2 F 44$ & 729 & 4 in 12 & 0.645 & 0.487 & 0.488 & 0.536 & 0.473 & 0.503 & 0.429 \\
\hline & $2 F 44$ & 730 & 8 in 12 & 0.637 & 0.505 & 0.491 & 0.556 & 0.488 & 0.531 & 0.436 \\
\hline \multirow[t]{3}{*}{ Apricot Buff } & CF50 & 731 & 2 in 12 & 0.644 & 0.489 & 0.451 & 0.513 & 0.440 & 0.482 & 0.426 \\
\hline & CF50 & 732 & 4 in 12 & 0.652 & 0.448 & 0.438 & 0.505 & 0.468 & 0.491 & 0.407 \\
\hline & CF50 & 733 & 8 in 12 & 0.606 & 0.458 & 0.454 & 0.522 & 0.470 & 0.511 & 0.429 \\
\hline \multirow[t]{3}{*}{ Adobe Gray } & $2 F 71$ & 734 & 2 in 12 & 0.406 & 0.367 & 0.358 & 0.369 & 0.347 & 0.362 & 0.354 \\
\hline & $2 F 71$ & 735 & 4 in 12 & 0.424 & 0.363 & 0.359 & 0.373 & 0.354 & 0.369 & 0.336 \\
\hline & $2 \mathrm{~F} 71$ & 736 & 8 in 12 & 0.428 & 0.352 & 0.358 & 0.371 & 0.344 & 0.373 & 0.341 \\
\hline \multirow[t]{3}{*}{ Regency Blue } & $2 \mathrm{~F} 52$ & 737 & 2 in 12 & 0.414 & 0.367 & 0.366 & 0.343 & 0.317 & 0.337 & 0.324 \\
\hline & $2 \mathrm{~F} 52$ & 738 & 4 in 12 & 0.413 & 0.360 & 0.367 & 0.359 & 0.328 & 0.345 & 0.326 \\
\hline & $2 \mathrm{~F} 52$ & 739 & 8 in 12 & 0.407 & 0.360 & 0.382 & 0.364 & 0.339 & 0.354 & 0.340 \\
\hline
\end{tabular}




\section{Shafter, CA Solar Reflectance Field Data}

Table A.4

\begin{tabular}{|c|c|c|c|c|c|c|c|c|c|c|}
\hline & & & & \multicolumn{7}{|c|}{ EXPOSURE TIME (YRS) } \\
\hline & Identifier & Code & Slope & 0.000 & 0.751 & 0.959 & 1.633 & 2.496 & 3.589 & 4.049 \\
\hline \multirow[t]{3}{*}{ Natural Red } & $\mathrm{F} 40$ & 740 & 2 in 12 & 0.470 & 0.415 & 0.413 & 0.407 & 0.368 & 0.385 & 0.362 \\
\hline & $\mathrm{F} 40$ & 741 & 4 in 12 & 0.457 & 0.410 & 0.429 & 0.407 & 0.380 & 0.396 & 0.362 \\
\hline & F40 & 742 & 8 in 12 & 0.460 & 0.409 & 0.401 & 0.414 & 0.382 & 0.402 & 0.368 \\
\hline \multirow[t]{3}{*}{$\begin{array}{r}\text { Weathered } \\
\text { Green }\end{array}$} & B305 & 743 & 2 in 12 & 0.425 & 0.362 & 0.341 & 0.369 & 0.345 & 0.360 & 0.333 \\
\hline & B305 & 744 & 4 in 12 & 0.406 & 0.333 & 0.328 & 0.352 & 0.329 & 0.344 & 0.320 \\
\hline & B305 & 745 & 8 in 12 & 0.401 & 0.334 & 0.334 & 0.364 & 0.339 & 0.364 & 0.336 \\
\hline \multirow[t]{3}{*}{ Ironwood } & $2 \mathrm{~F} 19$ & 746 & 2 in 12 & 0.266 & 0.260 & 0.275 & 0.231 & 0.240 & 0.246 & 0.270 \\
\hline & 2F19 & 747 & 4 in 12 & 0.267 & 0.267 & 0.273 & 0.237 & 0.247 & 0.256 & 0.266 \\
\hline & $2 \mathrm{~F} 19$ & 748 & 8 in 12 & 0.270 & 0.262 & 0.274 & 0.235 & 0.241 & 0.249 & 0.267 \\
\hline \multicolumn{3}{|l|}{ US Clay Tile } & & & & & & & & \\
\hline Buff Blend & & 779 & 2 in 12 & & 0.565 & 0.486 & 0.521 & Pulled & & \\
\hline \multirow[t]{2}{*}{ Bermuda Blend } & & 780 & 2 in 12 & & 0.489 & 0.436 & 0.447 & Pulled & & \\
\hline & & & & & & & & & & \\
\hline \multicolumn{3}{|c|}{ Monierlife Concrete Tile } & & & & & & & & \\
\hline \multirow[t]{3}{*}{ Terra Cotta Red } & 6978 & 749 & 2 in 12 & & 0.202 & 0.238 & 0.172 & 0.189 & 0.201 & 0.238 \\
\hline & 6978 & 750 & 4 in 12 & & 0.181 & 0.226 & 0.154 & 0.173 & 0.189 & 0.233 \\
\hline & 6978 & 751 & 8 in 12 & & 0.216 & 0.235 & 0.168 & 0.183 & 0.198 & 0.238 \\
\hline \multirow[t]{3}{*}{ Hearthside } & 3083 & 752 & 2 in 12 & & 0.121 & 0.196 & 0.136 & 0.162 & 0.165 & 0.217 \\
\hline & 3083 & 753 & 4 in 12 & & 0.125 & 0.194 & 0.142 & 0.184 & 0.194 & 0.230 \\
\hline & 3083 & 754 & 8 in 12 & & 0.131 & 0.199 & 0.144 & 0.164 & 0.169 & 0.213 \\
\hline \multirow[t]{3}{*}{ Riversidepebble } & 3080 & 755 & 2 in 12 & & 0.142 & 0.185 & 0.134 & 0.167 & 0.179 & 0.218 \\
\hline & 3080 & 756 & 4 in 12 & & 0.165 & 0.197 & 0.164 & 0.178 & 0.201 & 0.228 \\
\hline & 3080 & 757 & 8 in 12 & & 0.148 & 0.187 & 0.148 & 0.178 & 0.188 & 0.234 \\
\hline \multirow[t]{3}{*}{ Ebony } & 5047 & 758 & 2 in 12 & & 0.137 & 0.199 & 0.112 & 0.142 & 0.151 & 0.210 \\
\hline & 5047 & 759 & 4 in 12 & & 0.141 & 0.197 & 0.109 & 0.137 & 0.147 & 0.203 \\
\hline & 5047 & 760 & 8 in 12 & & 0.141 & 0.191 & 0.111 & 0.137 & 0.144 & 0.200 \\
\hline \multirow[t]{3}{*}{ Lincoln Green } & 4087 & 761 & 2 in 12 & & 0.155 & 0.210 & 0.151 & 0.170 & 0.190 & 0.224 \\
\hline & 4087 & 762 & 4 in 12 & & 0.177 & 0.217 & 0.157 & 0.189 & 0.201 & 0.237 \\
\hline & 4087 & 763 & 8 in 12 & & 0.185 & 0.218 & 0.161 & 0.186 & 0.197 & 0.228 \\
\hline \multicolumn{3}{|c|}{ Shepherd Artic Match } & & & & & & & & \\
\hline \multirow[t]{3}{*}{ Blue Artic } & & 764 & 2 in 12 & & 0.246 & 0.262 & 0.238 & 0.230 & 0.231 & 0.252 \\
\hline & & 765 & 4 in 12 & & 0.237 & 0.249 & 0.220 & 0.229 & 0.226 & 0.257 \\
\hline & & 766 & 8 in 12 & & 0.226 & 0.251 & 0.206 & 0.217 & 0.222 & 0.246 \\
\hline \multirow[t]{3}{*}{ Red Artic } & & 767 & 2 in 12 & & 0.312 & 0.294 & 0.377 & 0.279 & 0.287 & 0.285 \\
\hline & & 768 & 4 in 12 & & 0.331 & 0.297 & 0.313 & 0.316 & 0.323 & 0.311 \\
\hline & & 769 & 8 in 12 & & 0.321 & 0.297 & 0.302 & 0.299 & 0.300 & 0.297 \\
\hline \multirow[t]{3}{*}{ Brown Artic } & & 770 & 2 in 12 & & 0.251 & 0.264 & 0.250 & 0.242 & 0.245 & 0.263 \\
\hline & & 771 & 4 in 12 & & 0.259 & 0.266 & 0.253 & 0.253 & 0.251 & 0.266 \\
\hline & & 772 & 8 in 12 & & 0.260 & 0.263 & 0.248 & 0.248 & 0.248 & 0.263 \\
\hline
\end{tabular}




\section{Appendix A}

\section{Richmond Exposure Site (RS05)}

Painted metal, clay and concrete tile roof products with and without cool color pigments were placed on top of the steep-slope roof at Steelscape Inc.'s warehouse in Richmond, CA. Coupons of the roof products were installed in exposure rack assemblies, which are 5.5-ft high by 9-ft long, and divided into three sub-frames having respective slopes of 2-, 4- and 8-in of rise for 12-in of run (i.e., slopes of $9.5^{\circ}, 18.4^{\circ}$ and $33.7^{\circ}$ ). Each sub-frame can hold two "Sure-Grip" sub-assemblies, which are designed to have 6 rows of samples with 34-in of usable space in each row. Sample size is 3.5-in by 3.5-in. Orientation of the racks was set at $235^{\circ} \mathrm{CCW}$ (facing directly east represents $0^{\circ} \mathrm{CCW}$ ), so the roof coupons faced south, south-west to receive almost full solar exposure.

Access to the samples required the use of a high lift and trained operator. Personnel used fall protection while climbing onto the 15-ft elevated roof. On one occasion the lift was not available and data was therefore omitted for the 0.959 year time.

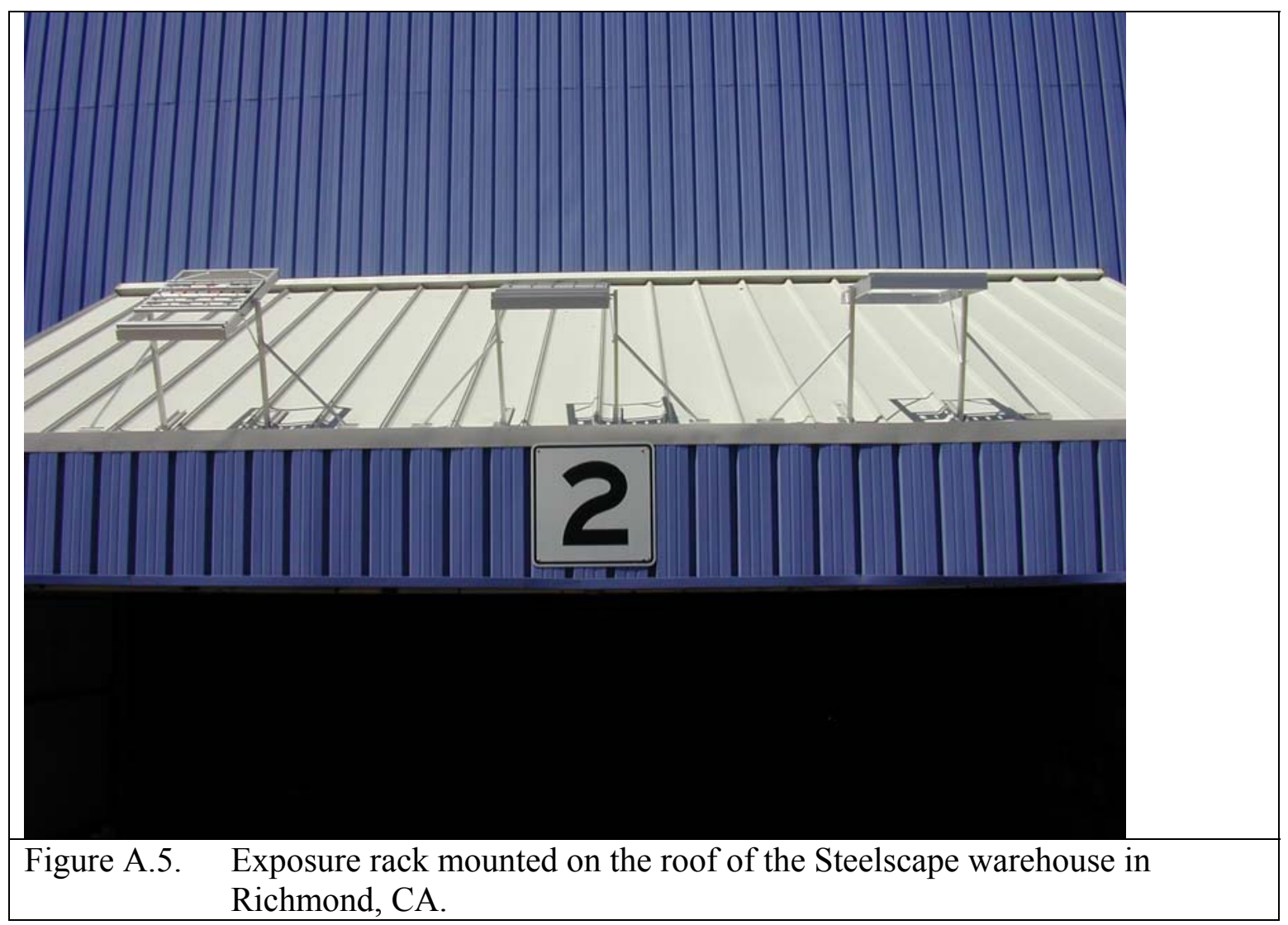




\section{Richmond, CA Solar Reflectance Field Data}

Table A.5

\begin{tabular}{|c|c|c|c|c|c|c|c|c|c|c|}
\hline & & & & \multicolumn{7}{|c|}{ EXPOSURE TIME (YRS) } \\
\hline & Identifier & Code & Slope & 0.000 & 0.748 & 0.959 & 1.638 & 2.501 & 3.589 & 4.055 \\
\hline \multicolumn{11}{|c|}{ BASF PVDF Painted Metal } \\
\hline \multirow[t]{4}{*}{ Regal White } & $872 W 2$ & 400 & 2 in 12 & 0.742 & 0.632 & & 0.718 & 0.720 & 0.716 & 0.692 \\
\hline & $872 W 2$ & 401 & 4 in 12 & 0.742 & 0.633 & & 0.716 & 0.720 & 0.720 & 0.682 \\
\hline & $872 W 2$ & 402 & 8 in 12 & 0.742 & 0.620 & & 0.713 & 0.724 & 0.666 & 0.676 \\
\hline & $815 \mathrm{~W} 98$ & 403 & 4 in 12 & 0.688 & 0.581 & & 0.661 & 0.670 & 0.669 & 0.493 \\
\hline & & & & & & & & & & \\
\hline \multirow[t]{4}{*}{ Rawhide } & $872 T 6$ & 404 & 2 in 12 & 0.569 & 0.492 & & 0.546 & Pulled & & \\
\hline & $872 T 6$ & 405 & 4 in 12 & 0.569 & 0.490 & & 0.544 & Pulled & & \\
\hline & $872 T 6$ & 406 & 8 in 12 & 0.568 & 0.484 & & 0.544 & Pulled & & \\
\hline & $836 T 223$ & 407 & 4 in 12 & 0.440 & 0.381 & & 0.415 & 0.429 & 0.428 & 0.424 \\
\hline & & & & & & & & & & \\
\hline \multirow[t]{4}{*}{ Slate Blue } & $872 \mathrm{~B} 7$ & 408 & 2 in 12 & 0.282 & 0.257 & & 0.262 & 0.265 & 0.273 & 0.278 \\
\hline & 872B7 & 409 & 4 in 12 & 0.281 & 0.259 & & 0.261 & 0.275 & 0.273 & 0.275 \\
\hline & $872 \mathrm{~B} 7$ & 410 & 8 in 12 & 0.280 & 0.256 & & 0.260 & 0.275 & 0.274 & 0.276 \\
\hline & 815B49 & 411 & 4 in 12 & 0.172 & 0.172 & & 0.161 & 0.174 & 0.175 & 0.180 \\
\hline \multirow[t]{4}{*}{ Brick Red } & 872 R10 & 412 & 2 in 12 & 0.374 & 0.341 & & 0.358 & 0.376 & 0.371 & 0.358 \\
\hline & $872 \mathrm{R} 10$ & 413 & 4 in 12 & 0.375 & 0.339 & & 0.360 & 0.375 & 0.370 & 0.357 \\
\hline & $872 \mathrm{R} 10$ & 414 & 8 in 12 & 0.373 & 0.340 & & 0.357 & 0.375 & 0.372 & 0.359 \\
\hline & $815 R 71$ & 415 & 4 in 12 & 0.195 & 0.192 & & 0.184 & 0.198 & 0.197 & 0.186 \\
\hline \multirow[t]{4}{*}{ Charcoal Gray } & $872 \mathrm{D} 6$ & 416 & 2 in 12 & 0.308 & 0.297 & & 0.301 & 0.319 & 0.313 & 0.302 \\
\hline & $872 \mathrm{D} 6$ & 417 & 4 in 12 & 0.308 & 0.295 & & 0.300 & 0.317 & 0.313 & 0.298 \\
\hline & $872 \mathrm{D} 6$ & 418 & 8 in 12 & 0.308 & 0.294 & & 0.299 & & 0.314 & 0.302 \\
\hline & $815 \mathrm{D} 119$ & 419 & 4 in 12 & 0.122 & 0.132 & & 0.115 & 0.126 & 0.127 & 0.132 \\
\hline \multirow[t]{4}{*}{ Hartford Green } & $872 \mathrm{G} 16$ & 420 & 2 in 12 & 0.272 & 0.264 & & 0.262 & 0.278 & 0.274 & 0.263 \\
\hline & $872 \mathrm{G} 16$ & 421 & 4 in 12 & 0.273 & 0.260 & & 0.261 & 0.275 & 0.272 & 0.267 \\
\hline & $872 \mathrm{G} 16$ & 422 & 8 in 12 & 0.272 & 0.260 & & 0.258 & 0.276 & 0.277 & 0.267 \\
\hline & $815 G 37$ & 423 & 4 in 12 & 0.088 & 0.106 & & 0.084 & 0.094 & 0.095 & 0.102 \\
\hline \multirow[t]{4}{*}{ Slate Bronze } & $872 \mathrm{T3}$ & 424 & 2 in 12 & 0.262 & 0.252 & & 0.254 & 0.269 & 0.267 & 0.264 \\
\hline & $872 T 3$ & 425 & 4 in 12 & 0.263 & 0.252 & & 0.254 & 0.270 & 0.268 & 0.234 \\
\hline & $872 \mathrm{T3}$ & 426 & 8 in 12 & 0.263 & 0.250 & & 0.251 & 0.266 & 0.268 & 0.262 \\
\hline & $815 T 119$ & 427 & 4 in 12 & 0.118 & 0.127 & & 0.112 & 0.123 & 0.123 & 0.130 \\
\hline \multirow{2}{*}{\multicolumn{11}{|c|}{ MCA Clay Tile }} \\
\hline & & & & & & & & & & \\
\hline \multirow[t]{3}{*}{ White Buff } & $2 \mathrm{~F} 44$ & 428 & 2 in 12 & 0.630 & 0.585 & & 0.585 & 0.583 & 0.546 & 0.541 \\
\hline & $2 \mathrm{~F} 44$ & 429 & 4 in 12 & 0.643 & 0.585 & & 0.603 & 0.601 & 0.576 & 0.520 \\
\hline & $2 \mathrm{~F} 44$ & 430 & 8 in 12 & 0.651 & 0.564 & & 0.586 & 0.590 & 0.567 & 0.572 \\
\hline \multirow[t]{3}{*}{ Apricot Buff } & CF50 & 431 & 2 in 12 & 0.602 & 0.529 & & 0.539 & 0.531 & 0.509 & 0.492 \\
\hline & CF50 & 432 & 4 in 12 & 0.599 & 0.511 & & 0.535 & 0.532 & 0.513 & 0.498 \\
\hline & CF50 & 433 & 8 in 12 & 0.607 & 0.549 & & 0.566 & 0.564 & 0.541 & 0.523 \\
\hline \multirow[t]{3}{*}{ Adobe Gray } & $2 \mathrm{~F} 71$ & 434 & 2 in 12 & 0.424 & 0.395 & & 0.397 & 0.404 & 0.387 & 0.385 \\
\hline & $2 \mathrm{~F} 71$ & 435 & 4 in 12 & 0.441 & 0.388 & & 0.393 & 0.400 & 0.380 & 0.370 \\
\hline & $2 \mathrm{~F} 71$ & 436 & 8 in 12 & 0.427 & 0.390 & & 0.395 & 0.401 & 0.386 & 0.372 \\
\hline \multirow{3}{*}{ Regency Blue } & $2 \mathrm{~F} 52$ & 437 & 2 in 12 & 0.435 & 0.389 & & 0.369 & 0.378 & 0.366 & 0.370 \\
\hline & $2 \mathrm{~F} 52$ & 438 & 4 in 12 & 0.433 & 0.385 & & 0.374 & 0.382 & 0.365 & 0.359 \\
\hline & $2 \mathrm{~F} 52$ & 439 & 8 in 12 & 0.432 & 0.372 & & 0.366 & 0.375 & 0.363 & 0.340 \\
\hline
\end{tabular}




\section{Richmond, CA Solar Reflectance Field Data}

Table A.5

\begin{tabular}{|c|c|c|c|c|c|c|c|c|c|c|}
\hline & & & & \multicolumn{7}{|c|}{ EXPOSURE TIME (YRS) } \\
\hline & Identifier & Code & Slope & 0.000 & 0.748 & 0.959 & 1.638 & 2.501 & 3.589 & 4.055 \\
\hline \multirow[t]{3}{*}{ Natural Red } & $\mathrm{F} 40$ & 440 & 2 in 12 & 0.459 & 0.408 & & 0.411 & 0.418 & 0.403 & 0.386 \\
\hline & $\mathrm{F} 40$ & 441 & 4 in 12 & 0.458 & 0.419 & & 0.427 & 0.433 & 0.417 & 0.420 \\
\hline & $\mathrm{F} 40$ & 442 & 8 in 12 & 0.461 & 0.428 & & 0.428 & 0.434 & 0.418 & 0.403 \\
\hline \multirow[t]{3}{*}{$\begin{array}{r}\text { Weathered } \\
\text { Green }\end{array}$} & B305 & 443 & 2 in 12 & 0.420 & 0.362 & & 0.373 & 0.373 & 0.359 & 0.340 \\
\hline & B305 & 444 & 4 in 12 & 0.411 & 0.385 & & 0.387 & 0.396 & 0.378 & 0.368 \\
\hline & B305 & 445 & 8 in 12 & 0.413 & 0.362 & & 0.374 & 0.382 & 0.370 & 0.355 \\
\hline \multirow[t]{3}{*}{ Ironwood } & $2 \mathrm{~F} 19$ & 446 & 2 in 12 & 0.269 & 0.258 & & 0.245 & 0.259 & 0.248 & 0.248 \\
\hline & $2 \mathrm{~F} 19$ & 447 & 4 in 12 & 0.272 & 0.259 & & 0.247 & 0.263 & 0.255 & 0.260 \\
\hline & $2 \mathrm{~F} 19$ & 448 & 8 in 12 & 0.268 & $\mathrm{NA}$ & & 0.249 & 0.265 & 0.258 & 0.253 \\
\hline \multicolumn{3}{|l|}{ US Clay Tile } & & & & & & & & \\
\hline Buff Blend & & 479 & 2 in 12 & & 0.585 & & 0.552 & 0.577 & 0.532 & 0.546 \\
\hline Bermuda Blend & & 480 & 2 in 12 & & 0.489 & & 0.457 & 0.467 & 0.438 & 0.441 \\
\hline \multicolumn{3}{|c|}{ Monierlife Concrete Tile } & & & & & & & & \\
\hline \multirow[t]{3}{*}{ Terra Cotta Red } & 6978 & 449 & 2 in 12 & & 0.196 & & 0.177 & 0.207 & 0.225 & 0.234 \\
\hline & 6978 & 450 & 4 in 12 & & 0.180 & & 0.176 & 0.210 & 0.215 & 0.200 \\
\hline & 6978 & 451 & 8 in 12 & & 0.194 & & 0.184 & 0.219 & 0.234 & 0.200 \\
\hline \multirow[t]{3}{*}{ Hearthside } & 3083 & 452 & 2 in 12 & & 0.125 & & 0.154 & 0.159 & 0.165 & 0.163 \\
\hline & 3083 & 453 & 4 in 12 & & 0.134 & & 0.142 & 0.160 & 0.162 & 0.167 \\
\hline & 3083 & 454 & 8 in 12 & & 0.125 & & 0.137 & 0.155 & 0.157 & 0.166 \\
\hline \multirow[t]{3}{*}{ Riversidepebble } & 3080 & 455 & 2 in 12 & & 0.154 & & 0.175 & 0.189 & 0.170 & 0.201 \\
\hline & 3080 & 456 & 4 in 12 & & 0.139 & & 0.161 & 0.171 & 0.168 & 0.171 \\
\hline & 3080 & 457 & 8 in 12 & & 0.143 & & 0.171 & 0.166 & 0.172 & 0.180 \\
\hline \multirow{3}{*}{ Ebony } & & & & & & & & & & \\
\hline & $\begin{array}{l}5047 \\
5047\end{array}$ & $\frac{458}{459}$ & $\frac{2 \text { in } 12}{4 \text { in } 12}$ & & $\begin{array}{l}0.146 \\
0.145\end{array}$ & & $\begin{array}{l}0.123 \\
0.130\end{array}$ & $\begin{array}{l}0.144 \\
0.151\end{array}$ & 0.153 & $\begin{array}{l}0.168 \\
0.158\end{array}$ \\
\hline & 5047 & 460 & 8 in 12 & & 0.141 & & 0.128 & 0.148 & 0.148 & 0.160 \\
\hline \multirow{3}{*}{ Lincoln Green } & 4087 & 461 & 2 in 12 & & 0.157 & & 0.165 & 0.193 & 0.198 & 0.190 \\
\hline & 4087 & 462 & 4 in 12 & & 0.171 & & 0.174 & 0.206 & 0.209 & 0.217 \\
\hline & 4087 & 463 & 8 in 12 & & 0.161 & & 0.163 & 0.192 & 0.202 & 0.207 \\
\hline \multicolumn{3}{|c|}{ Shepherd Artic Match } & & & & & & & & \\
\hline \multirow[t]{3}{*}{ Blue Artic } & & 464 & 2 in 12 & & 0.230 & & 0.214 & 0.223 & 0.224 & 0.225 \\
\hline & & 465 & 4 in 12 & & 0.234 & & 0.215 & 0.237 & 0.235 & 0.250 \\
\hline & & 466 & 8 in 12 & & 0.241 & & 0.219 & 0.229 & 0.233 & 0.236 \\
\hline \multirow[t]{3}{*}{ Red Artic } & & 467 & 2 in 12 & & 0.284 & & 0.266 & 0.266 & 0.257 & 0.267 \\
\hline & & 468 & 4 in 12 & & 0.277 & & 0.264 & 0.261 & 0.250 & 0.263 \\
\hline & & 469 & 8 in 12 & & 0.270 & & 0.258 & 0.260 & 0.249 & 0.255 \\
\hline \multirow[t]{3}{*}{ Brown Artic } & & 470 & 2 in 12 & & 0.262 & & 0.252 & 0.258 & & 0.253 \\
\hline & & 471 & 4 in 12 & & 0.249 & & 0.246 & 0.251 & 0.245 & 0.231 \\
\hline & & 472 & 8 in 12 & & 0.247 & & 0.253 & 0.251 & 0.249 & 0.247 \\
\hline
\end{tabular}




\section{Appendix A}

\section{Sacramento Exposure Site (RS06)}

Painted metal, clay and concrete tile roof products with and without cool color pigments were placed on top of the low-slope roof at Custom-Bilt's warehouse in Sacramento, CA. Coupons of the roof products were installed in exposure rack assemblies, which are 5.5-ft high by 9 -ft long, and divided into three sub-frames having respective slopes of 2-, 4- and 8-in of rise for 12-in of run (i.e., slopes of $9.5^{\circ}, 18.4^{\circ}$ and $33.7^{\circ}$ ). Each sub-frame can hold two "Sure-Grip" sub-assemblies, which are designed to have 6 rows of samples with 34-in of usable space in each row. Sample size is 3.5-in by 3.5 -in. Orientation of the racks was set at $270^{\circ} \mathrm{CCW}$ (facing directly east represents $0^{\circ}$ $\mathrm{CCW}$ ), so the roof coupons faced almost directly south to receive full solar exposure.

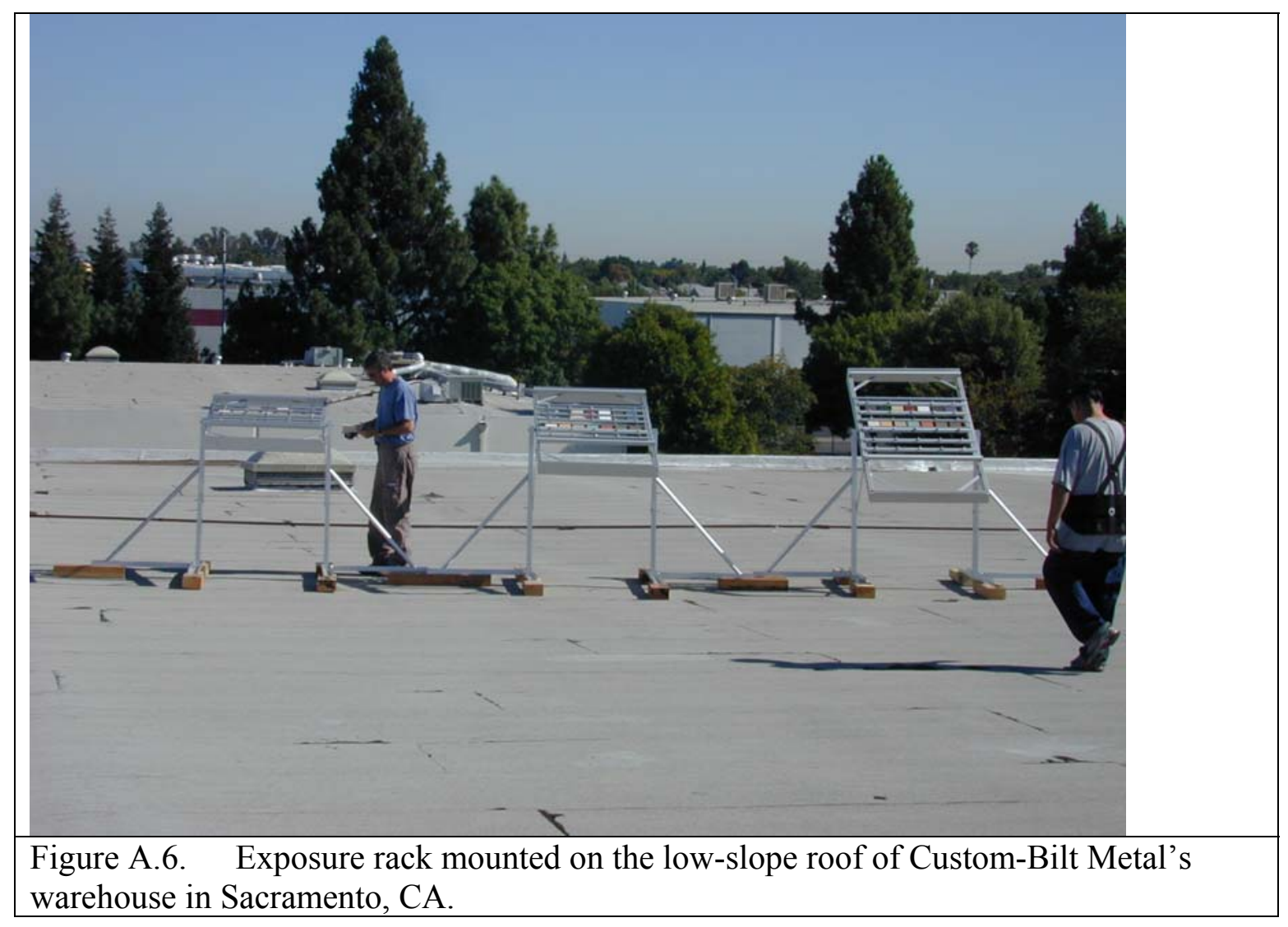


Sacramento, CA Solar Reflectance Field Data

Table A.6

\begin{tabular}{|c|c|c|c|c|c|c|c|c|c|c|}
\hline & & & & \multicolumn{7}{|c|}{ EXPOSURE TIME (YRS) } \\
\hline & Identifier & Code & Slope & 0.000 & 0.564 & 0.959 & 1.638 & 2.501 & 3.589 & 4.055 \\
\hline \multicolumn{11}{|c|}{ BASF PVDF Painted Metal } \\
\hline \multirow[t]{4}{*}{ Regal White } & $872 W 2$ & 300 & 1.359 in 12 & 0.743 & 0.699 & 0.646 & 0.689 & 0.685 & 0.642 & 0.591 \\
\hline & $872 W 2$ & 301 & 3.313 in 12 & 0.742 & 0.708 & 0.630 & 0.699 & 0.686 & 0.651 & 0.617 \\
\hline & $872 W 2$ & 302 & 7.122 in 12 & 0.744 & 0.706 & 0.659 & 0.698 & 0.688 & 0.674 & 0.625 \\
\hline & $815 W 98$ & 303 & 3.313 in 12 & 0.687 & 0.653 & 0.601 & 0.640 & 0.634 & 0.595 & 0.553 \\
\hline \multirow[t]{4}{*}{ Rawhide } & $872 T 6$ & 304 & 1.359 in 12 & 0.570 & 0.533 & 0.511 & 0.525 & 0.529 & 0.477 & 0.466 \\
\hline & $872 T 6$ & 305 & 3.313 in 12 & 0.568 & 0.533 & 0.510 & 0.529 & 0.528 & 0.525 & 0.509 \\
\hline & $872 T 6$ & 306 & 7.122 in 12 & 0.568 & 0.535 & 0.508 & 0.531 & 0.533 & 0.511 & 0.481 \\
\hline & 836T223 & 307 & 3.313 in 12 & 0.439 & 0.410 & 0.403 & 0.401 & 0.408 & 0.385 & 0.523 \\
\hline \multirow[t]{4}{*}{ Slate Blue } & $872 \mathrm{~B} 7$ & 308 & 1.359 in 12 & 0.281 & 0.263 & 0.282 & 0.257 & 0.267 & 0.247 & 0.266 \\
\hline & $872 \mathrm{~B} 7$ & 309 & 3.313 in 12 & 0.282 & 0.264 & 0.281 & 0.256 & 0.271 & 0.263 & 0.275 \\
\hline & $872 \mathrm{~B} 7$ & 310 & 7.122 in 12 & 0.282 & 0.264 & 0.281 & 0.259 & 0.270 & 0.263 & 0.273 \\
\hline & 815B49 & 311 & 3.313 in 12 & 0.172 & 0.162 & 0.194 & 0.161 & 0.176 & 0.170 & 0.198 \\
\hline \multirow[t]{4}{*}{ Brick Red } & 872R10 & 312 & 1.359 in 12 & 0.374 & 0.348 & 0.361 & 0.351 & 0.362 & 0.350 & 0.346 \\
\hline & $872 \mathrm{R} 10$ & 313 & 3.313 in 12 & 0.373 & 0.348 & 0.361 & 0.353 & 0.365 & 0.346 & 0.344 \\
\hline & 872R10 & 314 & 7.122 in 12 & 0.374 & 0.350 & 0.357 & 0.354 & 0.369 & 0.359 & 0.349 \\
\hline & $815 R 71$ & 315 & 3.313 in 12 & 0.195 & 0.182 & 0.214 & 0.183 & 0.196 & 0.191 & 0.214 \\
\hline \multirow[t]{4}{*}{ Charcoal Gray } & 872D6 & 316 & 1.359 in 12 & 0.309 & 0.286 & 0.308 & 0.293 & 0.307 & 0.285 & 0.274 \\
\hline & 872D6 & 317 & 3.313 in 12 & 0.308 & 0.288 & 0.310 & 0.296 & 0.311 & 0.304 & 0.269 \\
\hline & 872D6 & 318 & 7.122 in 12 & 0.308 & 0.289 & 0.308 & 0.297 & 0.311 & 0.306 & 0.304 \\
\hline & 815D119 & 319 & 3.313 in 12 & 0.123 & 0.113 & 0.154 & 0.116 & 0.128 & 0.126 & 0.130 \\
\hline \multirow[t]{4}{*}{ Hartford Green } & $872 \mathrm{G} 16$ & 320 & 1.359 in 12 & 0.272 & 0.253 & 0.279 & 0.257 & 0.270 & 0.256 & 0.267 \\
\hline & $872 G 16$ & 321 & 3.313 in 12 & 0.271 & 0.253 & 0.279 & 0.258 & 0.271 & 0.260 & 0.267 \\
\hline & $872 \mathrm{G} 16$ & 322 & 7.122 in 12 & 0.271 & 0.253 & 0.278 & 0.259 & 0.273 & 0.267 & 0.272 \\
\hline & $815 G 37$ & 323 & 3.313 in 12 & 0.088 & 0.084 & 0.126 & 0.085 & 0.097 & 0.095 & 0.130 \\
\hline \multirow[t]{4}{*}{ Slate Bronze } & $872 T 3$ & 324 & 1.359 in 12 & 0.262 & 0.244 & 0.272 & 0.251 & 0.261 & 0.253 & 0.265 \\
\hline & $872 T 3$ & 325 & 3.313 in 12 & 0.262 & 0.246 & 0.274 & 0.251 & 0.264 & 0.257 & 0.268 \\
\hline & $872 T 3$ & 326 & 7.122 in 12 & 0.262 & 0.247 & 0.271 & 0.251 & 0.264 & 0.261 & 0.278 \\
\hline & $815 T 119$ & 327 & 3.313 in 12 & 0.118 & 0.111 & 0.138 & 0.111 & 0.123 & 0.120 & 0.179 \\
\hline \multicolumn{3}{|l|}{ MCA Clay Tile } & & & & & & & & \\
\hline \multirow[t]{3}{*}{ White Buff } & $2 \mathrm{~F} 44$ & 328 & 1.359 in 12 & 0.644 & 0.597 & 0.572 & 0.568 & 0.583 & 0.505 & 0.464 \\
\hline & $2 \mathrm{~F} 44$ & 329 & 3.313 in 12 & 0.652 & 0.600 & 0.578 & 0.574 & 0.588 & 0.526 & 0.498 \\
\hline & $2 \mathrm{~F} 44$ & 330 & 7.122 in 12 & 0.630 & 0.596 & 0.584 & 0.585 & 0.580 & 0.515 & 0.492 \\
\hline \multirow[t]{3}{*}{ Apricot Buff } & CF50 & 331 & 1.359 in 12 & 0.600 & 0.535 & 0.529 & 0.520 & 0.509 & 0.442 & 0.418 \\
\hline & CF50 & 332 & 3.313 in 12 & 0.611 & 0.557 & 0.539 & 0.536 & 0.534 & 0.480 & 0.454 \\
\hline & CF50 & 333 & 7.122 in 12 & 0.606 & 0.554 & 0.545 & 0.539 & 0.537 & 0.482 & 0.457 \\
\hline \multirow[t]{3}{*}{ Adobe Gray } & $2 \mathrm{~F} 71$ & 334 & 1.359 in 12 & 0.423 & 0.397 & 0.404 & 0.390 & 0.401 & 0.363 & 0.352 \\
\hline & $2 \mathrm{~F} 71$ & 335 & 3.313 in 12 & 0.418 & 0.421 & 0.425 & 0.415 & 0.434 & 0.392 & 0.377 \\
\hline & $2 \mathrm{~F} 71$ & 336 & 7.122 in 12 & 0.423 & 0.412 & 0.419 & 0.409 & 0.419 & 0.383 & 0.368 \\
\hline \multirow[t]{3}{*}{ Regency Blue } & $2 \mathrm{~F} 52$ & 337 & 1.359 in 12 & 0.416 & 0.394 & 0.408 & 0.384 & 0.392 & 0.349 & 0.343 \\
\hline & $2 \mathrm{~F} 52$ & 338 & 3.313 in 12 & 0.428 & 0.388 & 0.398 & 0.375 & 0.384 & 0.341 & 0.377 \\
\hline & $2 \mathrm{~F} 52$ & 339 & 7.122 in 12 & 0.413 & 0.397 & 0.408 & 0.387 & 0.398 & 0.365 & 0.365 \\
\hline
\end{tabular}


Sacramento, CA Solar Reflectance Field Data

Table A.6

\begin{tabular}{|c|c|c|c|c|c|c|c|c|c|c|}
\hline & & & & \multicolumn{7}{|c|}{ EXPOSURE TIME (YRS) } \\
\hline & Identifier & Code & Slope & 0.000 & 0.748 & 0.959 & 1.638 & 2.501 & 3.589 & 4.055 \\
\hline \multirow[t]{3}{*}{ Natural Red } & $\mathrm{F} 40$ & 440 & 2 in 12 & 0.459 & 0.408 & 0.408 & 0.411 & 0.418 & 0.403 & 0.386 \\
\hline & $\mathrm{F} 40$ & 441 & 4 in 12 & 0.458 & 0.419 & 0.419 & 0.427 & 0.433 & 0.417 & 0.420 \\
\hline & $\mathrm{F} 40$ & 442 & 8 in 12 & 0.461 & 0.428 & 0.428 & 0.428 & 0.434 & 0.418 & 0.403 \\
\hline \multirow[t]{3}{*}{$\begin{array}{r}\text { Weathered } \\
\text { Green } \\
\end{array}$} & B305 & 443 & 2 in 12 & 0.420 & 0.362 & 0.362 & 0.373 & 0.373 & 0.359 & 0.340 \\
\hline & B305 & 444 & 4 in 12 & 0.411 & 0.385 & 0.385 & 0.387 & 0.396 & 0.378 & 0.368 \\
\hline & B305 & 445 & 8 in 12 & 0.413 & 0.362 & 0.362 & 0.374 & 0.382 & 0.370 & 0.355 \\
\hline \multirow[t]{3}{*}{ Ironwood } & $2 \mathrm{~F} 19$ & 446 & 2 in 12 & 0.269 & 0.258 & 0.258 & 0.245 & 0.259 & 0.248 & 0.248 \\
\hline & $2 \mathrm{~F} 19$ & 447 & 4 in 12 & 0.272 & 0.259 & 0.259 & 0.247 & 0.263 & 0.255 & 0.260 \\
\hline & $2 \mathrm{~F} 19$ & 448 & 8 in 12 & 0.268 & NA & NA & 0.249 & 0.265 & 0.258 & 0.253 \\
\hline \multicolumn{3}{|l|}{ US Clay Tile } & & & & & & & & \\
\hline Buff Blend & & 479 & 2 in 12 & & 0.585 & 0.585 & 0.552 & 0.577 & 0.532 & 0.546 \\
\hline Bermuda Blend & & 480 & 2 in 12 & & 0.489 & 0.489 & 0.457 & 0.467 & 0.438 & 0.441 \\
\hline \multicolumn{3}{|c|}{ Monierlife Concrete Tile } & & & & & & & & \\
\hline \multirow[t]{3}{*}{ Terra Cotta Red } & 6978 & 449 & 2 in 12 & & 0.196 & 0.196 & 0.177 & 0.207 & 0.225 & 0.234 \\
\hline & 6978 & 450 & 4 in 12 & & 0.180 & 0.180 & 0.176 & 0.210 & 0.215 & 0.200 \\
\hline & 6978 & 451 & 8 in 12 & & 0.194 & 0.194 & 0.184 & 0.219 & 0.234 & 0.200 \\
\hline \multirow[t]{3}{*}{ Hearthside } & 3083 & 452 & 2 in 12 & & 0.125 & 0.125 & 0.154 & 0.159 & 0.165 & 0.163 \\
\hline & 3083 & 453 & 4 in 12 & & 0.134 & 0.134 & 0.142 & 0.160 & 0.162 & 0.167 \\
\hline & 3083 & 454 & 8 in 12 & & 0.125 & 0.125 & 0.137 & 0.155 & 0.157 & 0.166 \\
\hline \multirow[t]{3}{*}{ Riversidepebble } & 3080 & 455 & 2 in 12 & & 0.154 & 0.154 & 0.175 & 0.189 & 0.170 & 0.201 \\
\hline & 3080 & 456 & 4 in 12 & & 0.139 & 0.139 & 0.161 & 0.171 & 0.168 & 0.171 \\
\hline & 3080 & 457 & 8 in 12 & & 0.143 & 0.143 & 0.171 & 0.166 & 0.172 & 0.180 \\
\hline \multirow[t]{3}{*}{ Ebony } & 5047 & 458 & 2 in 12 & & 0.146 & 0.146 & 0.123 & 0.144 & & 0.168 \\
\hline & 5047 & 459 & 4 in 12 & & 0.145 & 0.145 & 0.130 & 0.151 & 0.153 & 0.158 \\
\hline & 5047 & 460 & 8 in 12 & & 0.141 & 0.141 & 0.128 & 0.148 & 0.148 & 0.160 \\
\hline \multirow[t]{3}{*}{ Lincoln Green } & 4087 & 461 & 2 in 12 & & 0.157 & 0.157 & 0.165 & 0.193 & 0.198 & 0.190 \\
\hline & 4087 & 462 & 4 in 12 & & 0.171 & 0.171 & 0.174 & 0.206 & 0.209 & 0.217 \\
\hline & 4087 & 463 & 8 in 12 & & 0.161 & 0.161 & 0.163 & 0.192 & 0.202 & 0.207 \\
\hline \multicolumn{3}{|c|}{ Shepherd Artic Match } & & & & & & & & \\
\hline \multirow[t]{3}{*}{ Blue Artic } & & 464 & 2 in 12 & & 0.230 & 0.230 & 0.214 & 0.223 & 0.224 & 0.225 \\
\hline & & 465 & 4 in 12 & & 0.234 & 0.234 & 0.215 & 0.237 & 0.235 & 0.250 \\
\hline & & 466 & 8 in 12 & & 0.241 & 0.241 & 0.219 & 0.229 & 0.233 & 0.236 \\
\hline \multirow[t]{3}{*}{ Red Artic } & & 467 & 2 in 12 & & 0.284 & 0.284 & 0.266 & 0.266 & 0.257 & 0.267 \\
\hline & & 468 & 4 in 12 & & 0.277 & 0.277 & 0.264 & 0.261 & 0.250 & 0.263 \\
\hline & & 469 & 8 in 12 & & 0.270 & 0.270 & 0.258 & 0.260 & 0.249 & 0.255 \\
\hline \multirow[t]{3}{*}{ Brown Artic } & & 470 & 2 in 12 & & 0.262 & 0.262 & 0.252 & 0.258 & & 0.253 \\
\hline & & 471 & 4 in 12 & & 0.249 & 0.249 & 0.246 & 0.251 & 0.245 & 0.231 \\
\hline & & 472 & 8 in 12 & & 0.247 & 0.247 & 0.253 & 0.251 & 0.249 & 0.247 \\
\hline
\end{tabular}




\section{Appendix A}

\section{McArthur Exposure Site (RS07)}

Painted metal, clay and concrete tile roof products with and without cool color pigments were placed at ground level in a fenced pasture at McArthur Farms, McArthur, CA. Coupons of the roof products were installed in exposure rack assemblies, which are 5.5-ft high by 9 -ft long, and divided into three sub-frames having respective slopes of 2-, 4- and 8-in of rise for 12-in of run (i.e., slopes of $9.5^{\circ}, 18.4^{\circ}$ and $33.7^{\circ}$ ). Each sub-frame can hold two "Sure-Grip" sub-assemblies, which are designed to have 6 rows of samples with 34-in of usable space in each row. Sample size is 3.5-in by 3.5-in. Orientation of the racks was set at $0^{\circ} \mathrm{CCW}$ and faced directly east into the rising sun for representing exposure seen on an east facing residential roof.

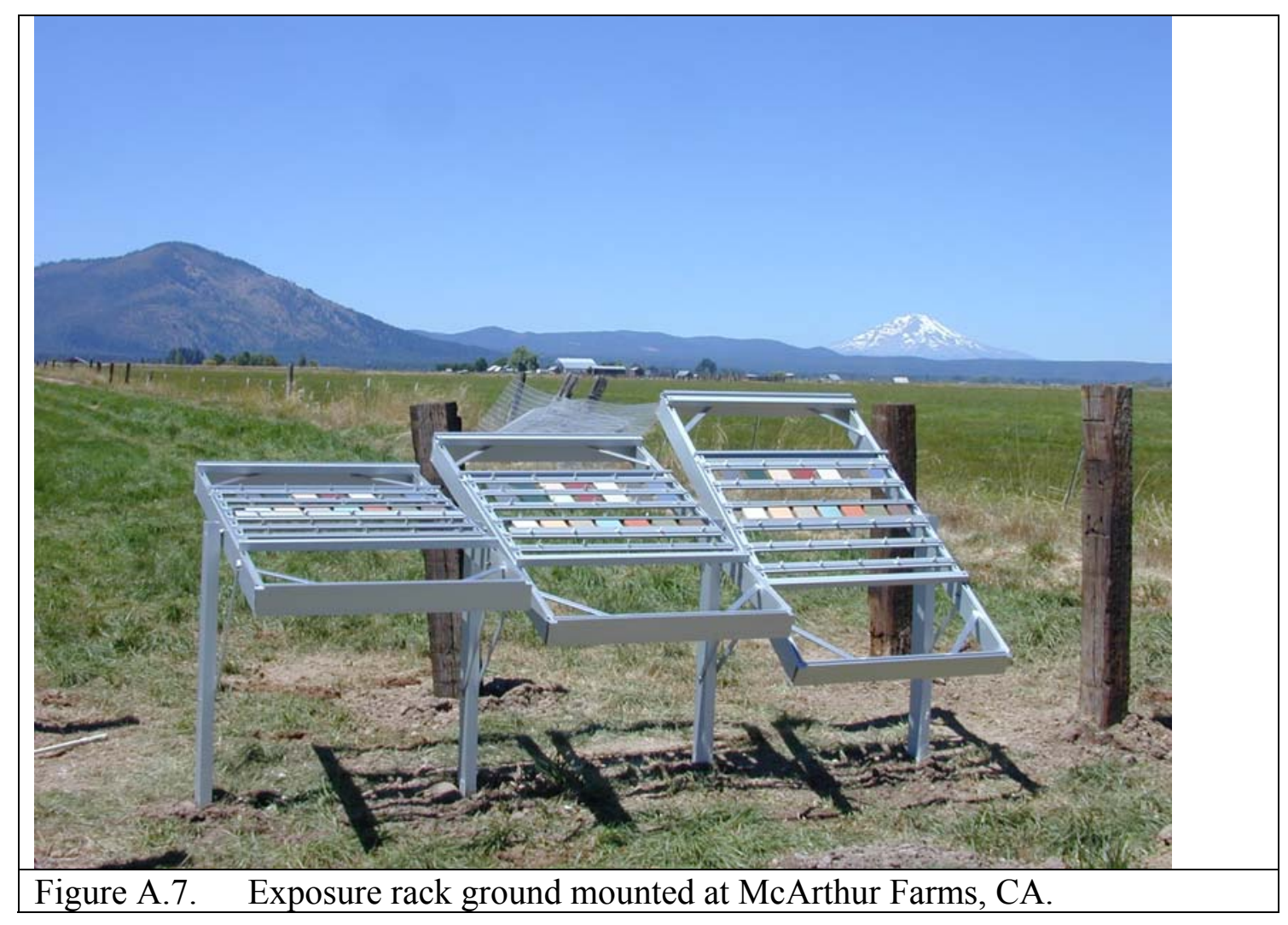


McArthur, CA Solar Reflectance Field Data

Table A.7

\begin{tabular}{|c|c|c|c|c|c|c|c|c|c|c|}
\hline & & & & \multicolumn{7}{|c|}{ EXPOSURE TIME (YRS) } \\
\hline & Identifier & Code & Slope & 0.000 & 0.764 & 0.959 & 1.644 & 2.507 & 3.589 & 4.060 \\
\hline \multicolumn{11}{|c|}{ BASF PVDF Painted Metal } \\
\hline \multirow[t]{4}{*}{ Regal White } & $872 W 2$ & 800 & 2 in 12 & 0.742 & 0.72 & 0.697 & 0.719 & 0.725 & 0.721 & 0.692 \\
\hline & $872 W 2$ & 801 & 4 in 12 & 0.741 & 0.723 & 0.704 & 0.725 & 0.729 & 0.731 & 0.714 \\
\hline & $872 W 2$ & 802 & 8 in 12 & 0.741 & 0.725 & 0.701 & 0.722 & 0.726 & 0.731 & 0.716 \\
\hline & $815 W 98$ & 803 & 4 in 12 & 0.69 & 0.665 & 0.658 & 0.667 & 0.667 & 0.676 & 0.655 \\
\hline \multirow[t]{4}{*}{ Rawhide } & $872 T 6$ & 804 & 2 in 12 & 0.571 & 0.548 & 0.543 & 0.551 & Pulled & & \\
\hline & $872 T 6$ & 805 & 4 in 12 & 0.57 & 0.546 & 0.544 & 0.547 & Pulled & & \\
\hline & $872 T 6$ & 806 & 8 in 12 & 0.571 & 0.545 & 0.545 & 0.547 & Pulled & & \\
\hline & $836 \mathrm{~T} 223$ & 807 & 4 in 12 & 0.44 & 0.42 & 0.426 & 0.416 & Pulled & & \\
\hline \multirow[t]{4}{*}{ Slate Blue } & $872 \mathrm{~B} 7$ & 808 & 2 in 12 & 0.282 & 0.271 & 0.277 & 0.265 & 0.280 & 0.277 & 0.182 \\
\hline & $872 \mathrm{~B} 7$ & 809 & 4 in 12 & 0.283 & 0.27 & 0.277 & 0.263 & 0.281 & 0.276 & 0.255 \\
\hline & $872 \mathrm{~B} 7$ & 810 & 8 in 12 & 0.282 & 0.271 & 0.227 & 0.265 & 0.279 & 0.276 & 0.285 \\
\hline & 815B49 & 811 & 4 in 12 & 0.171 & 0.164 & 0.176 & 0.161 & 0.175 & 0.172 & 0.260 \\
\hline \multirow[t]{4}{*}{ Brick Red } & $872 \mathrm{R} 10$ & 812 & 2 in 12 & 0.375 & 0.357 & 0.376 & 0.366 & 0.383 & 0.378 & 0.371 \\
\hline & $872 \mathrm{R} 10$ & 813 & 4 in 12 & 0.375 & 0.357 & 0.375 & 0.364 & 0.383 & 0.377 & 0.370 \\
\hline & $872 \mathrm{R} 10$ & 814 & 8 in 12 & 0.376 & 0.359 & 0.376 & 0.366 & 0.383 & 0.379 & 0.377 \\
\hline & $815 R 71$ & 815 & 4 in 12 & 0.195 & 0.186 & 0.201 & 0.184 & 0.277 & 0.197 & 0.206 \\
\hline \multirow[t]{4}{*}{ Charcoal Gray } & 872D6 & 816 & 2 in 12 & 0.308 & 0.294 & 0.316 & 0.304 & 0.317 & 0.315 & 0.300 \\
\hline & 872D6 & 817 & 4 in 12 & 0.308 & 0.294 & 0.317 & 0.302 & 0.320 & 0.315 & 0.308 \\
\hline & 872D6 & 818 & 8 in 12 & 0.307 & 0.294 & 0.316 & 0.304 & 0.320 & 0.316 & 0.310 \\
\hline & 815D119 & 819 & 4 in 12 & 0.122 & 0.119 & 0.133 & 0.116 & 0.128 & 0.124 & 0.146 \\
\hline \multirow[t]{4}{*}{ Hartford Green } & $872 \mathrm{G} 16$ & 820 & 2 in 12 & 0.272 & 0.258 & 0.281 & 0.264 & 0.280 & 0.270 & 0.271 \\
\hline & 872 G16 & 821 & 4 in 12 & 0.272 & 0.256 & 0.279 & 0.261 & 0.278 & 0.271 & 0.277 \\
\hline & 872 G16 & 822 & 8 in 12 & 0.27 & 0.259 & 0.279 & 0.266 & 0.280 & 0.274 & 0.269 \\
\hline & $815 G 37$ & 823 & 4 in 12 & 0.088 & 0.087 & 0.099 & 0.084 & 0.096 & 0.093 & 0.107 \\
\hline \multirow[t]{4}{*}{ Slate Bronze } & $872 T 3$ & 824 & 2 in 12 & 0.262 & 0.251 & 0.268 & 0.256 & 0.270 & 0.266 & 0.269 \\
\hline & $872 T 3$ & 825 & 4 in 12 & 0.263 & 0.251 & 0.27 & 0.255 & 0.272 & 0.269 & 0.269 \\
\hline & $872 T 3$ & 826 & 8 in 12 & 0.262 & 0.251 & 0.269 & 0.255 & 0.270 & 0.269 & 0.268 \\
\hline & $815 T 119$ & 827 & 4 in 12 & 0.117 & 0.115 & 0.128 & 0.112 & 0.125 & 0.122 & 0.153 \\
\hline \multicolumn{11}{|l|}{ MCA Clay Tile } \\
\hline \multirow[t]{3}{*}{ White Buff } & $2 \mathrm{~F} 44$ & 828 & 2 in 12 & 0.63 & 0.612 & 0.597 & 0.606 & 0.608 & 0.614 & 0.610 \\
\hline & $2 \mathrm{~F} 44$ & 829 & 4 in 12 & 0.632 & 0.612 & 0.614 & 0.611 & 0.617 & 0.616 & 0.621 \\
\hline & $2 \mathrm{~F} 44$ & 830 & 8 in 12 & 0.643 & 0.619 & 0.614 & 0.619 & 0.626 & 0.621 & 0.632 \\
\hline \multirow[t]{3}{*}{ Apricot Buff } & CF50 & 831 & 2 in 12 & 0.617 & 0.621 & 0.612 & 0.615 & 0.618 & 0.613 & 0.617 \\
\hline & CF50 & 832 & 4 in 12 & 0.597 & 0.567 & 0.568 & 0.567 & 0.577 & 0.563 & 0.573 \\
\hline & CF50 & 833 & 8 in 12 & 0.607 & 0.58 & 0.582 & 0.582 & 0.590 & 0.586 & 0.592 \\
\hline \multirow[t]{3}{*}{ Adobe Gray } & $2 \mathrm{~F} 71$ & 834 & 2 in 12 & 0.446 & 0.417 & 0.43 & 0.424 & 0.433 & 0.433 & 0.427 \\
\hline & $2 \mathrm{~F} 71$ & 835 & 4 in 12 & 0.448 & 0.403 & 0.419 & 0.407 & 0.423 & 0.417 & 0.413 \\
\hline & $2 \mathrm{~F} 71$ & 836 & 8 in 12 & 0.436 & 0.425 & 0.441 & 0.43 & 0.449 & 0.444 & 0.450 \\
\hline \multirow[t]{3}{*}{ Regency Blue } & $2 \mathrm{~F} 52$ & 837 & 2 in 12 & 0.424 & 0.413 & 0.418 & 0.41 & 0.418 & 0.418 & 0.421 \\
\hline & $2 \mathrm{~F} 52$ & 838 & 4 in 12 & 0.417 & 0.415 & 0.418 & 0.414 & 0.425 & 0.416 & 0.427 \\
\hline & $2 \mathrm{~F} 52$ & 839 & 8 in 12 & 0.42 & 0.4 & 0.406 & 0.4 & 0.405 & 0.401 & 0.406 \\
\hline
\end{tabular}




\section{McArthur, CA Solar Reflectance Field Data}

Table A.7

\begin{tabular}{|c|c|c|c|c|c|c|c|c|c|c|}
\hline & & & & \multicolumn{7}{|c|}{ EXPOSURE TIME (YRS) } \\
\hline & Identifier & Code & Slope & 0.000 & 0.764 & 0.959 & 1.644 & 2.507 & 3.589 & 4.060 \\
\hline \multirow[t]{3}{*}{ Natural Red } & $\mathrm{F} 40$ & 840 & 2 in 12 & 0.457 & 0.43 & 0.435 & 0.427 & 0.445 & 0.441 & 0.452 \\
\hline & $\mathrm{F} 40$ & 841 & 4 in 12 & 0.467 & 0.42 & 0.429 & 0.421 & 0.441 & 0.426 & 0.426 \\
\hline & $\mathrm{F} 40$ & 842 & 8 in 12 & 0.459 & 0.442 & 0.451 & 0.442 & 0.460 & 0.451 & 0.457 \\
\hline \multirow[t]{3}{*}{$\begin{array}{r}\text { Weathered } \\
\text { Green } \\
\end{array}$} & B305 & 843 & 2 in 12 & 0.405 & 0.378 & 0.387 & 0.376 & 0.398 & 0.382 & 0.389 \\
\hline & B305 & 844 & 4 in 12 & 0.402 & 0.396 & 0.418 & 0.397 & 0.413 & 0.404 & 0.416 \\
\hline & B305 & 845 & 8 in 12 & 0.408 & 0.387 & 0.399 & 0.391 & 0.408 & 0.390 & 0.401 \\
\hline \multirow[t]{3}{*}{ Ironwood } & $2 \mathrm{~F} 19$ & 846 & 2 in 12 & 0.261 & 0.25 & 0.269 & 0.253 & 0.265 & 0.263 & 0.267 \\
\hline & $2 \mathrm{~F} 19$ & 847 & 4 in 12 & 0.263 & 0.247 & 0.265 & 0.251 & 0.274 & 0.260 & 0.260 \\
\hline & $2 \mathrm{~F} 19$ & 848 & 8 in 12 & 0.263 & 0.249 & 0.265 & 0.25 & 0.268 & 0.264 & 0.264 \\
\hline \multicolumn{3}{|l|}{ US Clay Tile } & & & & & & & & \\
\hline Buff Blend & & 879 & 2 in 12 & & 0.578 & 0.576 & 0.577 & 0.563 & 0.559 & 0.562 \\
\hline Bermuda Blend & & 880 & 2 in 12 & & 0.493 & 0.486 & 0.49 & 0.496 & 0.471 & 0.460 \\
\hline \multicolumn{3}{|c|}{ Monierlife Concrete Tile } & & & & & & & & \\
\hline \multirow[t]{3}{*}{ Terra Cotta Red } & 6978 & 849 & 2 in 12 & & 0.186 & 0.192 & 0.176 & 0.204 & 0.209 & 0.210 \\
\hline & 6978 & 850 & 4 in 12 & & 0.196 & 0.2 & 0.2 & 0.204 & 0.220 & 0.231 \\
\hline & 6978 & 851 & 8 in 12 & & 0.186 & 0.194 & 0.182 & 0.213 & 0.216 & 0.222 \\
\hline \multirow[t]{3}{*}{ Hearthside } & 3083 & 852 & 2 in 12 & & 0.14 & 0.153 & 0.157 & 0.175 & 0.161 & 0.172 \\
\hline & 3083 & 853 & 4 in 12 & & 0.131 & 0.164 & 0.146 & 0.179 & 0.182 & 0.190 \\
\hline & 3083 & 854 & 8 in 12 & & 0.136 & 0.15 & 0.16 & 0.168 & 0.168 & 0.171 \\
\hline \multirow[t]{3}{*}{ Riversidepebble } & 3080 & 855 & 2 in 12 & & 0.136 & 0.149 & 0.148 & 0.138 & 0.150 & 0.147 \\
\hline & 3080 & 856 & 4 in 12 & & 0.135 & 0.139 & 0.146 & 0.160 & 0.159 & 0.164 \\
\hline & 3080 & 857 & 8 in 12 & & 0.143 & 0.152 & 0.145 & 0.155 & 0.156 & 0.152 \\
\hline \multirow[t]{3}{*}{ Ebony } & 5047 & 858 & 2 in 12 & & 0.137 & 0.145 & 0.125 & 0.157 & 0.151 & 0.147 \\
\hline & 5047 & 859 & 4 in 12 & & 0.14 & 0.135 & 0.115 & 0.133 & 0.145 & 0.152 \\
\hline & 5047 & 860 & 8 in 12 & & 0.137 & 0.134 & 0.117 & 0.148 & 0.147 & 0.150 \\
\hline \multirow[t]{3}{*}{ Lincoln Green } & 4087 & 861 & 2 in 12 & & 0.171 & 0.181 & 0.165 & 0.193 & 0.193 & 0.201 \\
\hline & 4087 & 862 & 4 in 12 & & 0.156 & 0.155 & 0.155 & 0.165 & 0.171 & 0.217 \\
\hline & 4087 & 863 & 8 in 12 & & 0.162 & 0.161 & 0.16 & 0.185 & 0.189 & 0.192 \\
\hline \multicolumn{3}{|c|}{ Shepherd Artic Match } & & & & & & & & \\
\hline \multirow[t]{3}{*}{ Blue Artic } & & 864 & 2 in 12 & & 0.24 & 0.258 & 0.229 & 0.245 & 0.206 & 0.237 \\
\hline & & 865 & 4 in 12 & & 0.236 & 0.249 & 0.227 & 0.239 & 0.240 & 0.252 \\
\hline & & 866 & 8 in 12 & & 0.24 & 0.243 & 0.227 & 0.228 & 0.209 & 0.210 \\
\hline \multirow[t]{3}{*}{ Red Artic } & & 867 & 2 in 12 & & 0.259 & 0.274 & 0.247 & 0.254 & 0.228 & 0.231 \\
\hline & & 868 & 4 in 12 & & 0.332 & 0.32 & 0.295 & 0.300 & 0.285 & 0.303 \\
\hline & & 869 & 8 in 12 & & 0.267 & 0.28 & 0.263 & 0.266 & 0.251 & 0.265 \\
\hline \multirow[t]{4}{*}{ Brown Artic } & & 870 & 2 in 12 & & 0.26 & 0.273 & 0.254 & 0.259 & 0.245 & 0.232 \\
\hline & & 871 & 4 in 12 & & 0.25 & 0.273 & 0.249 & 0.260 & 0.235 & 0.263 \\
\hline & & 872 & 8 in 12 & & 0.256 & 0.277 & 0.258 & 0.265 & 0.249 & 0.231 \\
\hline & & & & & & & & & & \\
\hline
\end{tabular}




\section{Appendix B \\ Additional notes on soil optical properties}

The soil parameters $a$ and $r$ can be determined by fitting if reflectance change measurements are available for two or more substrates with different Ro, using Eq.(2) in the main text. We plot the absolute change in reflectance versus the initial reflectance and show optimal values for soil absorption and reflectance using least squares fitting and Matlab's backslash operator. We also verified this automated approach through fitting by hand to detect confounding data patterns.

Figure B1 shows an example of the fitting procedure, for Shafter at 1 year. The data are taken from Appendix A using the PVDF samples. The slope chosen is that for which there are both cool and standard samples. The open squares are the fitted curve. A color photograph of a Shafter sample at 1 year is shown in Figure 3 of the main text. Figure B2 shows similar fits for the other 6 sites at 1 year. Figure B3 shows data for Shafter after 1.6 years. At this point it was spring in California and much of the soil deposits have been removed by rain. Some of the scatter in the data points is due to other factors such as spectrally selective interaction between the various substrates and the spectral properties of the soil. In the presence of data scatter, it is desirable to use substrates with widely different $R o$.

Figure B4 shows similar plots for the other 6 sites. Despite the scatter, in all cases we obtain a non-zero value for $a$. In most cases we obtain a value for $r$, but it is sometimes not distinguishable from zero.

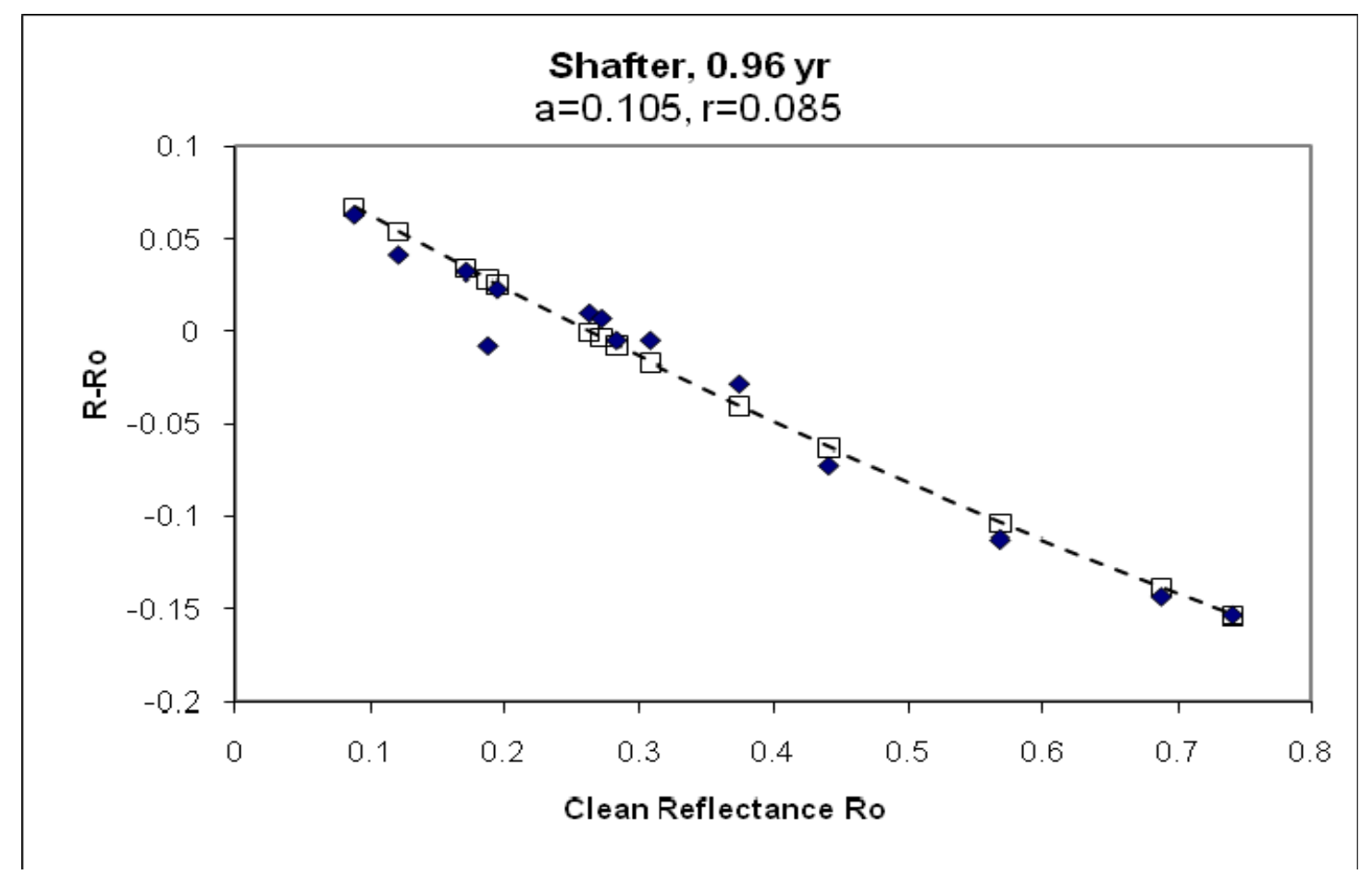

Fig. B1. Measured (filled diamonds) and fitted (open squares) absolute changes in reflectance due to sample soiling. High reflectance samples lose reflectance when soiled and low-reflectance samples gain reflectance. 


\section{Appendix B \\ Additional notes on soil optical properties}

The results of the curve fitting exercise are collected in Table B1. Judging by the absorptances, the amount of material remaining at 1.6 years is only $1 / 2$ to $1 / 8$ of that present at 1 year. Thus the weathering, presumably due to dew and rain transport, significantly cleaned the substrates. Note that already even at 1 year, the photograph of the Shafter sample in Fig. 3 of the main text shows transport of soil along the surface of the sample to the lower edge. Thus the weathering process significantly alters the original dry atmospheric deposition. Note that the $r$ values were reduced even more than $a$-values at 1.6 years, compared to 1 year. This means that the weathering process not only reduced the quantity of soil originally deposited, but that it altered the composition as well. Of course water-soluble components are expected to be transported by rain, but small and low-density particles are likely to be transported as well. Remaining particles are likely to be larger in size, higher in density, and/or able to adhere to the substrate.

Table B1. Soil absorptance and reflectance at 1 year, and at 1.6 years. The 1 year data were at the end of the dry summer period, while the 1.6 year data were obtained in the spring, after winter rainfall.

\begin{tabular}{|ccccccc|}
\hline Site & 1 year & $\mathbf{1}$ year & $\mathbf{1 ~ y r}$ & $\mathbf{1 . 6}$ years & $\mathbf{1 . 6}$ years & $\mathbf{1 . 6} \mathbf{~ y r}$ \\
\hline \hline & absorptance & reflectance & & absorptance & reflectance & \\
& $\boldsymbol{a}$ & $\boldsymbol{r}$ & $\boldsymbol{r} / \boldsymbol{a}$ & $\boldsymbol{a}$ & $\boldsymbol{r}$ & $\boldsymbol{r} / \boldsymbol{a}$ \\
El Centro & 0.10 & 0.13 & 1.3 & 0.012 & 0.009 & 0.8 \\
Corona & 0.090 & 0.085 & 0.9 & 0.048 & 0.013 & 0.3 \\
Colton & 0.14 & 0.15 & 1.1 & 0.045 & 0.008 & 0.2 \\
Shafter & 0.105 & 0.085 & 0.8 & 0.04 & 0.005 & 0.1 \\
Richmond & 0.075 & 0.036 & 0.5 & 0.025 & $<0.003$ & $<0.1$ \\
Sacramento & 0.060 & 0.058 & 1.0 & 0.03 & $<0.003$ & $<0.1$ \\
McArthur & 0.025 & 0.021 & 0.8 & 0.022 & $<0.003$ & $<0.2$ \\
\hline
\end{tabular}

Finally, Table B2 shows the measured concentrations of iron, organic carbon, and elemental carbon at 1.6 years. Plotting $a$ - and $r$-values against iron concentration in Fig. B5, we find that higher values of these parameters are associated with higher iron concentrations. The statistical $\mathrm{R}^{2}$ values are 0.48 for $a$ and 0.38 for $r$. Corresponding values for organic carbon $(0.03$ for $a$ ) and elemental carbon ( 0.01 for $a$ ) were quite low.

The tentative picture that emerges is that iron-containing mineral dust tends to remain on the Teflon-like PVDF surfaces washed by rain. Concentrations of iron were as large as about 70 $\mathrm{mg} / \mathrm{m}^{2}$. Iron in the ferric $3+$ valence state is associated with strong absorption in the short wavelength portion of the solar spectrum (wavelength $<550 \mathrm{~nm}$ ), as in the case of small hematite particles where the absorption strength is $4 \mathrm{~m}^{2} / \mathrm{g}$. Multiplying these two figures we obtain a crude estimate of 0.28 for short wavelength absorptance. The short wavelength part of 


\section{Appendix B \\ Additional notes on soil optical properties}

Table B2. Concentrations of three substances that could be associated with soil absorptance and reflectance. Iron has a significant correlation (see Fig. B5).

\begin{tabular}{|c|c|c|c|}
\hline \multirow[t]{2}{*}{ Site } & \multicolumn{3}{|c|}{ Exposure Time (1.6 years) } \\
\hline & $\begin{array}{c}\text { Iron } \\
\left(\mathrm{mg} / \mathrm{m}^{2}\right)\end{array}$ & $\begin{array}{c}\text { Organic C } \\
\left(\mathbf{m g} / \mathbf{m}^{2}\right)\end{array}$ & $\begin{array}{c}\text { Elemental C } \\
\left(\mathbf{m g} / \mathbf{m}^{\mathbf{2}}\right)\end{array}$ \\
\hline El Centro & 33 & 8.3 & 0.2 \\
\hline Corona & 68 & 5.5 & 0.2 \\
\hline Colton & 67 & 6.1 & 0.2 \\
\hline Shafter & 32 & 5.6 & 0.4 \\
\hline Richmond & 44 & 11 & 1.3 \\
\hline Sacramento & 42 & 4.5 & 0.2 \\
\hline McArthur & 5 & 1.3 & $\sim 0.02$ \\
\hline
\end{tabular}

the solar spectrum of interest here contains about $1 / 4$ of the total solar flux. Thus we estimate that the solar average absorptance due to $70 \mathrm{mg} / \mathrm{m}^{2}$ of iron could be about 0.07 . This number compares well with the $\sim 0.05$ absorptance at the sites with the highest iron concentration. This rough agreement could be an accident, but at least our picture is consistent.

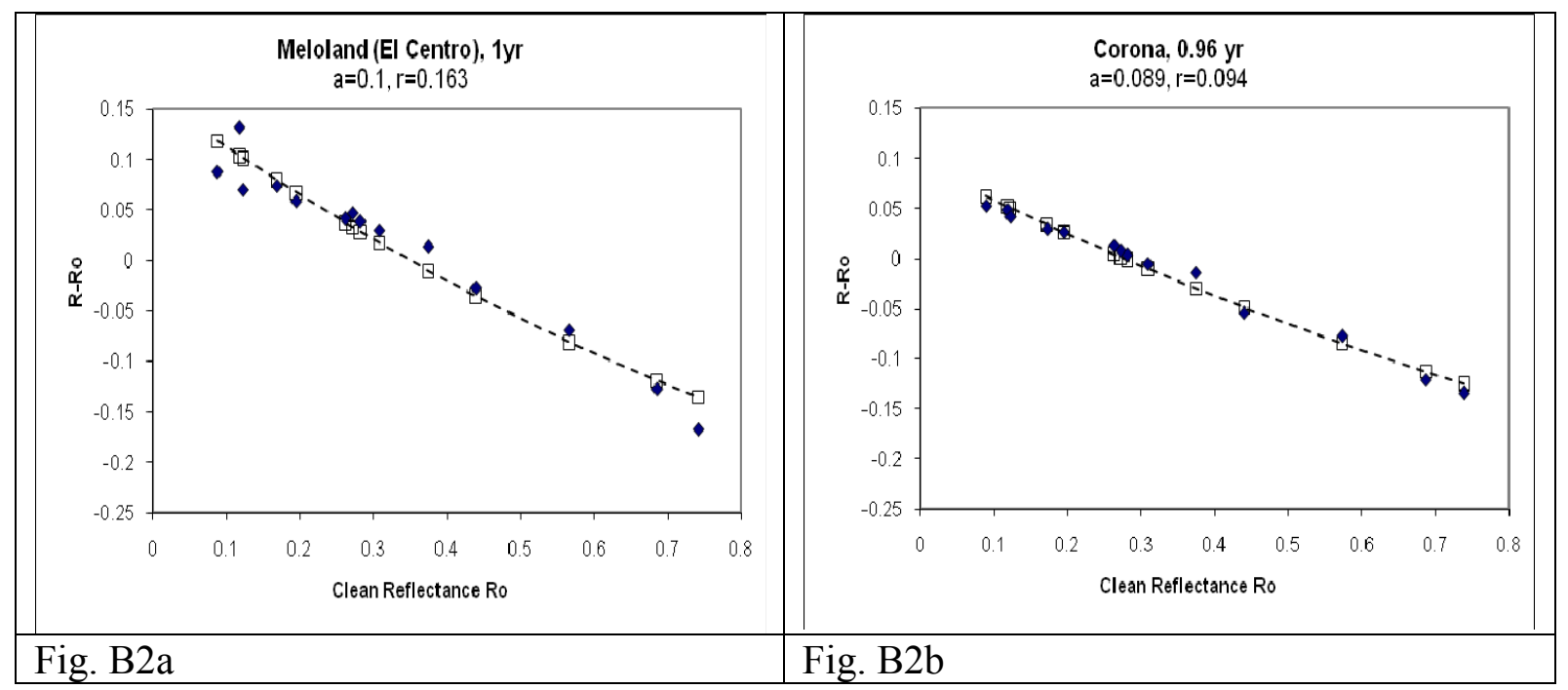




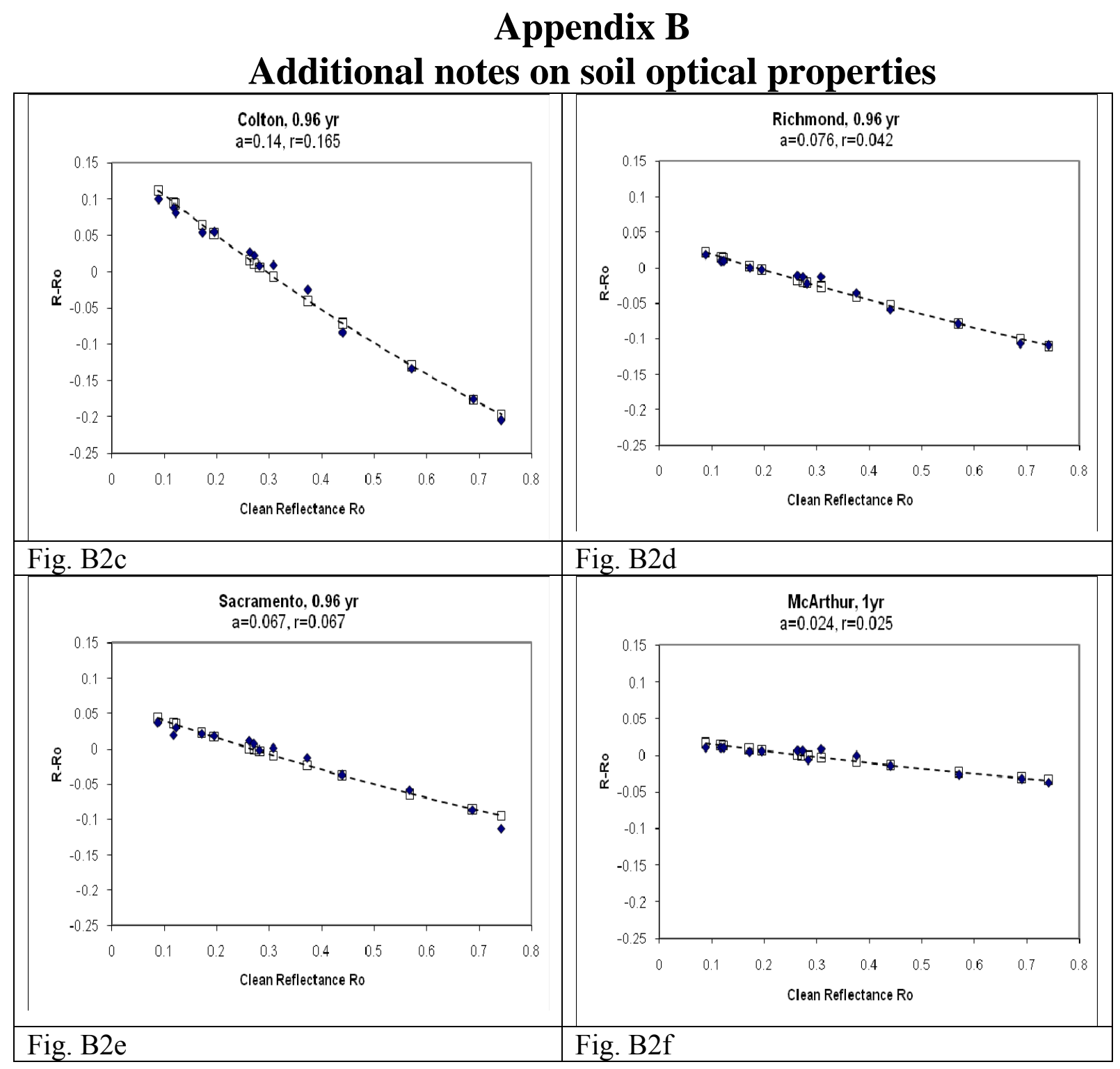




\section{Appendix B \\ Additional notes on soil optical properties}
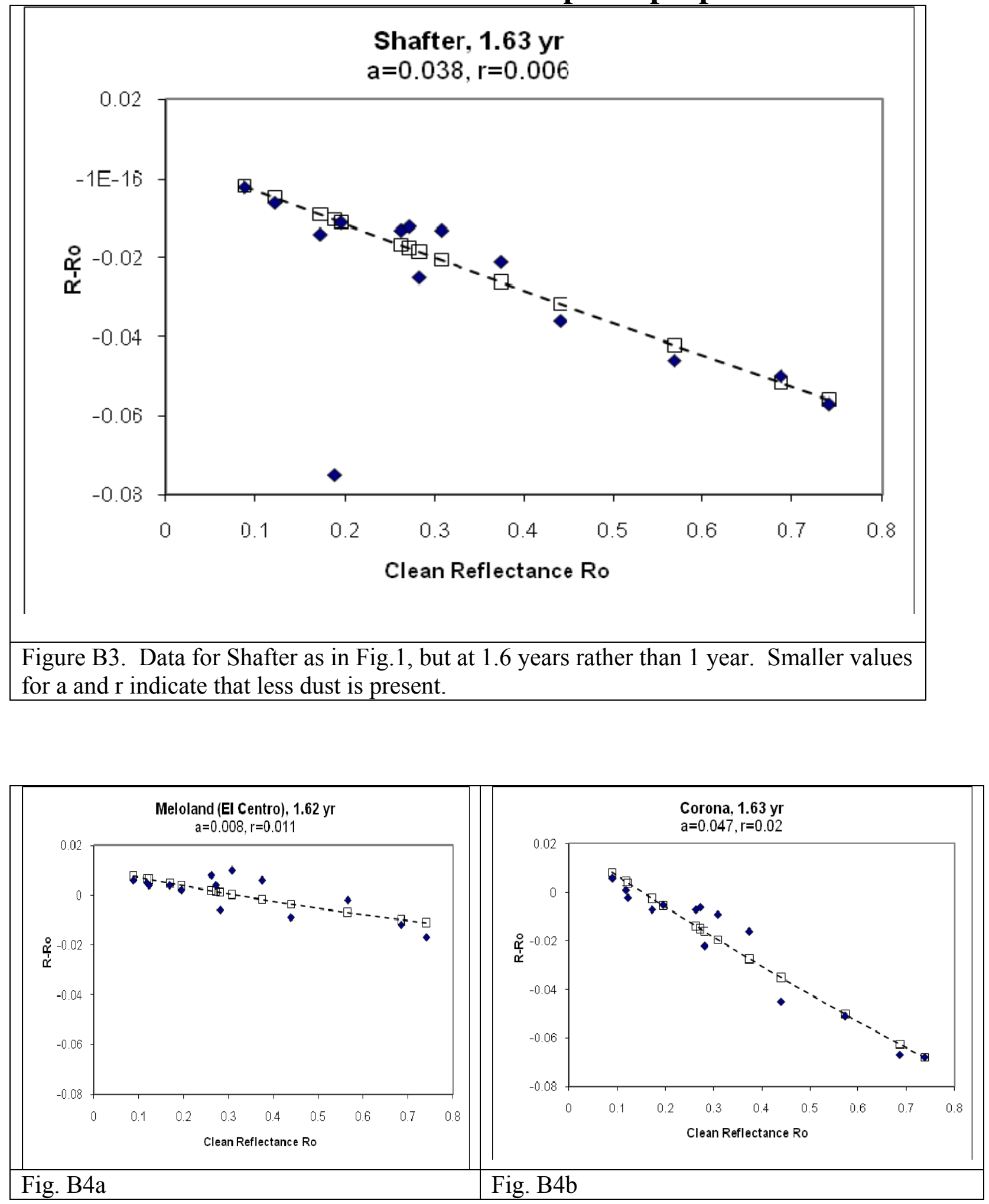


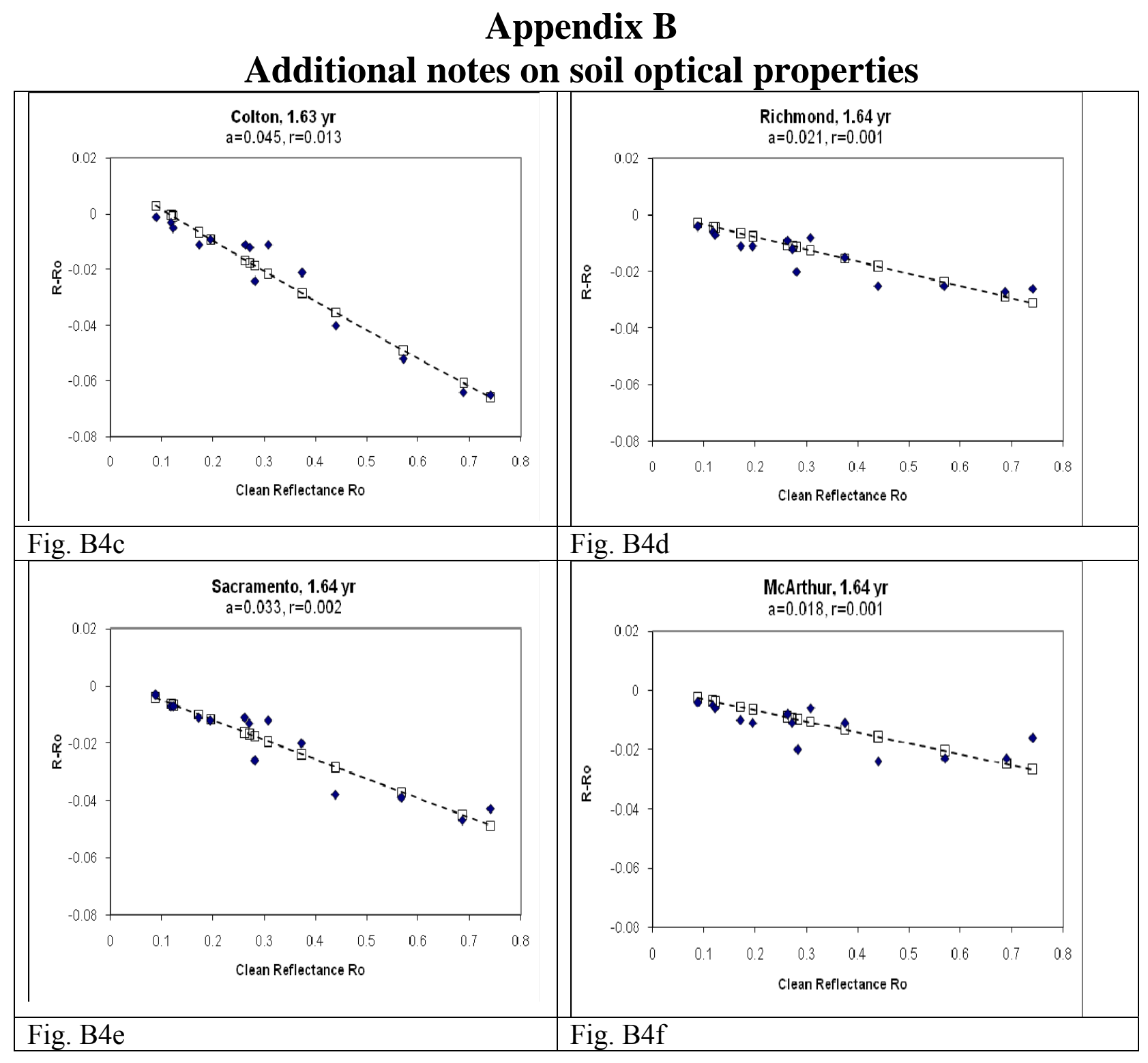




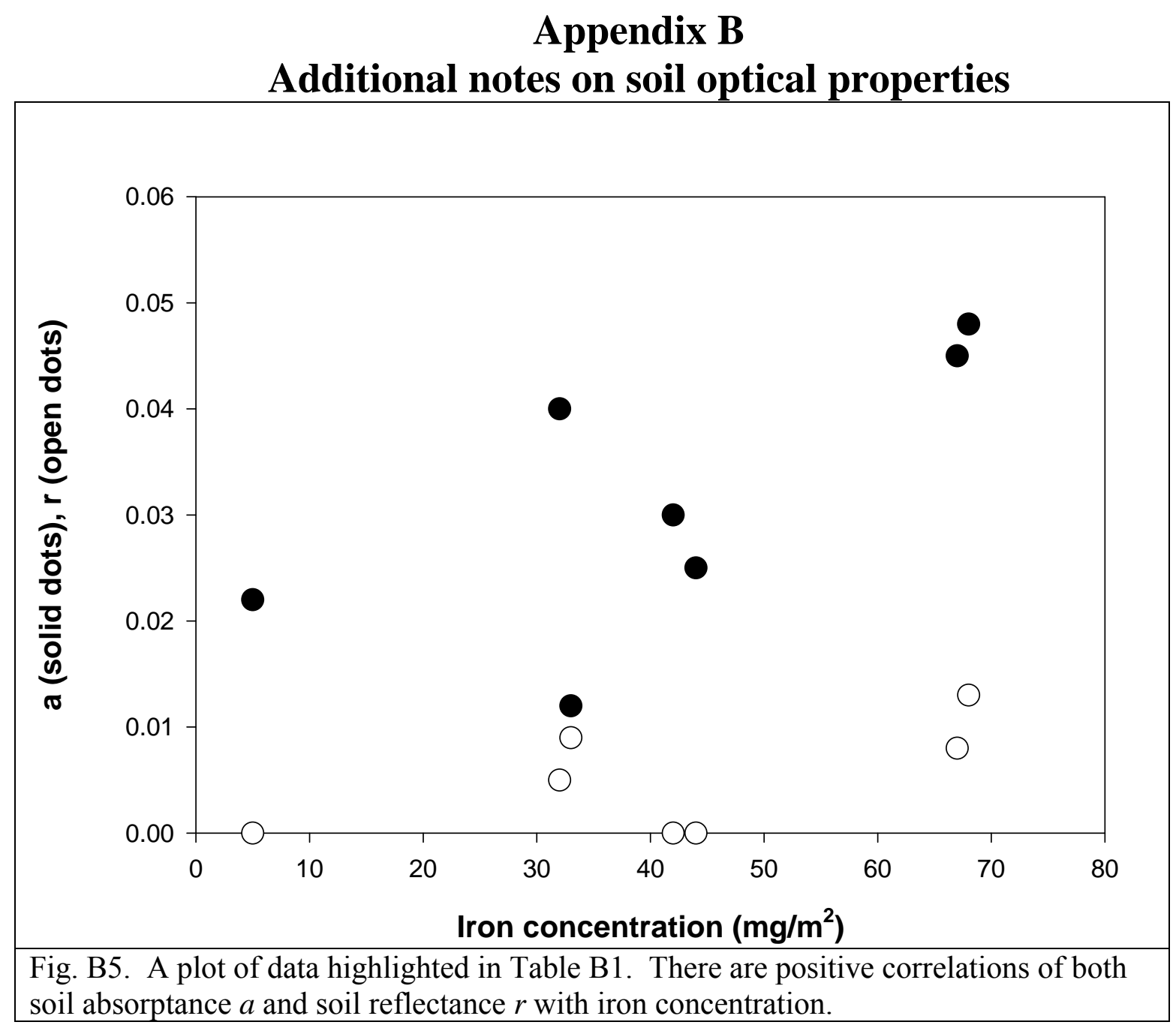

